\title{
Viscoelastometric Testing to Assess Hemostasis of COVID-19: A Systematic Review
}

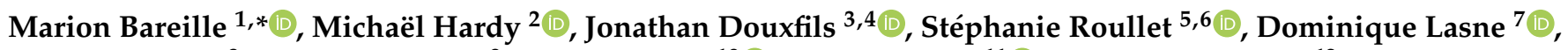 \\ Jerrold H. Levy ${ }^{8}$, Alain Stépanian ${ }^{9}$, Sophie Susen ${ }^{10}{ }^{\oplus}$, Corinne Frère ${ }^{11} \oplus$, Thomas Lecompte ${ }^{12}$ and \\ François Mullier ${ }^{1}$ (1)
}

check for updates

Citation: Bareille, M.; Hardy, M.; Douxfils, J.; Roullet, S.; Lasne, D.; Levy, J.H.; Stépanian, A.; Susen, S.; Frère, C.; Lecompte, T.; et al. Viscoelastometric Testing to Assess Hemostasis of COVID-19: A Systematic Review. J. Clin. Med. 2021, 10, 1740. https://doi.org/ $10.3390 /$ jcm 10081740

Academic Editor: Angelo Claudio Molinari

Received: 26 March 2021

Accepted: 12 April 2021

Published: 16 April 2021

Publisher's Note: MDPI stays neutral with regard to jurisdictional claims in published maps and institutional affiliations.

Copyright: (c) 2021 by the authors. Licensee MDPI, Basel, Switzerland. This article is an open access article distributed under the terms and conditions of the Creative Commons Attribution (CC BY) license (https:/ / creativecommons.org/licenses/by/ $4.0 /)$.
1 Namur Thrombosis and Hemostasis Center (NTHC), CHU UCL Namur, Université Catholique de Louvain, 5530 Yvoir, Belgium; francois.mullier@uclouvain.be

2 Service D'anesthésiologie, CHU UCL Namur, Université Catholique de Louvain, 5530 Yvoir, Belgium; michael.hardy@uclouvain.be

3 Namur Thrombosis and Hemostasis Center (NTHC), Département de Pharmacie, Université de Namur, 5000 Namur, Belgium; jonathan.douxfils@unamur.be

4 Qualiblood S.A., 5000 Namur, Belgium

5 CHU Bordeaux, Service D'Anesthésie-Réanimation Tripode, 33000 Bordeaux, France; stephanie.roullet@chu-bordeaux.fr

6 Biologie des Maladies Cardiovasculaire, University Bordeaux, INSERM U1034, 33600 Pessac, France

7 Laboratoire D’hématologie Générale, Hôpital Universitaire Necker-Enfants Malades, AP-HP, 75015 Paris, France; dominique.lasne@aphp.fr

8 Departments of Anesthesiology, Critical Care, and Surgery (Cardiothoracic), Duke University School of Medicine, Durham, NC 27710, USA; jerrold.levy@duke.edu

9 Hôpital Lariboisière, Service D'Hématologie Biologique, Institut de Recherche Saint-Louis, Université de Paris, AP-HP Nord-Université de Paris, EA 3518, 75010 Paris, France; alain.stepanian@aphp.fr

10 Laboratoire D’Hématologie-Hémostase, Université de Lille, CHU Lille, 59037 Lille, France; sophie.susen@chru-lille.fr

11 Department of Hematology, Pitié-Salpêtrière Hospital, Assistance Publique Hôpitaux de Paris, INSERM UMRS_1166, Sorbonne Université, 75013 Paris, France; corinne.frere@aphp.fr

12 Départements de Médecine, Service D'angiologie et D'hémostase et Faculté de Médecine Geneva Platelet Group (GpG), Université de Genève et Hôpitaux Universitaires de Genève, 1205 Genève, Switzerland; thomaspierre.lecompte@hcuge.ch

* Correspondence: marion.bareille@uclouvain.be

Abstract: Infection by SARS-CoV-2 is associated with a high risk of thrombosis. The laboratory documentation of hypercoagulability and impaired fibrinolysis remains a challenge. Our aim was to assess the potential usefulness of viscoelastometric testing (VET) to predict thrombotic events in COVID-19 patients according to the literature. We also (i) analyzed the impact of anticoagulation and the methods used to neutralize heparin, (ii) analyzed whether maximal clot mechanical strength brings more information than Clauss fibrinogen, and (iii) critically scrutinized the diagnosis of hypofibrinolysis. We performed a systematic search in PubMed and Scopus databases until 31 December 2020. VET methods and parameters, and patients' features and outcomes were extracted. VET was performed for 1063 patients (893 intensive care unit (ICU) and 170 non-ICU, 44 studies). There was extensive heterogeneity concerning study design, VET device used (ROTEM, TEG, Quantra and ClotPro) and reagents (with non-systematic use of heparin neutralization), timing of assay, and definition of hypercoagulable state. Notably, only 4 out of 25 studies using ROTEM reported data with heparinase (HEPTEM). The common findings were increased clot mechanical strength mainly due to excessive fibrinogen component and impaired to absent fibrinolysis, more conspicuous in the presence of an added plasminogen activator. Only 4 studies out of the 16 that addressed the point found an association of VETs with thrombotic events. So-called functional fibrinogen assessed by VETs showed a variable correlation with Clauss fibrinogen. Abnormal VET pattern, often evidenced despite standard prophylactic anticoagulation, tended to normalize after increased dosing. VET studies reported heterogeneity, and small sample sizes do not support an association between the poorly defined prothrombotic phenotype of COVID-19 and thrombotic events. 
Keywords: viscoelastic test; thromboelastometry; thromboelastography; sonorheometry; ROTEM; TEG; Quantra; ClotPro; coronavirus disease 2019; COVID-19; severe acute respiratory syndrome coronavirus 2; SARS-CoV-2

\section{Introduction}

In contrast to conventional clotting tests, viscoelastic tests (VETs) monitor changes of viscoelastic properties of a forming and evolving clot from whole blood, before and beyond the clotting point; they are often referred to as a global hemostasis test, although some aspects of hemostasis are not explored [1-3]. Coagulation occurs in the presence of platelets and red blood cells, and fibrinolysis can translate into a decrease in clot mechanical strength after its maximum has been reached, but clot retraction seems to play a role here as well [4-6]. VETs are based on the mechanical properties of the clot, like mechanical strength, and are influenced by its composition in platelets, fibrin, red blood cells, and factor XIII [7-9]. To our knowledge, the assessment of factor XIII by VETs has not been investigated in COVID-19 patients.

VETs have been considered to provide a comprehensive assessment of the dynamic process of blood clot formation and subsequent lysis. As they can be performed bedside as point-of-care testing and can give useable results about clot formation and a potential hyperfibrinolysis within one hour, they are chiefly considered as convenient tools for realtime assessment of coagulation and fibrinolysis in whole blood and have been gaining in popularity in various hemorrhagic situations, such as cardiac surgery, obstetrics, and traumatology over decades, for the management of acutely bleeding patients [3]. By contrast, COVID-19 disturbance of hemostasis is likely a combination of hypercoagulability and impaired fibrinolysis (a prothrombotic laboratory phenotype), at least in part, contributing to the thrombotic risk and the prothrombotic laboratory phenotype, but VETs have been nevertheless suggested to be potentially useful, in line with previous works on sepsis [10] and trauma [11,12], for example.

Of note, VETs share the same limitations as all currently available clinical lab tests, i.e., negligible effect of endogenous anticoagulants, absence of endothelium, and very low shear in a close system. Furthermore, there are good reasons to challenge the interpretation of hypercoagulability and to question the ability to sensitively detect and accurately quantify hypofibrinolysis, especially when a value equal to zero belongs to the manufacturer's reference range.

Our aim was to assess the potential clinical usefulness of VETs to predict clinical outcomes (mainly thrombotic events) in COVID-19 patients through this systematic review. We also (i) analyzed the impact of anticoagulation and the methods used to neutralize heparin (in other words, was heparin duly neutralized?), (ii) disentangled reported alterations in clotting dynamics and analyzed whether maximal clot mechanical strength brings more information than Clauss fibrinogen, and (iii) critically scrutinized the documentation of hypofibrinolysis with VET under various reactive conditions. The term 'hypercoagulable state' will be uniformly used to refer to the investigators' interpretation of VET findings; we will discuss to what extent this is an appropriate interpretation.

The preanalytical aspects, which are crucial in laboratory hemostasis but scarcely mentioned among the retrieved studies, are beyond the scope of this review and will not be addressed.

\section{Materials and Methods}

\subsection{Search Methodology}

We performed a systematic literature search in PubMed and Scopus databases, regardless of publication status, using the following keywords 'viscoelastic test OR thromboelastometry OR thromboelastography OR sonorheometry OR ROTEM OR TEG OR Quantra OR ClotPro' AND 'coronavirus disease 2019 OR COVID-19 OR severe acute respiratory 
syndrome coronavirus 2 OR SARS-CoV-2'. Search strategy is provided as Data S1. We also searched the reference lists of selected articles for additional relevant works, and we did not restrict our search to articles published in English and found some articles in Russian and Hungarian. In addition, reviewers performed manual searches and crossreferences in the retrieved papers. The last search was conducted on 31 December 2020. Our review followed the PRISMA (Preferred Reporting Items for Systematic Reviews and Meta-analysis) guidelines [13], and the PRISMA summary table can be found as Data S2. Due to a considerable heterogeneity among the retrieved studies, we did not extend our systematic review to a meta-analysis.

\subsection{Study Selection}

All references retrieved from our search were screened based upon their title and abstract to assess eligibility. If they were considered relevant, the full-text articles were analyzed to check if they met the selection criteria as follows. As COVID-19 pandemic is a recent phenomenon, and due to the relatively small number of published data on VETs, we did not restrict eligibility according to patients' characteristics, disease severity, or treatment modalities. Studies of any design and case reports, including original data from VETs in COVID-19 patients with neither pregnancy nor known history of coagulation disorder, were deemed eligible. All relevant studies regardless of methodological quality were included when the full-text article was available (Table 1).

Table 1. Eligibility criteria.

\begin{tabular}{|c|c|c|}
\hline PICOS & Inclusion & Exclusion \\
\hline Participants & All patients with confirmed COVID-19 infection regardless of age & $\begin{array}{c}\text { Pregnancy } \\
\text { Pre-existing coagulation disorder }\end{array}$ \\
\hline Intervention & Viscoelastometric testing performed & - \\
\hline Comparison & $\begin{array}{l}\text { Reference values (manufacturer's based or healthy controls) } \\
\text { ICU COVID-19 patients and non-ICU COVID-19 patients } \\
\text { ICU COVID-19 patients and ICU non-COVID-19 patients }\end{array}$ & - \\
\hline Outcomes & $\begin{array}{c}\text { VET parameters in COVID-19 patients } \\
\text { Difference in VET parameters between ICU COVID-19 patients and } \\
\text { non-ICU COVID-19 patients } \\
\text { Difference in VET parameters between ICU COVID-19 patients and } \\
\text { ICU non-COVID-19 patients } \\
\text { Association between VET parameters and clinical } \\
\text { outcomes } \\
\text { Association between VET parameters and Clauss } \\
\text { fibrinogen }\end{array}$ & - \\
\hline Study design & $\begin{array}{l}\text { Randomized controlled trials } \\
\text { Observational clinical studies } \\
\text { Case reports }\end{array}$ & $\begin{array}{c}\text { Opinion papers } \\
\text { Review papers } \\
\text { Healthcare guidelines } \\
\text { Protocol } \\
\text { Non-human or in vitro studies }\end{array}$ \\
\hline
\end{tabular}

Abbreviations: VET: viscoelastometric testing; ICU: Intensive care unit.

Reviews, position articles, and guidelines were excluded. All kind of VETs were included but were analyzed separately.

\subsection{Data Extraction}

For each study, data regarding author identification, geographic location, study design, number of patients and their characteristics (including comorbidities and thrombotic events), prospective design or not, timing of blood collection and anticoagulation status, type of VET device used and results, and the results of other conventional hemostasis 
tests (platelet count, fibrinogen and D-dimers plasma levels), and C-reactive protein were extracted with the aid of a systematic chart.

\subsection{A Concise Overview of the Different VET Devices}

Viscoelastometric testing (VET) should be performed either immediately with native whole blood or within four hours after drawing if performed with whole citrated blood, as most often done $[1,3]$.

ROTEM devices and TEG5000 all rely on the movement of a pin and a cup relative to each other; in the former, the cuvette is fixed, and the pin oscillates, and vice versa in the latter. The oscillations are recorded and graphically displayed with the characteristic normal tuning fork shape [3]. The conventional clotting point roughly corresponds to the reaction time $\mathrm{R}$ for TEG, and to the clotting time CT for ROTEM, ClotPro, and Quantra; extended fibrin polymerization is monitored with the kinetics time $\mathrm{K}$ and $\alpha$ angle for TEG and with CFT and $\alpha$ angle for ROTEM and ClotPro; the eventual result is maximal mechanical strength (maximal amplitude MA for TEG, maximal clot firmness MCF for ROTEM and ClotPro and clot stiffness CS for Quantra) and its subsequent decrease, as a result of 'endogenous' fibrinolysis monitored by lysis of the clot at given time $x \operatorname{LY}(x)$ for TEG and by maximal lysis ML or lysis of the clot at a given time $\mathrm{x}(\mathrm{LI}(\mathrm{x}))$ for ROTEM and ClotPro, at least in part $[2,3,14]$.

Coagulation can be initiated through the contact phase or the tissue factor pathway (often referred to as intrinsic or extrinsic pathways, respectively) and needs recalcification when citrated blood is used [3]. If the nature of the initiating agents is known, their concentrations are not disclosed. Regarding the former pathway, the limitations of aPTT testing apply, although 'clotting times' are longer, suggesting a lower amount of contact phase activator (kaolin, celite, or ellagic acid) and higher calcium concentration. The different well-known behaviors of those reagents in case of defective contact phase, abnormal factor VIII levels, high CRP (C-reactive protein) levels, lupus anticoagulant, or heparin must be borne in mind. Two reagents can be used to neutralize heparin, either polybrene (hexadimethrine bromide) or heparinase; two to inhibit the platelet contribution to mechanical clot properties, namely cytochalasin $\mathrm{D}$ and abciximab, sometimes both together; lastly, two to inhibit fibrinolysis, either aprotinin or tranexamic acid [3]. To what extent those inhibitions are fully achieved is not entirely clear.

\subsubsection{ROTEM}

Three versions of the ROTEM device exist: from the oldest to the most recent, ROTEMgamma, ROTEM-delta, and the brand-new version ROTEM-sigma. The main difference between them is that ROTEM-gamma and -delta need manual pipetting of the blood sample and the reagents into cups, whereas ROTEM-sigma is a completely automated, closed system. For the latter, reagents consist of a consumable ready-to-use cartridge with four parallel channels prefilled with specific lyophilized reagents [15]. All ROTEM versions can perform the same assays, namely INTEM, HEPTEM, EXTEM, FIBTEM, and APTEM, to investigate the intrinsic pathway (with and without heparinase), the extrinsic pathway, the fibrinogen component, and the fibrinolysis with aprotinin, respectively. Of note, EXTEM, FIBTEM, and APTEM reagents contain polybrene and HEPTEM contain heparinase to neutralize heparin (Table A1) $[2,16]$. They report the same parameters: clotting time (CT), clot formation time (CFT), $\alpha$ angle, "amplitude of the clot" at a given time $\mathrm{x}(\mathrm{A}(\mathrm{x}))$, maximum clot firmness $(\mathrm{MCF})$, clot lysis index $(\mathrm{LI}(\mathrm{x}))$, and maximum lysis (ML) (Table A2).

\subsubsection{TEG}

Briefly, regarding TEG5000 a blood sample is pipetted into a cup; liquid reagents are added; ultimately, a fixed pin connected to a detector system is then put in the cup. The graphical representation is called TEMogram. TEG6s for its part is a completely closed and automated system. In contrast to its predecessor TEG5000, it relies on sonorheometry. 
Reagents consist of a consumable, ready-to-use cartridge with four parallel channels prefilled with specific lyophilized reagents (Table A3) $[17,18]$.

The two versions of the TEG device can perform the same assays, namely Kaolin TEG with (CKH) or without heparinase (CK), RapidTEG (CRT), and TEG Functional Fibrinogen (CFF), and offer the same parameters: reaction time (R), kinetics time (K), $\alpha$ angle, maximum amplitude (MA), and fibrinolytic activity (Ly) $[3,19]$. Of note, heparin neutralization differs between TEG500, where neutralization can occur in virtually any channel by using heparinase-coated cups, and TEG6s, where neutralization occurs only in the CKH channel thanks to heparinase (Table A4) [3].

\subsubsection{Quantra}

The Quantra device also uses sonorheometry. Briefly, an acoustic radiation force is applied to the blood sample. As the blood clot forms, it starts to resonate: oscillations are then correlated with the shear modulus of the blood sample. The resistance of the sample to shear forces can be quantified by the time delay between the ultrasound pulse emission and the returning echoes [20-22].

Reagents consist of a consumable, ready-to-use cartridge with four parallel channels prefilled with specific lyophilized reagents [22]. There are currently two kinds of cartridges: the QPlus cartridge and the QStat one dedicated to exploring fibrinolysis [23]. Measurements of clot coagulation time with (CTH) or without (CT) heparinase and coagulation initiation with kaolin, clot stiffness (CS) after initiation with thromboplastin, and fibrinogen contribution to the overall clot stiffness (FCS) after platelet inhibition with abciximab are performed simultaneously in four parallel channels. Of note, channel 2 contains heparinase, and channels 3 and 4 contain polybrene to neutralize heparin. Platelet contribution to clot stiffness (PCS) results from the difference between total CS and FCS (Tables A5 and A6).

\subsubsection{ClotPro}

The ClotPro device uses rotational technology similar to ROTEM $®$ (Werfen, Barcelona, Spain), but some differences exist between the two devices. First, in contrast with ROTEM, the cuvette rotates and the pin is stationary $[24,25]$. Second, reagents for each assay are present in dry form in a sponge located in the pipette tip; during pipetting of the patient sample, the reagent is automatically added to the blood [25]. This device can perform the same kind of assays as the ROTEM device (EX-test, IN-test, HI-test, FIB-test, AP-test) plus some other specific ones (RVV-test, ECA-test), and offer similar parameters. Of note, EXtest, tPA-test, and FIB-test contain polybrene to neutralize heparin (Tables A7 and A8) [24].

\section{Results}

\subsection{Literature Search}

Our literature search and selection flow chart according to PRISMA statement [13] is summarized in Figure 1. 


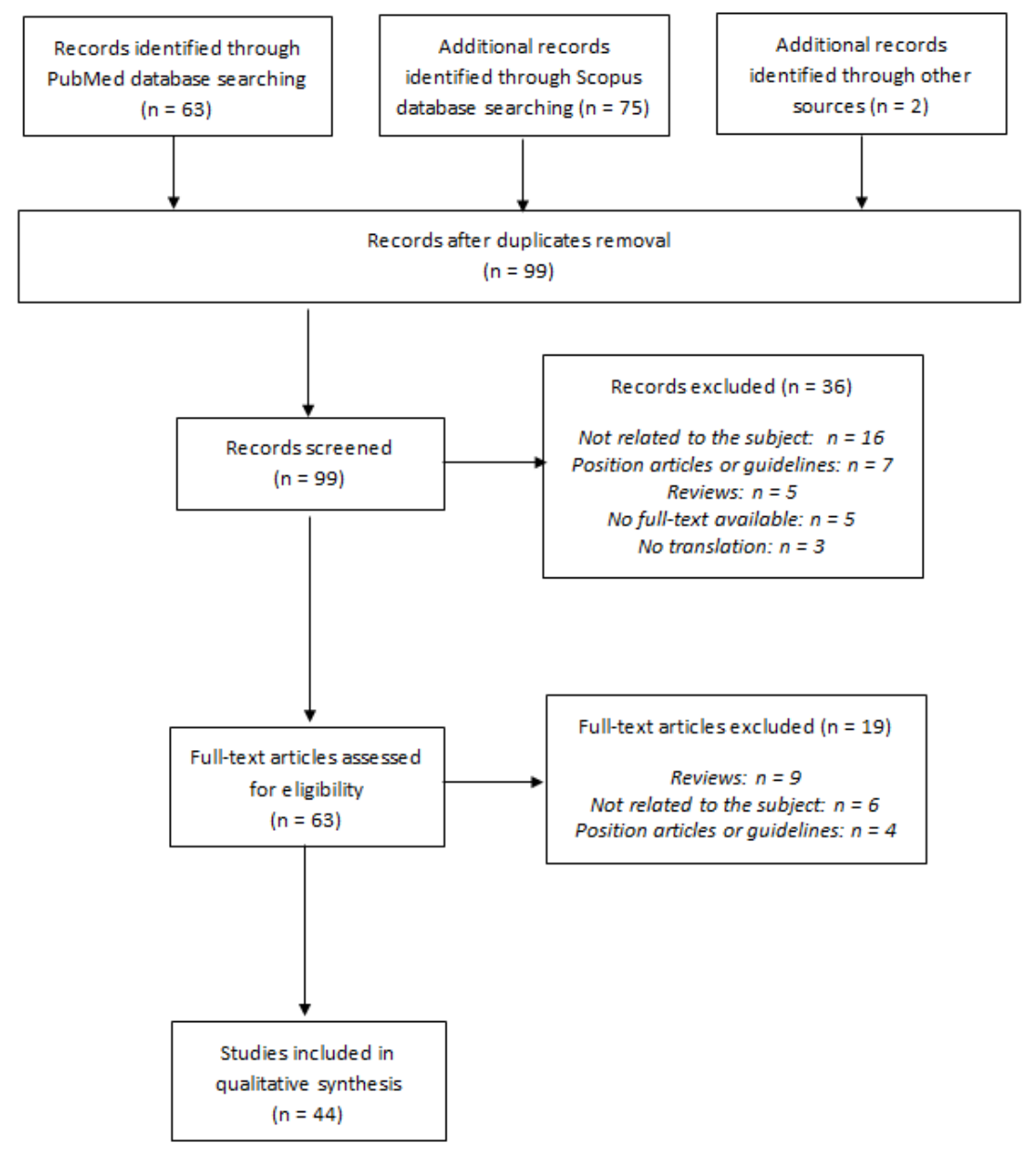

Figure 1. Literature search and selection flow chart according to PRISMA statement.

We identified 140 references, resulting in 97 unique citations after duplicates removal. Two additional articles were identified through other sources. Each title and abstract were screened, and 36 references were excluded either because they were not related to the subject $(n=16)$, because they were position articles or guidelines $(n=7)$ or reviews $(n=5)$, or because there was no full-text available at this time $(n=5)$ or no possible translation $(n=5)$. A total of 63 potentially eligible articles were considered for inclusion, and the full-text articles were retrieved. The most common reasons for exclusion after the full-text evaluation were that papers were reviews $(n=19)$, not related to the subject $(n=6)$, or position articles or guidelines $(n=4)$. Finally, 44 references $[24,26-68]$ met the eligibility criteria.

\subsection{Originality of Our Systematic Review as Compared to the Existing Ones on the Subject}

Reviews have already been published recently, two of them only being systematic [69-72], but none has so far investigated the four major commercially available VET devices (i.e., ROTEM, TEG, ClotPro, and Quantra) or included such a large number of studies $(n=44)$. Characteristics of each review are summarized in Table 2. 
Table 2. Characteristics of the reviews already published.

\begin{tabular}{|c|c|c|c|c|}
\hline First Author (Title) & Type of the Review & Aim of the Review & $\begin{array}{l}\text { Number and Type of } \\
\text { Studies Included }\end{array}$ & VET Devices \\
\hline $\begin{array}{c}\text { Görlinger et al. [69] } \\
\text { (COVID-19 associated } \\
\text { coagulopathy and } \\
\text { inflammatory response: } \\
\text { what do we know already } \\
\text { and what are the } \\
\text { knowledge gaps?) }\end{array}$ & Narrative review & $\begin{array}{l}\text { Review of } \\
\text { coagulation } \\
\text { abnormalities and } \\
\text { inflammatory } \\
\text { response associated } \\
\text { with COVID-19 }\end{array}$ & $\begin{array}{c}8 \text { studies (5 prospective, } \\
3 \text { retrospective) }\end{array}$ & ROTEM, TEG, Quantra \\
\hline $\begin{array}{c}\text { Tsantes et al. [70] } \\
\text { (COVID-19 } \\
\text { Infection-Related } \\
\text { Coagulopathy and } \\
\text { Viscoelastic Methods: A } \\
\text { Paradigm for Their Clinical } \\
\text { Utility in Critical Illness) }\end{array}$ & Narrative review & $\begin{array}{l}\text { Evaluation of the } \\
\text { usefulness of VETs in } \\
\text { clinical practice to } \\
\text { guide anticoagulant } \\
\text { treatments or predict } \\
\text { prognosis }\end{array}$ & $\begin{array}{l}13 \text { studies ( } 8 \\
\text { prospective, } 5 \\
\text { retrospective) }\end{array}$ & ROTEM, TEG, Quantra \\
\hline $\begin{array}{c}\text { Hartmann et al. [71] } \\
\text { (The Role of TEG Analysis } \\
\text { in Patients with } \\
\text { COVID-19-Associated } \\
\text { Coagulopathy: A } \\
\text { Systematic Review) }\end{array}$ & Systematic review & $\begin{array}{l}\text { Evaluation of the } \\
\text { usefulness of TEG in } \\
\text { clinical practice to } \\
\text { identify and manage } \\
\text { hypercoagulation } \\
\text { associated with } \\
\text { COVID-19 }\end{array}$ & $\begin{array}{c}15 \text { studies (5 } \\
\text { prospective, } 9 \\
\text { retrospective and one } \\
\text { case report) }\end{array}$ & TEG \\
\hline $\begin{array}{l}\text { Słomka et al. [72] } \\
\text { (Hemostasis in } \\
\text { Coronavirus Disease } \\
\text { 2019-Lesson from } \\
\text { Viscoelastic Methods: A } \\
\text { Systematic Review) }\end{array}$ & Systematic review & $\begin{array}{l}\text { Evaluation of the } \\
\text { performance of TEG } \\
\text { and TEM in the } \\
\text { assessment of blood } \\
\text { coagulation and } \\
\text { fibrinolysis in } \\
\text { patients with } \\
\text { COVID-19 }\end{array}$ & $\begin{array}{l}10 \text { studies ( } 2 \\
\text { prospective, } 8 \\
\text { retrospective) }\end{array}$ & ROTEM, TEG \\
\hline
\end{tabular}

Overall, case reports were excluded (except for one systematic review [71]); few studies were available and presented extensive heterogeneity.

\subsection{Characteristics of the Selected Studies}

Quality assessment of the selected study was performed using the Scottish Intercollegiate Guidelines Network (SIGN) grading system [73]. Overall, the retrieved studies were of low $(3$, "non analytic studies") to moderate quality (2+, "well-conducted case control or cohort studies with a low risk of confounding or bias and a moderate probability that the relationship is causal"), and details can be found as Data S3. Characteristics of the selected studies are summarized in Table 3. 
Table 3. Characteristics of the included studies.

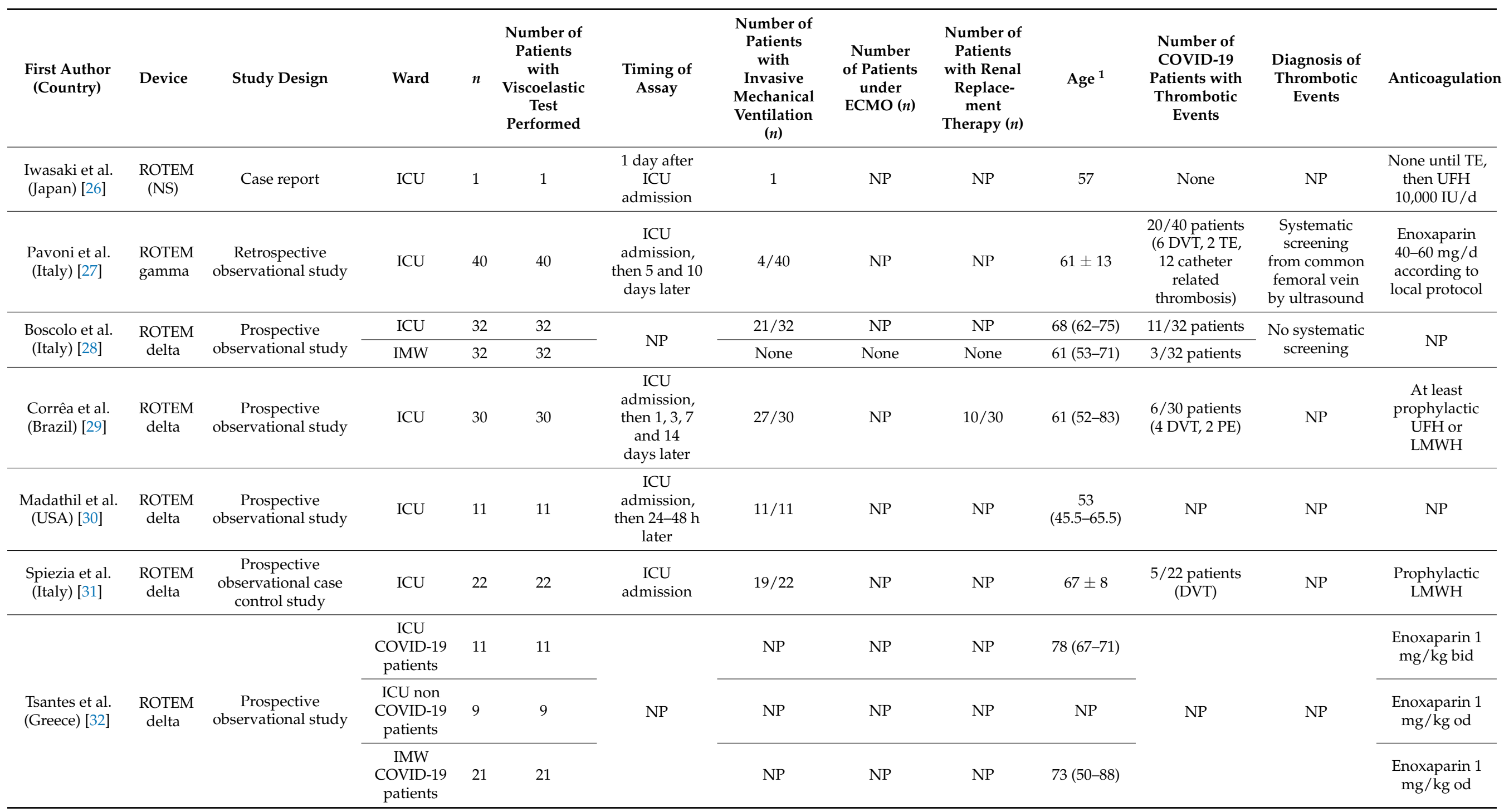


Table 3. Cont.

\begin{tabular}{|c|c|c|c|c|c|c|c|c|c|c|c|c|c|}
\hline $\begin{array}{c}\text { First } \\
\text { Author } \\
\text { (Country) }\end{array}$ & Device & Study Design & Ward & $n$ & $\begin{array}{c}\text { Number of } \\
\text { Patients with } \\
\text { Viscoelastic } \\
\text { Test } \\
\text { Performed }\end{array}$ & $\begin{array}{l}\text { Timing of } \\
\text { Assay }\end{array}$ & $\begin{array}{l}\text { Number of } \\
\text { Patients } \\
\text { with } \\
\text { Invasive } \\
\text { Mechanical } \\
\text { Ventilation } \\
\quad(n)\end{array}$ & $\begin{array}{c}\text { Number of } \\
\text { Patients } \\
\text { under ECMO } \\
\text { (n) }\end{array}$ & $\begin{array}{c}\text { Number of } \\
\text { Patients } \\
\text { with Renal } \\
\text { Replace- } \\
\text { ment } \\
\text { Therapy }(n)\end{array}$ & Age $^{1}$ & $\begin{array}{c}\text { Number of } \\
\text { COVID-19 } \\
\text { Patients with } \\
\text { Thrombotic } \\
\text { Events }\end{array}$ & $\begin{array}{c}\text { Diagnosis } \\
\text { of Throm- } \\
\text { botic } \\
\text { Events }\end{array}$ & Anticoagulation \\
\hline $\begin{array}{l}\text { Al-Ghafry } \\
\text { et al. } \\
\text { (USA) [33] }\end{array}$ & $\begin{array}{c}\text { ROTEM } \\
\text { delta }\end{array}$ & $\begin{array}{c}\text { Retrospective } \\
\text { observational } \\
\text { study }\end{array}$ & $\begin{array}{c}\mathrm{PICU}(n=5) \\
\text { and PW }(n= \\
\text { 3) }\end{array}$ & 8 & 8 & $\begin{array}{l}1 \text { to } 4 \text { days } \\
\text { after } \\
\text { hospital } \\
\text { admission }\end{array}$ & None & None & None & $\begin{array}{c}12.9 \\
(2-20)\end{array}$ & None & $\mathrm{NP}$ & $\begin{array}{c}\text { Prophylactic } \\
\text { enoxaparin } 0.5 \\
\mathrm{mg} / \mathrm{kg} \text { bid } \\
\text { according to } \\
\text { oxygen } \\
\text { requirement } \\
\text { and D-dimers } \\
\text { levels, escalated } \\
\text { to therapeutic } \\
\text { dose }(1 \mathrm{mg} / \mathrm{kg} \\
\text { bid) if clinical } \\
\text { deterioration }\end{array}$ \\
\hline $\begin{array}{l}\text { Creel-Bulos } \\
\text { et al. } \\
\text { (USA) [34] }\end{array}$ & $\begin{array}{c}\text { ROTEM } \\
\text { delta }\end{array}$ & $\begin{array}{c}\text { Retrospective } \\
\text { observational } \\
\text { study }\end{array}$ & ICU & 25 & 25 & $\mathrm{NP}$ & $\mathrm{NP}$ & $\mathrm{NP}$ & $\mathrm{NP}$ & $63(53-77)$ & $\begin{array}{c}\text { 9/25 patients (7 } \\
\text { DVT, } 4 \mathrm{PE}, 1 \\
\text { arterial } \\
\text { thrombosis) }\end{array}$ & $\begin{array}{l}\text { Ultrasound } \\
\text { or CT } \\
\text { imaging } \\
\text { based on } \\
\text { clinical } \\
\text { suspicion }\end{array}$ & $\begin{array}{l}\text { Prophylactic } \\
\text { LMWH or UFH }\end{array}$ \\
\hline \multirow{2}{*}{$\begin{array}{c}\text { Hoechter } \\
\text { et al. } \\
\text { (Germany) } \\
\text { [35] }\end{array}$} & \multirow[t]{2}{*}{$\begin{array}{c}\text { ROTEM } \\
\text { delta }\end{array}$} & \multirow{2}{*}{$\begin{array}{l}\text { Retrospective } \\
\text { observational } \\
\text { case control } \\
\text { study }\end{array}$} & $\begin{array}{c}\text { ICU } \\
\text { COVID-19 } \\
\text { pneumonia }\end{array}$ & 22 & 11 & $\begin{array}{l}\text { Within } 48 \mathrm{~h} \\
\text { after ICU } \\
\text { admission }\end{array}$ & $22 / 22$ & NP & $\mathrm{NP}$ & $64(52-70)$ & \multirow[t]{2}{*}{ NP } & \multirow[t]{2}{*}{ NP } & \multirow{2}{*}{$\begin{array}{l}\text { Prophylactic } \\
\text { UFH according } \\
\text { to local } \\
\text { guidelines }\end{array}$} \\
\hline & & & $\begin{array}{c}\text { ICU non } \\
\text { COVID-19 } \\
\text { pneumonia }\end{array}$ & 14 & 14 & $\mathrm{NP}$ & $14 / 14$ & NP & $\mathrm{NP}$ & $49(36-57)$ & & & \\
\hline $\begin{array}{l}\text { Roh et al. } \\
\text { (USA) [36] }\end{array}$ & $\begin{array}{c}\text { ROTEM } \\
\text { delta }\end{array}$ & $\begin{array}{c}\text { Retrospective } \\
\text { observational } \\
\text { case control } \\
\text { study }\end{array}$ & ICU & 30 & 30 & $\begin{array}{c}\text { ICU } \\
\text { admission }\end{array}$ & $\mathrm{NP}$ & $\mathrm{NP}$ & $\mathrm{NP}$ & $63 \pm 12$ & $\begin{array}{l}\text { 10/30 patients ( } 3 \\
\text { DVT, } 1 \text { PE, } 1 \text { both } \\
\text { DVT and PE, } 4 \\
\text { arterial } \\
\text { thrombosis, } 1 \text { both } \\
\text { arterial } \\
\text { thrombosis and } \\
\text { DVT) }\end{array}$ & $\begin{array}{l}\text { Ultrasound } \\
\text { or CT } \\
\text { imaging } \\
\text { based on } \\
\text { clinical } \\
\text { suspicion }\end{array}$ & $\begin{array}{c}\text { At least } \\
\text { prophylactic } \\
\text { UFH or LMWH }\end{array}$ \\
\hline
\end{tabular}


Table 3. Cont.

\begin{tabular}{|c|c|c|c|c|c|c|c|c|c|c|c|c|c|}
\hline $\begin{array}{l}\text { First Author } \\
\text { (Country) }\end{array}$ & Device & Study Design & Ward & $n$ & $\begin{array}{l}\text { Number of } \\
\text { Patients } \\
\text { with } \\
\text { Viscoelastic } \\
\text { Test } \\
\text { Performed }\end{array}$ & $\begin{array}{l}\text { Timing of } \\
\text { Assay }\end{array}$ & $\begin{array}{l}\text { Number of } \\
\text { Patients } \\
\text { with } \\
\text { Invasive } \\
\text { Mechanical } \\
\text { Ventilation } \\
\quad(n)\end{array}$ & $\begin{array}{c}\text { Number } \\
\text { of } \\
\text { Patients } \\
\text { under } \\
\text { ECMO } \\
(n)\end{array}$ & $\begin{array}{c}\text { Number } \\
\text { of } \\
\text { Patients } \\
\text { with } \\
\text { Renal } \\
\text { Replace- } \\
\text { ment } \\
\text { Therapy } \\
(n)\end{array}$ & Age $^{1}$ & $\begin{array}{l}\text { Number of } \\
\text { COVID-19 } \\
\text { Patients with } \\
\text { Thrombotic } \\
\text { Events }\end{array}$ & $\begin{array}{l}\text { Diagnosis of } \\
\text { Thrombotic } \\
\text { Events }\end{array}$ & Anticoagulation \\
\hline \multirow{2}{*}{$\begin{array}{l}\text { Kong et al. } \\
\text { (United } \\
\text { Kingdom) [37] }\end{array}$} & \multirow[t]{2}{*}{$\begin{array}{l}\text { ROTEM } \\
\text { delta }\end{array}$} & \multirow[t]{2}{*}{ Case report } & ICU & 1 & 1 & $\begin{array}{l}2 \mathrm{~h} \text { after } \\
\text { ICU } \\
\text { admission }\end{array}$ & No & No & No & 48 & None & \multirow[t]{2}{*}{$\mathrm{NP}$} & $\begin{array}{c}\text { None until ROTEM } \\
\text { analysis }\end{array}$ \\
\hline & & & ICU & 1 & 1 & $\mathrm{NP}$ & 1 & No & 1 & 68 & None & & $\mathrm{NP}$ \\
\hline $\begin{array}{l}\text { Raval et al. } \\
\text { (USA) [38] }\end{array}$ & $\begin{array}{l}\text { ROTEM } \\
\text { delta }\end{array}$ & Case report & ICU & 1 & 1 & $\begin{array}{c}\text { ICU } \\
\text { admission }\end{array}$ & 1 & No & No & 63 & None & NP & $\begin{array}{c}\text { None at admission, } \\
\text { then UFH } 7500 \text { IU } / 8 \\
h\end{array}$ \\
\hline $\begin{array}{l}\text { Nougier et al. } \\
\text { (France) [39] }\end{array}$ & $\begin{array}{c}\text { Modified } \\
\text { ROTEM } \\
\text { delta } \\
\text { (TEM-tPA) }\end{array}$ & $\begin{array}{c}\text { Prospective } \\
\text { observational case } \\
\text { control study }\end{array}$ & ICU & 40 & 19 & $\mathrm{NP}$ & $33 / 40$ & NP & $7 / 40$ & $62.8 \pm 13.1$ & $\begin{array}{c}14 / 40 \text { patients } \\
\text { (8 PE, } 5 \text { DVT, } 1 \\
\text { arterial } \\
\text { thrombosis) }\end{array}$ & $\begin{array}{l}\text { Ultrasound or } \\
\text { CT imaging } \\
\text { based on clinical } \\
\text { suspicion }\end{array}$ & $\begin{array}{l}\text { At least prophylactic } \\
\text { UFH or LMWH }\end{array}$ \\
\hline $\begin{array}{l}\text { Weiss et al. } \\
\text { (France) [40] }\end{array}$ & $\begin{array}{c}\text { Modified } \\
\text { ROTEM } \\
\text { delta } \\
\text { (TEM-tPA) }\end{array}$ & $\begin{array}{c}\text { Prospective } \\
\text { observational case } \\
\text { control study }\end{array}$ & ICU & 5 & 5 & $\mathrm{NP}$ & NP & NP & $\mathrm{NP}$ & $57 \pm 15$ & $3 / 5$ patients & NP & $\begin{array}{l}\text { Thromboprophylaxis } \\
\text { according to current } \\
\text { guidelines }\end{array}$ \\
\hline \multirow{2}{*}{$\begin{array}{l}\text { Almskog et al. } \\
\text { (Sweden) [41] }\end{array}$} & \multirow{2}{*}{$\begin{array}{l}\text { ROTEM } \\
\text { sigma }\end{array}$} & \multirow{2}{*}{$\begin{array}{c}\text { Prospective } \\
\text { observational study }\end{array}$} & ICU & 20 & 20 & \multirow{2}{*}{$\begin{array}{l}1 \text { day after } \\
\text { hospital } \\
\text { admission }\end{array}$} & $\mathrm{NP}$ & $\mathrm{NP}$ & $\mathrm{NP}$ & $62(55-66)$ & \multirow[b]{2}{*}{$\mathrm{NP}$} & \multirow[b]{2}{*}{$\mathrm{NP}$} & \multirow{2}{*}{$\begin{array}{c}\text { At least prophylactic } \\
\text { tinzaparin }\end{array}$} \\
\hline & & & IMW & 40 & 40 & & $\mathrm{NP}$ & $\mathrm{NP}$ & $\mathrm{NP}$ & $61(51-74)$ & & & \\
\hline $\begin{array}{l}\text { Collett et al. } \\
\text { (Australia) [42] }\end{array}$ & $\begin{array}{l}\text { ROTEM } \\
\text { sigma }\end{array}$ & $\begin{array}{l}\text { Prospective } \\
\text { observational } \\
\text { study }\end{array}$ & ICU & 6 & 6 & NP & $5 / 6$ & None & $2 / 6$ & $\begin{array}{c}69 \\
(64.2-73)\end{array}$ & $\begin{array}{l}3 / 6 \text { patients }(1 \\
\text { PE, } 1 \text { catheter } \\
\text { related } \\
\text { thrombosis, } 1 \\
\text { TE not clinically } \\
\text { suspected) }\end{array}$ & NP & $\begin{array}{c}\text { Enoxaparin } 40 \mathrm{mg} \\
\text { od }\end{array}$ \\
\hline
\end{tabular}


Table 3. Cont.

\begin{tabular}{|c|c|c|c|c|c|c|c|c|c|c|c|c|c|}
\hline $\begin{array}{c}\text { First } \\
\text { Author } \\
\text { (Country) }\end{array}$ & Device & $\begin{array}{l}\text { Study } \\
\text { Design }\end{array}$ & Ward & $n$ & $\begin{array}{c}\text { Number of } \\
\text { Patients with } \\
\text { Viscoelastic } \\
\text { Test Performed }\end{array}$ & $\begin{array}{l}\text { Timing of } \\
\text { Assay }\end{array}$ & $\begin{array}{l}\text { Number of } \\
\text { Patients } \\
\text { with } \\
\text { Invasive } \\
\text { Mechanical } \\
\text { Ventilation } \\
\quad(n) \\
\end{array}$ & $\begin{array}{c}\text { Number of } \\
\text { Patients } \\
\text { under ECMO } \\
(n)\end{array}$ & $\begin{array}{c}\text { Number of } \\
\text { Patients with } \\
\text { Renal } \\
\text { Replacement } \\
\text { Therapy }(n)\end{array}$ & Age $^{1}$ & $\begin{array}{c}\text { Number of } \\
\text { COVID-19 } \\
\text { Patients with } \\
\text { Thrombotic } \\
\text { Events }\end{array}$ & $\begin{array}{l}\text { Diagnosis } \\
\text { of Throm- } \\
\text { botic } \\
\text { Events }\end{array}$ & Anticoagulation \\
\hline $\begin{array}{l}\text { Ibañez et al. } \\
\text { (Spain) [43] }\end{array}$ & $\begin{array}{c}\text { ROTEM } \\
\text { sigma }\end{array}$ & $\begin{array}{c}\text { Prospective } \\
\text { observa- } \\
\text { tional } \\
\text { study }\end{array}$ & ICU & 19 & 19 & $\begin{array}{l}24-48 \mathrm{~h} \\
\text { after ICU } \\
\text { admission }\end{array}$ & NP & NP & NP & $61(55-73)$ & $\begin{array}{c}\text { 5/19 patients (2 } \\
\text { DVT, } 2 \text { PE, } 1 \\
\text { arterial } \\
\text { thrombosis) }\end{array}$ & NP & $\begin{array}{l}\text { Enoxaparin } \\
40-80 \mathrm{mg} / \mathrm{d} \\
\text { according to } \\
\text { local protocol }\end{array}$ \\
\hline $\begin{array}{c}\text { Kruse et al. } \\
\text { (Germany) } \\
\text { [44] }\end{array}$ & $\begin{array}{l}\text { ROTEM } \\
\text { sigma }\end{array}$ & $\begin{array}{l}\text { Prospective } \\
\text { observa- } \\
\text { tional } \\
\text { study }\end{array}$ & ICU & 40 & 40 & $\begin{array}{c}\text { ICU } \\
\text { admission }\end{array}$ & $31 / 40$ & $10 / 40$ & $21 / 40$ & $\begin{array}{c}67(57.3- \\
76.6)\end{array}$ & $\begin{array}{c}\text { 23/40 patients } \\
\text { (14 DVT, } 4 \text { PE, } 3 \\
\text { ischemic stroke, } \\
1 \text { clotted ECMO } \\
\text { cannula, } 1 \\
\text { complete } \\
\text { thrombosis of } \\
\text { the ECMO } \\
\text { circuit) }\end{array}$ & $\begin{array}{c}\text { Systematic } \\
\text { screening } \\
\text { by ultra- } \\
\text { sound } \\
\text { once a } \\
\text { week }\end{array}$ & $\begin{array}{c}\text { At least } \\
\text { prophylactic } \\
\text { LMWH (or } \\
\text { argatroban if } \\
\text { ECMO) }\end{array}$ \\
\hline \multirow{2}{*}{$\begin{array}{l}\text { Pavoni et al. } \\
\text { (Italy) [45] }\end{array}$} & \multirow{2}{*}{$\begin{array}{l}\text { ROTEM } \\
\text { sigma }\end{array}$} & \multirow{2}{*}{$\begin{array}{l}\text { Prospective } \\
\text { case } \\
\text { controls ob- } \\
\text { servational } \\
\text { study }\end{array}$} & $\begin{array}{c}\text { ICU } \\
\text { COVID-19 } \\
\text { pneumonia }\end{array}$ & 20 & 20 & \multirow{2}{*}{$\begin{array}{c}\text { ICU } \\
\text { admission, } \\
\text { then } 5 \text { and } \\
10 \text { days later }\end{array}$} & $2 / 20$ & $\mathrm{NP}$ & $\mathrm{NP}$ & $\begin{array}{c}60.3 \pm \\
15.2\end{array}$ & $\mathrm{NP}$ & \multirow[t]{2}{*}{ NP } & \multirow{2}{*}{$\begin{array}{l}\text { Enoxaparin } \\
40-60 \mathrm{mg} / \mathrm{d} \\
\text { according to } \\
\text { local protocol }\end{array}$} \\
\hline & & & $\begin{array}{c}\text { ICU non } \\
\text { COVID-19 } \\
\text { pneumonia }\end{array}$ & 25 & 25 & & $8 / 25$ & NP & $\mathrm{NP}$ & $\begin{array}{c}66.5 \pm \\
18.8\end{array}$ & $\mathrm{NP}$ & & \\
\hline \multirow{2}{*}{$\begin{array}{l}\text { Spiezia et al. } \\
\text { (Italy) [46] }\end{array}$} & \multirow{2}{*}{$\begin{array}{c}\text { ROTEM } \\
\text { sigma }\end{array}$} & \multirow{2}{*}{$\begin{array}{l}\text { Prospective } \\
\quad \text { case } \\
\text { controls ob- } \\
\text { servational } \\
\text { study }\end{array}$} & $\begin{array}{c}\text { IMW } \\
\text { COVID-19 } \\
\text { pneumonia }\end{array}$ & 56 & 56 & \multirow{2}{*}{$\begin{array}{l}\text { Within } 6 \mathrm{~h} \\
\text { after } \\
\text { hospital } \\
\text { admission }\end{array}$} & \multirow[t]{2}{*}{ NP } & \multirow[t]{2}{*}{ NP } & \multirow[t]{2}{*}{$\mathrm{NP}$} & $64 \pm 15$ & $\mathrm{NP}$ & \multirow[t]{2}{*}{ NP } & \multirow[t]{2}{*}{ NP } \\
\hline & & & $\begin{array}{l}\text { IMW non } \\
\text { COVID-19 } \\
\text { pneumonia }\end{array}$ & 56 & 56 & & & & & $76 \pm 11$ & $\mathrm{NP}$ & & \\
\hline \multirow{2}{*}{$\begin{array}{c}\text { Van der } \\
\text { Linden et al. } \\
\text { (Sweden) } \\
\text { [47] }\end{array}$} & \multirow{2}{*}{$\begin{array}{l}\text { ROTEM } \\
\text { sigma }\end{array}$} & \multirow{2}{*}{$\begin{array}{l}\text { Cross- } \\
\text { sectional } \\
\text { study }\end{array}$} & $\begin{array}{l}\text { ICU before } \\
\text { enhanced } \\
\text { anticoagula- } \\
\text { tion }\end{array}$ & 12 & 12 & $\begin{array}{c}13(7-16) \\
\text { days after } \\
\text { ICU } \\
\text { admission }\end{array}$ & $12 / 12$ & $\mathrm{NP}$ & $6 / 12$ & $54 \pm 9$ & $\begin{array}{l}7 / 12 \text { patients }(6 \\
\text { PE, } 1 \text { DVT) }\end{array}$ & \multirow{2}{*}{$\begin{array}{l}\text { Ultrasound } \\
\text { or CT } \\
\text { imaging } \\
\text { based on } \\
\text { clinical } \\
\text { suspicion }\end{array}$} & $\begin{array}{c}\text { LMWH } 129 \pm \\
53 \mathrm{IU} / \mathrm{kg} / 24 \mathrm{~h} \\
\text { or UFH infusion }\end{array}$ \\
\hline & & & $\begin{array}{l}\text { ICU after } \\
\text { enhanced } \\
\text { anticoagula- } \\
\text { tion }\end{array}$ & 14 & 14 & $\begin{array}{c}18(13-29) \\
\text { days after } \\
\text { ICU } \\
\text { admission }\end{array}$ & $14 / 14$ & NP & $8 / 14$ & $59 \pm 8$ & $\begin{array}{c}\text { 5/14 patients ( } \\
\text { PE, } 2 \text { DVT) }\end{array}$ & & $\begin{array}{c}\text { LMWH } 200 \pm \\
82 \mathrm{IU} / \mathrm{kg} / 24 \mathrm{~h} \\
\text { or UFH infusion }\end{array}$ \\
\hline
\end{tabular}


Table 3. Cont.

\begin{tabular}{|c|c|c|c|c|c|c|c|c|c|c|c|c|c|}
\hline $\begin{array}{l}\text { First Author } \\
\text { (Country) }\end{array}$ & Device & Study Design & Ward & $n$ & $\begin{array}{c}\text { Number of } \\
\text { Patients with } \\
\text { Viscoelastic } \\
\text { Test } \\
\text { Performed }\end{array}$ & $\begin{array}{l}\text { Timing of } \\
\text { Assay }\end{array}$ & $\begin{array}{l}\text { Number of } \\
\text { Patients } \\
\text { with } \\
\text { Invasive } \\
\text { Mechanical } \\
\text { Ventilation } \\
\quad(n)\end{array}$ & $\begin{array}{c}\text { Number of } \\
\text { Patients } \\
\text { under ECMO } \\
(n)\end{array}$ & $\begin{array}{l}\text { Number of } \\
\text { Patients } \\
\text { with Renal } \\
\text { Replace- } \\
\text { ment } \\
\text { Therapy }(n)\end{array}$ & Age $^{1}$ & $\begin{array}{c}\text { Number of } \\
\text { COVID-19 } \\
\text { Patients with } \\
\text { Thrombotic } \\
\text { Events }\end{array}$ & $\begin{array}{c}\text { Diagnosis } \\
\text { of } \\
\text { Thrombotic } \\
\text { Events }\end{array}$ & Anticoagulation \\
\hline \multirow{2}{*}{$\begin{array}{l}\text { Blasi et al. } \\
\text { (Spain) [48] }\end{array}$} & \multirow{2}{*}{$\begin{array}{l}\text { ROTEM } \\
\text { sigma }\end{array}$} & \multirow{2}{*}{$\begin{array}{c}\text { Retrospective } \\
\text { observational study }\end{array}$} & ICU & 12 & 12 & \multirow{2}{*}{$\begin{array}{l}4 \text { days after } \\
\text { hospital } \\
\text { admission }\end{array}$} & $12 / 12$ & $\mathrm{NP}$ & $\mathrm{NP}$ & $69(57-76)$ & \multirow{2}{*}{ NP } & \multirow{2}{*}{$\mathrm{NP}$} & \multirow{2}{*}{$\begin{array}{c}\text { At least } \\
\text { prophylactic } \\
\text { LMWH }\end{array}$} \\
\hline & & & IMW & 11 & 11 & & None & NP & NP & $58(42-74)$ & & & \\
\hline $\begin{array}{c}\text { Van Veenendaal } \\
\text { et al. } \\
\text { (The } \\
\text { Netherlands) } \\
\text { [49] }\end{array}$ & $\begin{array}{l}\text { ROTEM } \\
\text { sigma }\end{array}$ & $\begin{array}{c}\text { Retrospective } \\
\text { observational study }\end{array}$ & ICU & 47 & 47 & NP & $47 / 47$ & NP & NP & $63(29-79)$ & $\begin{array}{l}\text { 10/47 patients } \\
\text { (10 PE) }\end{array}$ & $\begin{array}{l}\text { Ultrasound } \\
\text { or CT } \\
\text { imaging } \\
\text { based on } \\
\text { clinical } \\
\text { suspicion }\end{array}$ & $\begin{array}{c}\text { At least } \\
\text { prophylactic } \\
\text { UFH or LMWH }\end{array}$ \\
\hline \multirow{2}{*}{$\begin{array}{l}\text { Lazar et al. } \\
\text { (USA) [50] }\end{array}$} & \multirow{2}{*}{$\begin{array}{l}\text { ROTEM } \\
\text { sigma }\end{array}$} & \multirow{2}{*}{ Case report } & IMW & 1 & 1 & \multirow{2}{*}{$\begin{array}{l}\text { Hospital } \\
\text { admission }\end{array}$} & No & No & No & NP & NP & \multirow{2}{*}{$\mathrm{NP}$} & $\begin{array}{c}\text { None at } \\
\text { admission, then } \\
\text { prophylactic } \\
\text { UFH }\end{array}$ \\
\hline & & & IMW & 1 & 1 & & No & No & No & NP & $\mathrm{NP}$ & & $\begin{array}{c}\text { None at } \\
\text { admission, then } \\
\text { enoxaparin } 60 \\
\text { mg od }\end{array}$ \\
\hline $\begin{array}{l}\text { Wright et al. } \\
\text { (USA) [51] }\end{array}$ & $\begin{array}{l}\text { TEG } \\
\text { (NS) }\end{array}$ & $\begin{array}{c}\text { Retrospective } \\
\text { observational study }\end{array}$ & ICU & 44 & 44 & NP & $43 / 44$ & $20 / 44$ & NP & $54(42-59)$ & $\begin{array}{c}\text { 11/39 TE, } 6 / 39 \\
\text { thrombotic } \\
\text { stroke, } 16 / 39 \\
\text { acute renal } \\
\text { failure requiring } \\
\text { dialysis }\end{array}$ & $\begin{array}{l}\text { Ultrasound } \\
\text { or CT } \\
\text { imaging } \\
\text { based on } \\
\text { clinical } \\
\text { suspicion }\end{array}$ & $\begin{array}{c}\text { At least } \\
\text { enoxaparin } \\
40-60 \mathrm{mg} \text { od or } \\
\text { UFH } \\
10,000-15,000 \mathrm{IU} \\
\text { per day }\end{array}$ \\
\hline $\begin{array}{l}\text { Panigada et al. } \\
\text { (Italy) [52] }\end{array}$ & TEG5000 & $\begin{array}{c}\text { Prospective } \\
\text { observational study }\end{array}$ & ICU & 24 & 24 & NP & $24 / 24$ & $\mathrm{NP}$ & NP & $56(23-71)$ & NP & $\mathrm{NP}$ & $\begin{array}{c}\text { At least } \\
\text { prophylactic } \\
\text { dose of LMWH } \\
\text { or UFH }\end{array}$ \\
\hline
\end{tabular}


Table 3. Cont

\begin{tabular}{|c|c|c|c|c|c|c|c|c|c|c|c|c|c|}
\hline $\begin{array}{l}\text { First Author } \\
\text { (Country) }\end{array}$ & Device & Study Design & Ward & $n$ & $\begin{array}{c}\text { Number of } \\
\text { Patients with } \\
\text { Viscoelastic } \\
\text { Test Performed }\end{array}$ & $\begin{array}{c}\text { Timing of } \\
\text { Assay }\end{array}$ & $\begin{array}{l}\text { Number of } \\
\text { Patients with } \\
\text { Invasive } \\
\text { Mechanical } \\
\text { Ventilation ( } n \text { ) }\end{array}$ & $\begin{array}{c}\text { Number of } \\
\text { Patients under } \\
\text { ECMO }(n)\end{array}$ & $\begin{array}{c}\text { Number of } \\
\text { Patients } \\
\text { with Renal } \\
\text { Replace- } \\
\text { ment } \\
\text { Therapy }(n)\end{array}$ & Age $^{1}$ & $\begin{array}{c}\text { Number of } \\
\text { COVID-19 } \\
\text { Patients with } \\
\text { Thrombotic } \\
\text { Events }\end{array}$ & $\begin{array}{c}\text { Diagnosis } \\
\text { of } \\
\text { Thrombotic } \\
\text { Events }\end{array}$ & Anticoagulation \\
\hline $\begin{array}{l}\text { Cordier et al. } \\
\text { (France) [53] }\end{array}$ & TEG5000 & $\begin{array}{c}\text { Retrospective } \\
\text { observational } \\
\text { study }\end{array}$ & $\mathrm{ICU}$ & 24 & 24 & $\begin{array}{c}\text { ICU } \\
\text { admission, } \\
\text { then at } \\
\text { discharge } \\
\text { from the } \\
\text { ICU }\end{array}$ & NP & NP & NP & $\begin{array}{c}69 \\
(61-71)\end{array}$ & $\begin{array}{c}6 / 24 \text { patients (4 } \\
\text { isolated PE, } 1 \\
\text { ischemic stroke, } \\
1 \text { both PE and } \\
\text { ischemic stroke) }\end{array}$ & $\begin{array}{l}\text { Ultrasound } \\
\text { or CT } \\
\text { imaging } \\
\text { based on } \\
\text { clinical } \\
\text { suspicion }\end{array}$ & $\begin{array}{l}\text { Thromboprophylaxis } \\
\text { according to } \\
\text { current guidelines }\end{array}$ \\
\hline $\begin{array}{l}\text { Hightower } \\
\text { et al. } \\
\text { (USA) [54] }\end{array}$ & TEG5000 & $\begin{array}{c}\text { Retrospective } \\
\text { observational } \\
\text { study }\end{array}$ & ICU & 5 & 5 & NP & $4 / 5$ & None & None & $\begin{array}{c}59 \\
(38-69.5)\end{array}$ & $2 / 5$ patients & $\begin{array}{l}\text { Ultrasound } \\
\text { or CT } \\
\text { imaging } \\
\text { based on } \\
\text { clinical } \\
\text { degradation } \\
\end{array}$ & $\begin{array}{c}\text { Enoxaparin } 40 \mathrm{mg} \\
\text { od or therapeutic } \\
\text { UFH }\end{array}$ \\
\hline $\begin{array}{l}\text { Maatman et al. } \\
\text { (USA) [55] }\end{array}$ & TEG5000 & $\begin{array}{c}\text { Retrospective } \\
\text { multi-center } \\
\text { observational } \\
\text { study }\end{array}$ & ICU & 109 & 12 & $\begin{array}{l}3.5 \text { days } \\
\text { after } \\
\text { hospital } \\
\text { admission }\end{array}$ & $102 / 109$ & $\mathrm{NP}$ & $16 / 109$ & $61 \pm 16$ & $\begin{array}{l}\text { 31/109 patients: } \\
2 / 31 \text { upon } \\
\text { admission and } \\
29 / 31 \text { despite } \\
\text { anticoagulation } \\
\text { (26 isolated } \\
\text { DVT, } 1 \text { isolated } \\
\text { PE, } 4 \text { both DVT } \\
\text { and PE) }\end{array}$ & $\begin{array}{l}\text { Ultrasound } \\
\text { or CT } \\
\text { imaging } \\
\text { based on } \\
\text { clinical } \\
\text { suspicion }\end{array}$ & $\begin{array}{l}\text { UFH } 5000 \mathrm{IU} / 8 \mathrm{~h} \text {, } \\
40 \mathrm{mg} \text { enoxaparin } \\
\text { od or } 30 \mathrm{mg} \\
\text { enoxaparin bid }\end{array}$ \\
\hline $\begin{array}{l}\text { Mortus et al. } \\
\text { (USA) [56] }\end{array}$ & TEG5000 & $\begin{array}{l}\text { Retrospective } \\
\text { cohort study }\end{array}$ & ICU & 21 & 21 & $\begin{array}{c}\text { ICU } \\
\text { admission }\end{array}$ & NP & $2 / 21$ & $18 / 21$ & $68 \pm 11$ & $\begin{array}{l}13 / 21 \text { patients } \\
\text { for a total of } 46 \\
\text { recorded events }\end{array}$ & NP & $\begin{array}{c}\text { Standard DVT } \\
\text { chemoprophylaxis } \\
\text { upon admission } \\
\text { with subsequent } \\
\text { therapeutic } \\
\text { anticoagulation } \\
\text { (UFH or } \\
\text { enoxaparin } 2 \\
\mathrm{mg} / \mathrm{kg} / \mathrm{d} \text { ) if } \\
\text { thrombotic } \\
\text { complications }\end{array}$ \\
\hline
\end{tabular}


Table 3. Cont

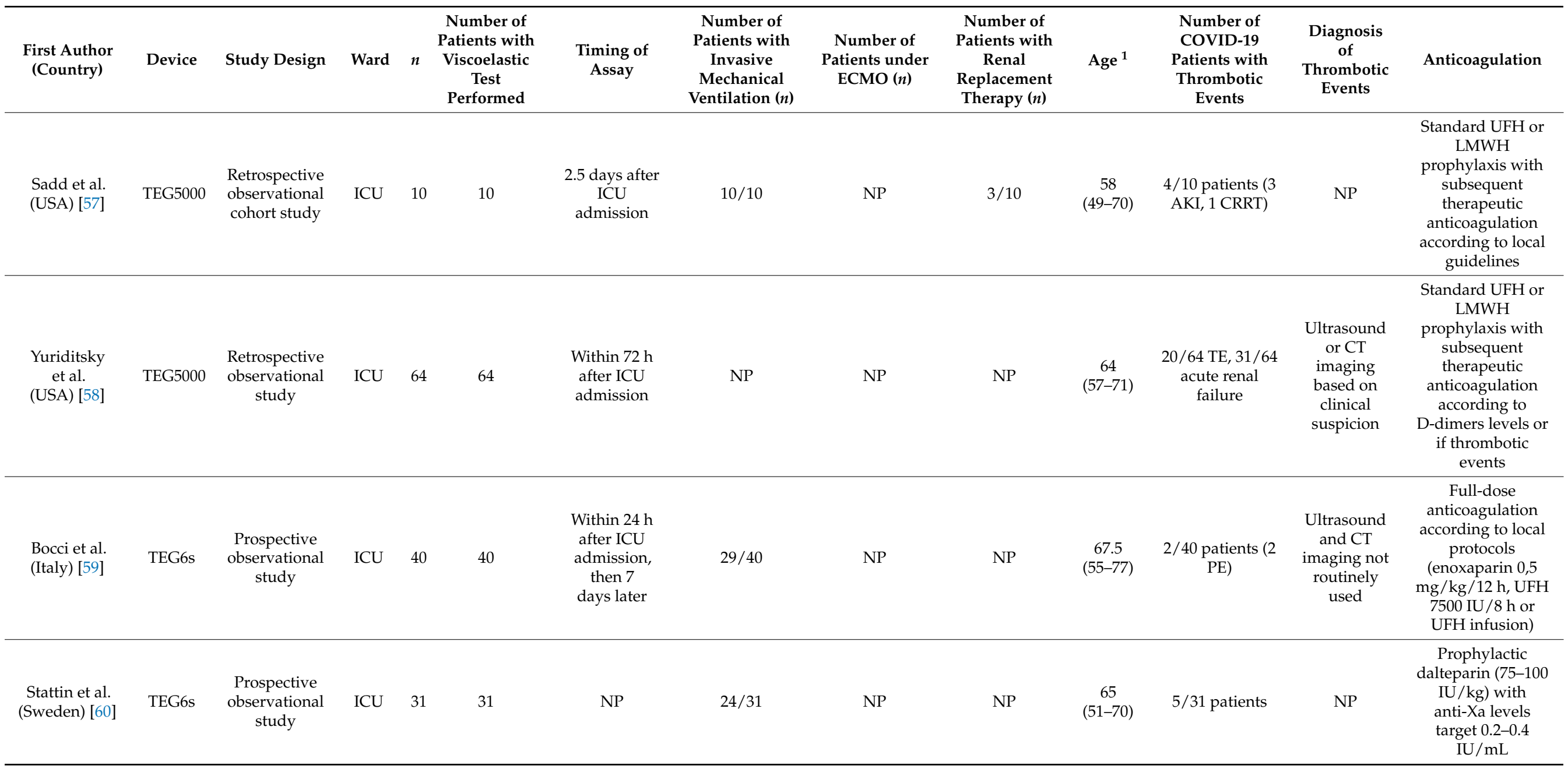


Table 3. Cont

\begin{tabular}{|c|c|c|c|c|c|c|c|c|c|c|c|c|c|}
\hline $\begin{array}{l}\text { First Author } \\
\text { (Country) }\end{array}$ & Device & Study Design & Ward & $n$ & $\begin{array}{c}\text { Number of } \\
\text { Patients with } \\
\text { Viscoelastic } \\
\text { Test } \\
\text { Performed }\end{array}$ & $\begin{array}{l}\text { Timing } \\
\text { of Assay }\end{array}$ & $\begin{array}{l}\text { Number of } \\
\text { Patients with } \\
\text { Invasive } \\
\text { Mechanical } \\
\text { Ventilation }(n)\end{array}$ & $\begin{array}{l}\text { Number of } \\
\text { Patients under } \\
\text { ECMO }(n)\end{array}$ & $\begin{array}{c}\text { Number of } \\
\text { Patients } \\
\text { with Renal } \\
\text { Replace- } \\
\text { ment } \\
\text { Therapy }(n)\end{array}$ & Age $^{1}$ & $\begin{array}{l}\text { Number of } \\
\text { COVID-19 } \\
\text { Patients with } \\
\text { Thrombotic } \\
\text { Events }\end{array}$ & $\begin{array}{l}\text { Diagnosis of } \\
\text { Thrombotic } \\
\text { Events }\end{array}$ & Anticoagulation \\
\hline $\begin{array}{l}\text { Vlot et al. } \\
\text { (The } \\
\text { Netherlands) } \\
\text { [61] }\end{array}$ & TEG6s & $\begin{array}{c}\text { Prospective } \\
\text { observational } \\
\text { study }\end{array}$ & ICU & 16 & 16 & NP & $16 / 16$ & NP & $6 / 16$ & $67(56-73)$ & None & $\begin{array}{l}\text { No systematic } \\
\text { screening }\end{array}$ & $\begin{array}{c}\text { Increase } \\
\text { prophylactic dose } \\
\text { of LMWH: } \\
\text { nadroparin } 5700 \\
\text { IU bid (or } 7600 \mathrm{IU} \\
\text { according to body } \\
\text { weight) instead of } \\
2850 \mathrm{IU} \text { od }\end{array}$ \\
\hline $\begin{array}{l}\text { Patel et al. } \\
\text { (United } \\
\text { Kingdom) } \\
\text { [62] }\end{array}$ & TEG6s & $\begin{array}{l}\text { Retrospective } \\
\text { observational } \\
\text { study }\end{array}$ & ICU & 39 & 39 & NP & $39 / 39$ & $20 / 39$ & NP & $\begin{array}{c}52.5 \\
(29-79)\end{array}$ & $\begin{array}{l}15 / 39 \text { patients } \\
\text { with acute } P E \text {, } \\
4 / 22 \text { with DVT }\end{array}$ & $\begin{array}{c}\text { Systematic } \\
\text { screening by } \\
\text { CT } \\
\text { pulmonary } \\
\text { angiography }\end{array}$ & $\begin{array}{c}\text { At least } \\
\text { prophylactic dose } \\
\text { of LMWH or UFH } \\
\text { with anti-Xa levels } \\
\text { of } 0.2-0.3 \mathrm{IU} / \mathrm{mL}\end{array}$ \\
\hline $\begin{array}{l}\text { Salem et al. } \\
\text { (United Arab } \\
\text { Emirates) [63] }\end{array}$ & TEG6s & $\begin{array}{l}\text { Retrospective } \\
\text { observational } \\
\text { study }\end{array}$ & ICU & 52 & 52 & NP & $46 / 52$ & $7 / 52$ & $16 / 52$ & $53(39-62)$ & $\begin{array}{c}\text { 14/52 patients (8 } \\
\text { DVT, } 6 \text { PE, } 2 \\
\text { arterial } \\
\text { thrombosis) }\end{array}$ & NP & $\begin{array}{l}\text { Standard UFH or } \\
\text { LMWH } \\
\text { prophylaxis with } \\
\text { subsequent } \\
\text { therapeutic } \\
\text { anticoagulation } \\
\text { according to local } \\
\text { guidelines }\end{array}$ \\
\hline $\begin{array}{l}\text { Shah et al. } \\
\text { (United } \\
\text { Kingdom) } \\
\text { [64] }\end{array}$ & TEG6s & $\begin{array}{l}\text { Multicenter } \\
\text { retrospective } \\
\text { observational } \\
\text { study }\end{array}$ & ICU & 187 & 20 & NP & $166 / 187$ & $6 / 187$ & $80 / 187$ & $57(49-64)$ & $\begin{array}{c}\text { 81/187 patients } \\
\text { (42 PE, } 22 \text { DVT, } 25 \\
\text { arterial thrombo- } \\
\text { sis)Extracorporeal } \\
\text { circuit disruption } \\
n=23\end{array}$ & $\begin{array}{l}\text { Ultrasound or } \\
\text { CT imaging } \\
\text { based on } \\
\text { clinical } \\
\text { suspicion }\end{array}$ & $\begin{array}{c}\text { Standard } \\
\text { weight-based } \\
\text { LWMH } \\
\text { prophylaxis with } \\
\text { subsequent } \\
\text { therapeutic } \\
\text { anticoagulation if } \\
\text { thrombotic events }\end{array}$ \\
\hline
\end{tabular}


Table 3. Cont.

\begin{tabular}{|c|c|c|c|c|c|c|c|c|c|c|c|c|c|}
\hline $\begin{array}{l}\text { First Author } \\
\text { (Country) }\end{array}$ & Device & $\begin{array}{l}\text { Study } \\
\text { Design }\end{array}$ & Ward & $n$ & $\begin{array}{c}\text { Number of } \\
\text { Patients with } \\
\text { Viscoelastic } \\
\text { Test } \\
\text { Performed }\end{array}$ & $\begin{array}{l}\text { Timing of } \\
\text { Assay }\end{array}$ & $\begin{array}{l}\text { Number of } \\
\text { Patients with } \\
\text { Invasive } \\
\text { Mechanical } \\
\text { Ventilation } \\
(n)\end{array}$ & $\begin{array}{c}\text { Number of } \\
\text { Patients } \\
\text { under ECMO } \\
(n)\end{array}$ & $\begin{array}{c}\text { Number of } \\
\text { Patients } \\
\text { with Renal } \\
\text { Replace- } \\
\text { ment } \\
\text { Therapy }(n)\end{array}$ & Age $^{1}$ & $\begin{array}{l}\text { Number of } \\
\text { COVID-19 } \\
\text { Patients with } \\
\text { Thrombotic } \\
\text { Events }\end{array}$ & $\begin{array}{l}\text { Diagnosis } \\
\text { of Throm- } \\
\text { botic } \\
\text { Events }\end{array}$ & Anticoagulation \\
\hline $\begin{array}{c}\text { Fan et al. } \\
\text { (Singapore) } \\
\text { [65] }\end{array}$ & TEG6s & Case report & IMW & 1 & 1 & $\begin{array}{c}13 \text { days } \\
\text { after } \\
\text { admission, } \\
1 \mathrm{~h} \text { after } \\
\text { clinical sign } \\
\text { of TE }\end{array}$ & No & No & No & 39 & 1 & $\begin{array}{l}\text { Ultrasound } \\
\text { or CT } \\
\text { imaging } \\
\text { based on } \\
\text { clinical } \\
\text { suspicion }\end{array}$ & $\begin{array}{l}\text { None until TE, then } \\
\text { therapeutic UFH } \\
1300 \mathrm{IU} / \mathrm{h}(\mathrm{anti}-\mathrm{Xa} \\
\text { levels } 0.4-0.6 \mathrm{IU} / \mathrm{mL})\end{array}$ \\
\hline \multirow{2}{*}{$\begin{array}{l}\text { Masi et al. } \\
\text { (France) [66] }\end{array}$} & \multirow{2}{*}{ Quantra } & \multirow{2}{*}{$\begin{array}{l}\text { Prospective } \\
\text { single- } \\
\text { center } \\
\text { cohort } \\
\text { study }\end{array}$} & $\begin{array}{l}\text { ICU } \\
\text { COVID-19 } \\
\text { ARDS }\end{array}$ & 17 & 17 & \multirow{2}{*}{$\begin{array}{c}\text { ICU } \\
\text { admission }\end{array}$} & $17 / 17$ & NP & NP & $\begin{array}{c}48 \\
(42-58)\end{array}$ & $\begin{array}{l}\text { 3/17 patients ( } 3 \\
\text { PE) }\end{array}$ & \multirow{2}{*}{$\mathrm{NP}$} & $\begin{array}{l}\text { Thromboprophylaxis } \\
\text { according to current } \\
\text { guidelines }\end{array}$ \\
\hline & & & $\begin{array}{l}\text { ICU non } \\
\text { COVID-19 } \\
\text { ARDS }\end{array}$ & 11 & 11 & & $11 / 11$ & NP & NP & $\begin{array}{c}34 \\
(28-55)\end{array}$ & NP & & NP \\
\hline $\begin{array}{l}\text { Ranucci et al. } \\
\text { (Italy) [67] }\end{array}$ & Quantra & $\begin{array}{l}\text { Prospective } \\
\text { observa- } \\
\text { tional } \\
\text { study }\end{array}$ & $\mathrm{ICU}$ & 16 & 16 & $\begin{array}{l}2-5 \text { days } \\
\text { after ICU } \\
\text { admission, } \\
\text { then } 14 \\
\text { days after }\end{array}$ & $16 / 16$ & $\mathrm{NP}$ & NP & $\begin{array}{c}61 \\
(55-65)\end{array}$ & None & $\mathrm{NP}$ & $\begin{array}{c}\text { Nadroparin } 4000 \text { IU } \\
\text { bid then } 6000 \text { or } 8000 \\
\text { IU bid according to } \\
\text { BMI }\end{array}$ \\
\hline $\begin{array}{l}\text { Bachler et al. } \\
\text { (Austria) [24] }\end{array}$ & ClotPro & $\begin{array}{l}\text { Retrospective } \\
\text { study }\end{array}$ & ICU & 20 & 20 & $\begin{array}{l}8.5(4.5-15) \\
\text { days after } \\
\text { ICU } \\
\text { admission }\end{array}$ & NP & NP & NP & $\begin{array}{c}61.5 \\
(56.25- \\
68)\end{array}$ & $2 / 20$ patients & NP & $\begin{array}{c}\text { Enoxaparin } 80 \\
\text { (60-100) mg/day }(n= \\
\text { 16) or argatroban } \\
(n=4)\end{array}$ \\
\hline \multirow{3}{*}{$\begin{array}{l}\text { Zátroch et al. } \\
\text { (Hungary) } \\
\text { [68] }\end{array}$} & \multirow{3}{*}{ ClotPro } & \multirow{3}{*}{ Case report } & \multirow{3}{*}{ ICU } & 1 & 1 & NP & No & No & No & 62 & 1 & \multirow{3}{*}{ NP } & $\begin{array}{l}\text { Enoxaparin } \\
80 \mathrm{mg} \text { bid }\end{array}$ \\
\hline & & & & 1 & 1 & $\mathrm{NP}$ & 1 & No & 1 & 80 & 1 & & Enoxaparin $60 \mathrm{mg}$ od \\
\hline & & & & 1 & 1 & $\mathrm{NP}$ & 1 & No & No & 84 & 1 & & Enoxaparin $20 \mathrm{mg}$ od \\
\hline
\end{tabular}

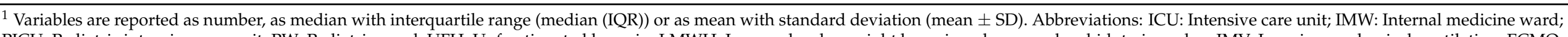

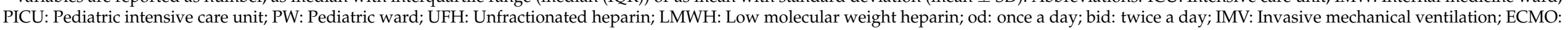

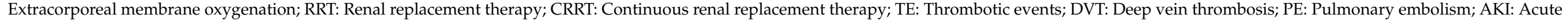
kidney injury; NP: Not provided; NS: Not specified; TEG: Thromboelastography; ROTEM: Rotational thromboelastometry; TEM: Thromboelastometry; tPA: tissue plasminogen activator. 
A total of 1538 inpatients were studied, of which 1393 were COVID-19-positive, among whom 1189 were ICU patients. At least one VET was performed during the hospital stay of 1208 patients, of whom 1063 were COVID-19 patients hospitalized either in an ICU (893 patients) or in a medical ward (IMW, 170 patients). The remaining 145 patients were sex- and age-matched non-COVID-19 controls hospitalized either in the ICU (89 patients) or in IMW (56 patients) for ARDS (acute respiratory distress syndrome) or pneumonia non-related to SARS-CoV-2, or for postoperative care. One article [33] reported data about eight hospitalized children either in a pediatric ward or in a pediatric ICU (PICU).

Among the 44 retrieved studies, 19 were prospective [28-32,39-46,52,59-61,66,67], 18 were retrospective $[24,27,33-36,48,49,51,53-58,62-64]$, one was a cross-sectional study [47], and six were case reports $[26,37,38,50,65,68]$. There was no randomized controlled trial (VET versus no VET).

VETs were performed using ROTEM (25 studies), TEG (15 studies), Quantra (two prospective studies [66,67]) and ClotPro (one retrospective study [24] and one case report [68]); no study compared two devices. Among articles reporting data about TEG, four were prospective studies [52,59-61], ten were retrospective studies [51,53-58,62-64], and one was a case report [65]. Among articles dealing with ROTEM, thirteen were prospective studies [28-32,39-46], seven were retrospective studies [27,33-36,48,49], one was a cross-sectional study [47], and four were case reports [26,37,38,50].

Testing was carried out either on admission or within the following days, but the timing of blood collection for VET was specified only for 29 studies [24,26,27,29-31,33,35$38,41,43-48,50,53,55-59,65-67]$. In some studies, the measurements were repeated during the patient's stay, either because of a pre-established protocol $[26,27,29,45,53,59,60,67]$ or because of the occurrence of a thromboembolic event $[65,68]$. Number of VETs performed during a patient's stay ranged from 1 to 5 [29].

\subsection{Characteristics of the Included Patients}

Characteristics of the included patients are shown in Table 4. 
Table 4. Characteristics of the included patients.

\begin{tabular}{|c|c|c|c|c|c|c|c|c|c|c|c|c|c|c|c|c|c|}
\hline $\begin{array}{l}\text { First Author } \\
\text { (Country) }\end{array}$ & Device & $n$ & Ward & Age & M:F Ratio & $\begin{array}{l}\text { SOFA } \\
\text { Score }\end{array}$ & $\begin{array}{l}\text { APACH } \\
\text { II } \\
\text { Score }\end{array}$ & $\begin{array}{l}\text { E SAPS } \\
\text { II } \\
\text { Score }\end{array}$ & $\begin{array}{l}\text { SAPS } \\
\text { III } \\
\text { Score }\end{array}$ & $\begin{array}{l}\text { DIC } \\
\text { Score }\end{array}$ & $\begin{array}{l}\text { SIC } \\
\text { Score }\end{array}$ & $\begin{array}{c}\text { BMI } \\
(18.5-24.9 \\
\left.\mathrm{kg} / \mathrm{m}^{2}\right)\end{array}$ & Comorbidities & $\begin{array}{l}\text { CRP }(\mathrm{mg} / \mathrm{L}) \\
(<5 \mathrm{mg} / \mathrm{L})^{*}\end{array}$ & $\begin{array}{c}\text { Fibrinogen } \\
\text { (mg/dL) } \\
(200-400 \\
\mathrm{mg} / \mathrm{dL}) *\end{array}$ & $\begin{array}{c}\text { D- } \\
\text { Dimers } \\
(\mu \mathrm{g} / \mathrm{L})\end{array}$ & $\begin{array}{c}\text { Platelets } \\
\left(10^{3} / \mu \mathrm{L}\right) \\
(150-450 \times \\
\left.10^{3} / \mu \mathrm{L}\right) *\end{array}$ \\
\hline $\begin{array}{l}\text { Iwasaki et al. } \\
\text { (Japan) [26] }\end{array}$ & $\begin{array}{c}\text { ROTEM } \\
\text { (NS) }\end{array}$ & 1 & ICU & 57 & $\mathrm{~F}$ & NP & NP & NP & $\mathrm{NP}$ & NP & NP & $\mathrm{NP}$ & NP & 391 & 334 & 1500 & 203 \\
\hline $\begin{array}{l}\text { Pavoni et al. } \\
\text { (Italy) [27] }\end{array}$ & $\begin{array}{l}\text { ROTEM } \\
\text { gamma }\end{array}$ & 40 & ICU & $61 \pm 13$ & $24 \mathrm{M}: 16 \mathrm{~F}$ & $4 \pm 1$ & NP & NP & NP & $\mathrm{NP}$ & NP & $28.4 \pm 4.7$ & Yes $^{5}$ & $\mathrm{NP}$ & $896 \pm 110$ & $\begin{array}{c}1556 \pm \\
1090 \\
\end{array}$ & $318 \pm 168$ \\
\hline \multirow{2}{*}{$\begin{array}{l}\text { Boscolo et al. } \\
\text { (Italy) [28] }\end{array}$} & \multirow{2}{*}{$\begin{array}{c}\text { ROTEM } \\
\text { delta }\end{array}$} & 32 & ICU & $\begin{array}{c}68 \\
(62-75) \\
\end{array}$ & 26 M: 6 F & $3(3-6)$ & $\mathrm{NP}$ & $\mathrm{NP}$ & NP & $1(0-2)$ & $\begin{array}{c}2 \\
(2-2) \\
\end{array}$ & $29(27-32)$ & \multirow[b]{2}{*}{ NP } & $110(55-167)$ & $\begin{array}{c}500 \\
(450-570) \\
\end{array}$ & $\begin{array}{c}315(164- \\
1326)\end{array}$ & $\begin{array}{c}283 \\
(194-336) \\
\end{array}$ \\
\hline & & 32 & IMW & $\begin{array}{c}61 \\
(53-71) \\
\end{array}$ & $24 \mathrm{M}: 8 \mathrm{~F}$ & $2(1-2)$ & NP & NP & $\mathrm{NP}$ & $\begin{array}{c}0 \\
(0-1.8) \\
\end{array}$ & $\begin{array}{c}2 \\
(1-2)\end{array}$ & $29(24-32)$ & & $46(16-96)$ & $\begin{array}{c}450 \\
(330-530)\end{array}$ & $\begin{array}{c}263 \\
(193-598)\end{array}$ & $\begin{array}{c}234 \\
(197-290)\end{array}$ \\
\hline $\begin{array}{l}\text { Corrêa et al. } \\
\text { (Brazil) [29] }\end{array}$ & $\begin{array}{c}\text { ROTEM } \\
\text { delta }\end{array}$ & 30 & ICU & $\begin{array}{c}61 \\
(52-83)\end{array}$ & $15 \mathrm{M}: 15 \mathrm{~F}$ & $\begin{array}{c}10 \\
(7-12)\end{array}$ & NP & $\mathrm{NP}$ & $\begin{array}{c}49 \\
(41- \\
61)\end{array}$ & / & / & $\begin{array}{c}29.3 \\
(24.4-32.2)\end{array}$ & Yes ${ }^{10}$ & $\mathrm{NP}$ & $\begin{array}{c}600 \\
(480-680)\end{array}$ & $\begin{array}{c}1287(798- \\
2202)\end{array}$ & $\begin{array}{c}226 \\
(176-261)\end{array}$ \\
\hline $\begin{array}{l}\text { Madathil } \\
\text { et al. } \\
\text { (USA) [30] }\end{array}$ & $\begin{array}{c}\text { ROTEM } \\
\text { delta }\end{array}$ & 11 & ICU & $\begin{array}{c}53(45.5- \\
65.5)\end{array}$ & $7 \mathrm{M}: 4 \mathrm{~F}$ & NP & NP & NP & $\mathrm{NP}$ & $\mathrm{NP}$ & NP & $\begin{array}{c}28.1 \\
(27.1-34.6)\end{array}$ & Yes $^{11}$ & $\mathrm{NP}$ & NP & NP & NP \\
\hline $\begin{array}{l}\text { Spiezia et al. } \\
\text { (Italy) [31] }\end{array}$ & $\begin{array}{c}\text { ROTEM } \\
\text { delta }\end{array}$ & 22 & ICU & $67 \pm 8$ & $20 \mathrm{M}: 2 \mathrm{~F}$ & $4 \pm 2$ & $\mathrm{NP}$ & NP & $\mathrm{NP}$ & $\mathrm{NP}$ & NP & $30 \pm 6$ & Yes $^{4}$ & $\mathrm{NP}$ & $517 \pm 148$ & $\begin{array}{c}5343 \pm \\
2099\end{array}$ & $240 \pm 119$ \\
\hline \multirow{3}{*}{$\begin{array}{l}\text { Tsantes et al. } \\
\text { (Greece) [32] }\end{array}$} & \multirow{3}{*}{$\begin{array}{c}\text { ROTEM } \\
\text { delta }\end{array}$} & 11 & $\begin{array}{c}\text { ICU } \\
\text { COVID } \\
\text { patients }\end{array}$ & $\begin{array}{c}78 \\
(67-71)\end{array}$ & $10 \mathrm{M}: 1 \mathrm{~F}$ & $\mathrm{NP}$ & NP & NP & $\mathrm{NP}$ & $\mathrm{NP}$ & $\mathrm{NP}$ & $\mathrm{NP}$ & \multirow{3}{*}{$\mathrm{NP}$} & $48(23-128)$ & $\begin{array}{c}439 \\
(313-440)\end{array}$ & $\begin{array}{c}2420 \\
(1470- \\
7320)\end{array}$ & $\begin{array}{c}262 \\
(120-350)\end{array}$ \\
\hline & & 9 & $\begin{array}{l}\text { ICU non } \\
\text { COVID } \\
\text { patients }\end{array}$ & NP & NP & NP & NP & NP & NP & NP & NP & $\mathrm{NP}$ & & $\mathrm{NP}$ & $\mathrm{NP}$ & NP & $\mathrm{NP}$ \\
\hline & & 21 & $\begin{array}{l}\text { IMW } \\
\text { COVID } \\
\text { patients }\end{array}$ & $\begin{array}{c}73 \\
(50-88)\end{array}$ & $11 \mathrm{M}: 10 \mathrm{~F}$ & NP & NP & NP & NP & NP & NP & $\mathrm{NP}$ & & $32(9-55)$ & $\begin{array}{c}437 \\
(399-503)\end{array}$ & $\begin{array}{c}860(540- \\
1210)\end{array}$ & $\begin{array}{c}253 \\
(207-396)\end{array}$ \\
\hline
\end{tabular}


Table 4. Cont.

\begin{tabular}{|c|c|c|c|c|c|c|c|c|c|c|c|c|c|c|c|c|c|}
\hline $\begin{array}{l}\text { First Author } \\
\text { (Country) }\end{array}$ & Device & $n$ & Ward & Age & M:F Ratio & $\begin{array}{l}\text { SOFA } \\
\text { Score }\end{array}$ & $\begin{array}{l}\text { APACHE } \\
\text { II } \\
\text { Score }\end{array}$ & $\begin{array}{l}\text { SAPS } \\
\text { II } \\
\text { Score }\end{array}$ & $\begin{array}{l}\text { SAPS } \\
\text { III } \\
\text { Score }\end{array}$ & $\begin{array}{l}\text { DIC } \\
\text { Score }\end{array}$ & $\begin{array}{l}\text { SIC } \\
\text { Score }\end{array}$ & $\begin{array}{c}\text { BMI } \\
(18.5-24.9 \\
\left.\mathrm{kg} / \mathrm{m}^{2}\right)\end{array}$ & Comorbidities & $\begin{array}{l}\mathrm{CRP}(\mathrm{mg} / \mathrm{L}) \\
(<5 \mathrm{mg} / \mathrm{L}) *\end{array}$ & $\begin{array}{c}\text { Fibrinogen } \\
(\mathrm{mg} / \mathrm{dL}) \\
(200-400 \\
\mathrm{mg} / \mathrm{dL})^{*}\end{array}$ & $\begin{array}{c}\text { D-Dimers } \\
(\mu \mathrm{g} / \mathrm{L})\end{array}$ & $\begin{array}{c}\text { Platelets } \\
\left(10^{3} / \mu \mathrm{L}\right) \\
(150-450 \times \\
\left.10^{3} / \mu \mathrm{L}\right) *\end{array}$ \\
\hline $\begin{array}{l}\text { Al-Ghafry et al. } \\
\text { (USA) [33] }\end{array}$ & $\begin{array}{c}\text { ROTEM } \\
\text { delta }\end{array}$ & 8 & $\begin{array}{c}\text { PICU }(n \\
=5) \text { and } \\
\text { PW }(n= \\
3)\end{array}$ & $\begin{array}{c}12.9 \\
(2-20)\end{array}$ & $4 \mathrm{M}: 4 \mathrm{~F}$ & $\mathrm{NP}$ & $\mathrm{NP}$ & $\mathrm{NP}$ & $\mathrm{NP}$ & $\mathrm{NP}$ & $\mathrm{NP}$ & $\begin{array}{c}21.9(13.3- \\
31.9)\end{array}$ & $\mathrm{NP}$ & $86(4-130)$ & $\begin{array}{c}540 \\
(329-732)\end{array}$ & $\begin{array}{c}932 \\
(151-2451)\end{array}$ & $\begin{array}{c}258 \\
(104-446)\end{array}$ \\
\hline $\begin{array}{l}\text { Creel-Bulos } \\
\text { et al. } \\
\text { (USA) [34] }\end{array}$ & $\begin{array}{c}\text { ROTEM } \\
\text { delta }\end{array}$ & 25 & ICU & $\begin{array}{c}63 \\
(53-77)\end{array}$ & $\mathrm{NP}$ & $\mathrm{NP}$ & $\mathrm{NP}$ & $\mathrm{NP}$ & $\mathrm{NP}$ & $\mathrm{NP}$ & $\mathrm{NP}$ & $\mathrm{NP}$ & $\mathrm{NP}$ & $\begin{array}{c}276 \\
(229-326)\end{array}$ & $\mathrm{NP}$ & $\begin{array}{c}7287(4939- \\
23,912)\end{array}$ & $\mathrm{NP}$ \\
\hline \multirow{2}{*}{$\begin{array}{l}\text { Hoechter et al. } \\
\text { (Germany) [35] }\end{array}$} & \multirow{2}{*}{$\begin{array}{c}\text { ROTEM } \\
\text { delta }\end{array}$} & 22 & $\begin{array}{c}\text { ICU } \\
\text { COVID+ } \\
\text { (ROTEM } \\
n=11)\end{array}$ & $\begin{array}{c}64 \\
(52-70)\end{array}$ & $19 \mathrm{M}: 3 \mathrm{~F}$ & $\begin{array}{c}11.5 \\
(10.3-12)\end{array}$ & $\mathrm{NP}$ & $\mathrm{NP}$ & $\mathrm{NP}$ & $\begin{array}{c}1 \\
(1-1)\end{array}$ & $\mathrm{NP}$ & $27(24-31)$ & Yes $^{4}$ & $\begin{array}{c}156 \\
(103-188)\end{array}$ & $\begin{array}{c}709 \\
(530-786)\end{array}$ & $\begin{array}{c}2400(2000- \\
3900)\end{array}$ & $\begin{array}{c}227 \\
(175-324)\end{array}$ \\
\hline & & 14 & $\begin{array}{l}\text { ICU } \\
\text { COVID- }\end{array}$ & $\begin{array}{c}49 \\
(36-57)\end{array}$ & $9 \mathrm{M}: 5 \mathrm{~F}$ & $\begin{array}{c}15 \\
(13.3-15)\end{array}$ & $\mathrm{NP}$ & $\mathrm{NP}$ & $\mathrm{NP}$ & $\begin{array}{c}3 \\
(1-4)\end{array}$ & $\mathrm{NP}$ & $26(22-32)$ & $\mathrm{NP}$ & $\begin{array}{c}274 \\
(160-328)\end{array}$ & $\begin{array}{c}598 \\
(502-645)\end{array}$ & $\begin{array}{l}11,300 \\
(4100- \\
31,000)\end{array}$ & $\begin{array}{c}175 \\
(113-347)\end{array}$ \\
\hline $\begin{array}{l}\text { Roh et al. } \\
\text { (USA) [36] }\end{array}$ & $\begin{array}{c}\text { ROTEM } \\
\text { delta }\end{array}$ & 30 & ICU & $63 \pm 12$ & $15 \mathrm{M}: 15 \mathrm{~F}$ & $\mathrm{NP}$ & $\mathrm{NP}$ & $\mathrm{NP}$ & $\mathrm{NP}$ & $\mathrm{NP}$ & $\mathrm{NP}$ & $33 \pm 8.1$ & Yes $^{1}$ & $\mathrm{NP}$ & $\mathrm{NP}$ & $\begin{array}{c}11,400 \pm \\
7300\end{array}$ & $255 \pm 103$ \\
\hline $\begin{array}{c}\text { Kong et al. } \\
\text { (United } \\
\text { Kingdom) [37] }\end{array}$ & $\begin{array}{l}\text { ROTEM } \\
\text { delta }\end{array}$ & 1 & ICU & 68 & $\mathrm{M}$ & $\mathrm{NP}$ & $\mathrm{NP}$ & NP & $\mathrm{NP}$ & $\mathrm{NP}$ & $\mathrm{NP}$ & 27.1 & Yes $^{4}$ & 336 & 680 & $>20,000$ & 126 \\
\hline $\begin{array}{l}\text { Raval et al. } \\
\text { (USA) [38] }\end{array}$ & $\begin{array}{c}\text { ROTEM } \\
\text { delta }\end{array}$ & 1 & ICU & 63 & $\mathrm{M}$ & $\mathrm{NP}$ & $\mathrm{NP}$ & $\mathrm{NP}$ & $\mathrm{NP}$ & $\mathrm{NP}$ & $\mathrm{NP}$ & $\mathrm{NP}$ & $\mathrm{NP}$ & $\mathrm{NP}$ & $\mathrm{NP}$ & 2143 & $\mathrm{NP}$ \\
\hline \multirow{2}{*}{$\begin{array}{l}\text { Nougier et al. } \\
\text { (France) [39] }\end{array}$} & \multirow{2}{*}{$\begin{array}{c}\text { Modified } \\
\text { ROTEM } \\
\text { delta } \\
\text { (TEM- } \\
\text { tPA) }\end{array}$} & 40 & $\begin{array}{c}\text { ICU } \\
\text { (ROTEM } \\
n=19)\end{array}$ & $\begin{array}{c}62.8 \pm \\
13.1\end{array}$ & $\mathrm{NP}$ & $5.4 \pm 3.1$ & $\mathrm{NP}$ & $\begin{array}{l}37.9 \\
\pm 13\end{array}$ & $\mathrm{NP}$ & $\mathrm{NP}$ & $\mathrm{NP}$ & $29 \pm 5.5$ & \multirow{2}{*}{$\mathrm{NP}$} & $\mathrm{NP}$ & $610 \pm 190$ & $\begin{array}{c}3456 \pm \\
2641\end{array}$ & $\mathrm{NP}$ \\
\hline & & 38 & $\begin{array}{c}\text { IMW } \\
(\text { ROTEM } \\
n=4)\end{array}$ & $\begin{array}{c}60.2 \pm \\
14.6\end{array}$ & $\mathrm{NP}$ & / & / & / & / & / & / & $26.2 \pm 4.8$ & & $\mathrm{NP}$ & $560 \pm 170$ & $874 \pm 539$ & $\mathrm{NP}$ \\
\hline
\end{tabular}


Table 4. Cont.

\begin{tabular}{|c|c|c|c|c|c|c|c|c|c|c|c|c|c|c|c|c|c|}
\hline $\begin{array}{l}\text { First Author } \\
\text { (Country) }\end{array}$ & Device & $n$ & Ward & Age & M:F Ratio & $\begin{array}{l}\text { SOFA } \\
\text { Score }\end{array}$ & $\begin{array}{l}\text { APACHE } \\
\text { II } \\
\text { Score }\end{array}$ & $\begin{array}{l}\text { SAPS } \\
\text { II } \\
\text { Score }\end{array}$ & $\begin{array}{l}\text { SAPS } \\
\text { III } \\
\text { Score }\end{array}$ & $\begin{array}{l}\text { DIC } \\
\text { Score }\end{array}$ & $\begin{array}{l}\text { SIC } \\
\text { Score }\end{array}$ & $\begin{array}{c}\text { BMI } \\
(18.5-24.9 \\
\left.\mathrm{kg} / \mathrm{m}^{2}\right)\end{array}$ & Comorbidities & $\begin{array}{l}\mathrm{CRP}(\mathrm{mg} / \mathrm{L}) \\
(<5 \mathrm{mg} / \mathrm{L}) *\end{array}$ & $\begin{array}{c}\text { Fibrinogen } \\
\text { (mg/dL) } \\
(200-400 \\
\mathrm{mg} / \mathrm{dL}) *\end{array}$ & $\begin{array}{l}\text { D-Dimers } \\
(\mu \mathrm{g} / \mathrm{L})\end{array}$ & $\begin{array}{c}\text { Platelets } \\
\left(10^{3} / \mu \mathrm{L}\right) \\
(150-450 \times \\
\left.10^{3} / \mu \mathrm{L}\right) *\end{array}$ \\
\hline $\begin{array}{l}\text { Weiss et al. } \\
\text { (France) [40] }\end{array}$ & $\begin{array}{c}\text { Modified } \\
\text { ROTEM } \\
\text { delta } \\
\text { (TEM- } \\
\text { tPA) }\end{array}$ & 5 & $\mathrm{ICU}$ & $57 \pm 15$ & $5 \mathrm{M}: 0 \mathrm{~F}$ & $9 \pm 2$ & $\mathrm{NP}$ & $\mathrm{NP}$ & $\mathrm{NP}$ & $\mathrm{NP}$ & $\mathrm{NP}$ & $\mathrm{NP}$ & $\mathrm{NP}$ & $\mathrm{NP}$ & $740 \pm 240$ & $\begin{array}{c}1975 \pm \\
1623\end{array}$ & $440 \pm 270$ \\
\hline \multirow{2}{*}{$\begin{array}{l}\text { Almskog et al. } \\
\text { (Sweden) [41] }\end{array}$} & \multirow{2}{*}{$\begin{array}{l}\text { ROTEM } \\
\text { sigma }\end{array}$} & 20 & ICU & $\begin{array}{c}62 \\
(55-66) \\
\end{array}$ & $12 \mathrm{M}: 8 \mathrm{~F}$ & $\mathrm{NP}$ & $\mathrm{NP}$ & $\mathrm{NP}$ & $\mathrm{NP}$ & $\mathrm{NP}$ & $\mathrm{NP}$ & $28(25-32)$ & \multirow[b]{2}{*}{ Yes $^{5}$} & $\mathrm{NP}$ & $\begin{array}{c}680 \\
(480-760) \\
\end{array}$ & $\begin{array}{c}1500 \\
(700-4000)\end{array}$ & $\begin{array}{c}252 \\
(206-341) \\
\end{array}$ \\
\hline & & 40 & IMW & $\begin{array}{c}61 \\
(51-74) \\
\end{array}$ & $28 \mathrm{M}: 12 \mathrm{~F}$ & / & / & / & / & / & / & $26(24-32)$ & & $\mathrm{NP}$ & $\begin{array}{c}540 \\
(430-650) \\
\end{array}$ & $\begin{array}{c}600 \\
(500-1000) \\
\end{array}$ & $\begin{array}{c}212 \\
(175-259) \\
\end{array}$ \\
\hline $\begin{array}{l}\text { Collett et al. } \\
\text { (Australia) [42] }\end{array}$ & $\begin{array}{l}\text { ROTEM } \\
\text { sigma }\end{array}$ & 6 & ICU & $\begin{array}{c}69 \\
(64.2- \\
73)\end{array}$ & $5 \mathrm{M}: 1 \mathrm{~F}$ & $\begin{array}{l}7.5(6.25- \\
11.75)\end{array}$ & $\begin{array}{c}75.5 \\
(65.75- \\
105.5)\end{array}$ & $\mathrm{NP}$ & $\mathrm{NP}$ & $\mathrm{NP}$ & $\mathrm{NP}$ & $\mathrm{NP}$ & $\mathrm{NP}$ & $\mathrm{NP}$ & $\begin{array}{c}750 \\
(721-808)\end{array}$ & $\begin{array}{l}6100(2585- \\
9660)\end{array}$ & $\begin{array}{c}291 \\
(213-338)\end{array}$ \\
\hline $\begin{array}{l}\text { Ibañez et al. } \\
\text { (Spain) [43] }\end{array}$ & $\begin{array}{c}\text { ROTEM } \\
\text { sigma }\end{array}$ & 19 & ICU & $\begin{array}{c}61 \\
(55-73) \\
\end{array}$ & $10 \mathrm{M}: 9 \mathrm{~F}$ & $4(2-6)$ & $\mathrm{NP}$ & $\mathrm{NP}$ & $\mathrm{NP}$ & $\begin{array}{c}1 \\
(0-3) \\
\end{array}$ & $\begin{array}{l}1.8 \\
(0.9)\end{array}$ & $28(27-32)$ & Yes ${ }^{10}$ & $\mathrm{NP}$ & $\begin{array}{c}620 \\
(480-760)\end{array}$ & $\begin{array}{c}1000 \\
(600-4200)\end{array}$ & $\begin{array}{c}236 \\
(136-364)\end{array}$ \\
\hline $\begin{array}{l}\text { Kruse et al. } \\
\text { (Germany) [44] }\end{array}$ & $\begin{array}{l}\text { ROTEM } \\
\text { sigma }\end{array}$ & 40 & ICU & $\begin{array}{c}67 \\
(57.3- \\
76.6)\end{array}$ & $35 \mathrm{M}: 5 \mathrm{~F}$ & $\begin{array}{c}9 \\
(6.3-11.8)\end{array}$ & $\begin{array}{c}28 \\
(22-33)\end{array}$ & $\mathrm{NP}$ & $\mathrm{NP}$ & $\mathrm{NP}$ & $\begin{array}{l}3 \\
(2- \\
4)\end{array}$ & $\begin{array}{l}28.1(24.8- \\
32.8)\end{array}$ & Yes ${ }^{10}$ & $\begin{array}{c}124 \\
(84-217)\end{array}$ & $\begin{array}{c}667 \\
(470-770)\end{array}$ & $\begin{array}{l}3950(2600- \\
5900)\end{array}$ & $\begin{array}{c}194 \\
(131-316)\end{array}$ \\
\hline \multirow{2}{*}{$\begin{array}{l}\text { Pavoni et al. } \\
\text { (Italy) [45] }\end{array}$} & \multirow{2}{*}{$\begin{array}{c}\text { ROTEM } \\
\text { sigma }\end{array}$} & 20 & $\begin{array}{c}\text { ICU } \\
\text { COVID- } \\
19 \\
\text { pneumo- } \\
\text { nia }\end{array}$ & $\begin{array}{c}60.3 \pm \\
15.2\end{array}$ & $11 \mathrm{M}: 9 \mathrm{~F}$ & $4.4 \pm 0.8$ & $\mathrm{NP}$ & $\mathrm{NP}$ & $\mathrm{NP}$ & $\mathrm{NP}$ & $\mathrm{NP}$ & $28.4 \pm 4.7$ & \multirow{2}{*}{ Yes $^{4}$} & $\mathrm{NP}$ & $698 \pm 8$ & $1364 \pm 965$ & $289 \pm 155$ \\
\hline & & 25 & $\begin{array}{c}\text { ICU non } \\
\text { COVID- } \\
19 \\
\text { pneumo- } \\
\text { nia }\end{array}$ & $\begin{array}{c}66.5 \pm \\
18.8\end{array}$ & $10 \mathrm{M}: 15 \mathrm{~F}$ & $2.8 \pm 1.1$ & $\mathrm{NP}$ & $\mathrm{NP}$ & $\mathrm{NP}$ & $\mathrm{NP}$ & $\mathrm{NP}$ & $25.2 \pm 2.3$ & & $\mathrm{NP}$ & $349 \pm 81$ & $1476 \pm 770$ & $183 \pm 70$ \\
\hline
\end{tabular}


Table 4. Cont.

\begin{tabular}{|c|c|c|c|c|c|c|c|c|c|c|c|c|c|c|c|c|c|}
\hline $\begin{array}{l}\text { First Author } \\
\text { (Country) }\end{array}$ & Device & $n$ & Ward & Age & M:F Ratio & $\begin{array}{l}\text { SOFA } \\
\text { Score }\end{array}$ & $\begin{array}{l}\text { APACHE } \\
\text { II } \\
\text { Score }\end{array}$ & $\begin{array}{l}\text { SAPS } \\
\text { II } \\
\text { Score }\end{array}$ & $\begin{array}{l}\text { SAPS } \\
\text { III } \\
\text { Score }\end{array}$ & $\begin{array}{l}\text { DIC } \\
\text { Score }\end{array}$ & $\begin{array}{l}\text { SIC } \\
\text { Score }\end{array}$ & $\begin{array}{c}\text { BMI } \\
(18.5-24.9 \\
\left.\mathrm{kg} / \mathrm{m}^{2}\right)\end{array}$ & Comorbidities & $\begin{array}{l}\mathrm{CRP}(\mathrm{mg} / \mathrm{L}) \\
(<5 \mathrm{mg} / \mathrm{L})^{*}\end{array}$ & $\begin{array}{c}\text { Fibrinogen } \\
(\mathrm{mg} / \mathrm{dL}) \\
(200-400 \\
\mathrm{mg} / \mathrm{dL}) *\end{array}$ & $\begin{array}{c}\text { D-Dimers } \\
(\mu \mathrm{g} / \mathrm{L})\end{array}$ & $\begin{array}{c}\text { Platelets } \\
\left(10^{3} / \mu \mathrm{L}\right) \\
(150-450 \times \\
\left.10^{3} / \mu \mathrm{L}\right)^{*}\end{array}$ \\
\hline \multirow{2}{*}{$\begin{array}{l}\text { Spiezia et al. } \\
\text { (Italy) [46] }\end{array}$} & \multirow{2}{*}{$\begin{array}{l}\text { ROTEM } \\
\text { sigma }\end{array}$} & 56 & $\begin{array}{c}\text { IMW } \\
\text { COVID-19 } \\
\text { pneumo- } \\
\text { nia }\end{array}$ & $64 \pm 15$ & $37 \mathrm{M}: 19 \mathrm{~F}$ & $2 \pm 1$ & $\mathrm{NP}$ & $\mathrm{NP}$ & $\mathrm{NP}$ & $\mathrm{NP}$ & $\mathrm{NP}$ & $30 \pm 4$ & \multirow{2}{*}{ Yes $^{4}$} & $60 \pm 56$ & $451 \pm 168$ & $1079 \pm 666$ & $277 \pm 131$ \\
\hline & & 56 & $\begin{array}{l}\text { IMW non } \\
\text { COVID-19 } \\
\text { pneumo- } \\
\text { nia }\end{array}$ & $76 \pm 11$ & $35 \mathrm{M}: 21 \mathrm{~F}$ & $3 \pm 1$ & $\mathrm{NP}$ & $\mathrm{NP}$ & $\mathrm{NP}$ & $\mathrm{NP}$ & $\mathrm{NP}$ & $27 \pm 6$ & & $114 \pm 77$ & $488 \pm 198$ & $1296 \pm 8$ & $274 \pm 89$ \\
\hline \multirow{2}{*}{$\begin{array}{c}\text { Van der } \\
\text { Linden et al. } \\
\text { (Sweden) [47] }\end{array}$} & \multirow{2}{*}{$\begin{array}{l}\text { ROTEM } \\
\text { sigma }\end{array}$} & 12 & $\begin{array}{l}\text { ICU before } \\
\text { enhanced } \\
\text { anticoagu- } \\
\text { lation }\end{array}$ & $54 \pm 9$ & $12 \mathrm{M}: 0 \mathrm{~F}$ & $\mathrm{NP}$ & $\mathrm{NP}$ & $\mathrm{NP}$ & $\mathrm{NP}$ & $\mathrm{NP}$ & $\mathrm{NP}$ & $30.3 \pm 5.6$ & \multirow[b]{2}{*}{ Yes $^{1}$} & $\begin{array}{c}258 \\
(135-348)\end{array}$ & $870 \pm 200$ & $\begin{array}{c}6900(5700- \\
10,000)\end{array}$ & $393 \pm 151$ \\
\hline & & 14 & $\begin{array}{l}\text { ICU after } \\
\text { enhanced } \\
\text { anticoagu- } \\
\text { lation }\end{array}$ & $59 \pm 8$ & $14 \mathrm{M}: 0 \mathrm{~F}$ & $\mathrm{NP}$ & $\mathrm{NP}$ & $\mathrm{NP}$ & $\mathrm{NP}$ & $\mathrm{NP}$ & $\mathrm{NP}$ & $28.2 \pm 4.2$ & & $57(37-137)$ & $630 \pm 250$ & $\begin{array}{l}3900(2200- \\
6800)\end{array}$ & $320 \pm 93$ \\
\hline $\begin{array}{l}\text { Blasi et al. } \\
\text { (Spain) [48] }\end{array}$ & $\begin{array}{l}\text { ROTEM } \\
\text { sigma }\end{array}$ & 11 & IMW & $\begin{array}{c}58 \\
(42-74)\end{array}$ & $8 \mathrm{M}: 3 \mathrm{~F}$ & / & / & / & / & / & / & $29(27-31)$ & Yes $^{1}$ & $\begin{array}{c}3.28 \\
(2.33-8.96)\end{array}$ & $\begin{array}{c}502 \\
(172-552)\end{array}$ & $\begin{array}{c}565 \\
(425-2188)\end{array}$ & $\begin{array}{c}167 \\
(154-239)\end{array}$ \\
\hline $\begin{array}{c}\text { Van } \\
\text { Veenendaal } \\
\text { et al. } \\
\text { (The } \\
\text { Netherlands) } \\
\text { [49] }\end{array}$ & $\begin{array}{l}\text { ROTEM } \\
\text { sigma }\end{array}$ & 47 & $\mathrm{ICU}$ & $\begin{array}{c}63 \\
(29-79)\end{array}$ & $38 \mathrm{M}: 9 \mathrm{~F}$ & / & I & $\begin{array}{l}42 \\
(17- \\
70)\end{array}$ & / & / & / & $\begin{array}{c}28.8(24.4- \\
48.4)\end{array}$ & Yes $^{4}$ & $\mathrm{NP}$ & $720 \pm 160$ & $\mathrm{NP}$ & $404 \pm 154$ \\
\hline $\begin{array}{l}\text { Lazar et al. } \\
\text { (USA) [50] }\end{array}$ & $\begin{array}{c}\text { ROTEM } \\
\text { sigma }\end{array}$ & $\begin{array}{l}1 \\
1\end{array}$ & $\begin{array}{l}\text { IMW } \\
\text { IMW }\end{array}$ & $\begin{array}{l}\mathrm{NP} \\
\mathrm{NP}\end{array}$ & $\begin{array}{l}\mathrm{NP} \\
\mathrm{NP}\end{array}$ & ' & ' & ' & / & ' & ' & $\begin{array}{l}\mathrm{NP} \\
\mathrm{NP}\end{array}$ & $\begin{array}{l}\mathrm{NP} \\
\mathrm{NP}\end{array}$ & $\begin{array}{l}\mathrm{NP} \\
\mathrm{NP}\end{array}$ & $\begin{array}{l}653 \\
820\end{array}$ & $\begin{array}{c}760 \\
1330\end{array}$ & $\begin{array}{l}\mathrm{NP} \\
\mathrm{NP}\end{array}$ \\
\hline $\begin{array}{l}\text { Wright et al. } \\
\text { (USA) [51] }\end{array}$ & $\begin{array}{l}\text { TEG } \\
\text { (NS) }\end{array}$ & 44 & ICU & $\begin{array}{c}54 \\
(42-59) \\
\end{array}$ & $28 \mathrm{M}: 16 \mathrm{~F}$ & $\mathrm{NP}$ & $\mathrm{NP}$ & $\mathrm{NP}$ & $\mathrm{NP}$ & $\mathrm{NP}$ & $\mathrm{NP}$ & $30(27-37)$ & Yes $^{5}$ & $\mathrm{NP}$ & $\begin{array}{c}656 \\
(560-779)\end{array}$ & $\begin{array}{c}1840 \\
(935-4085)\end{array}$ & $\begin{array}{c}232 \\
(186-298) \\
\end{array}$ \\
\hline $\begin{array}{l}\text { Panigada et al. } \\
\text { (Italy) [52] }\end{array}$ & TEG5000 & 24 & $\mathrm{ICU}$ & $\begin{array}{c}56 \\
(23-71)\end{array}$ & $\mathrm{NP}$ & $\mathrm{NP}$ & $\mathrm{NP}$ & $\mathrm{NP}$ & $\mathrm{NP}$ & $\mathrm{NP}$ & $\mathrm{NP}$ & $\mathrm{NP}$ & $\mathrm{NP}$ & $\begin{array}{c}161 \\
(39-342)\end{array}$ & $\begin{array}{c}680(234- \\
1344)\end{array}$ & $\begin{array}{c}4877(1197- \\
16,954)\end{array}$ & $\begin{array}{c}348 \\
(59-577)\end{array}$ \\
\hline
\end{tabular}


Table 4. Cont.

\begin{tabular}{|c|c|c|c|c|c|c|c|c|c|c|c|c|c|c|c|c|c|}
\hline $\begin{array}{l}\text { First Author } \\
\text { (Country) }\end{array}$ & Device & $n$ & Ward & Age & M:F Ratio & $\begin{array}{l}\text { SOFA } \\
\text { Score }\end{array}$ & $\begin{array}{l}\text { APACHE } \\
\text { II Score }\end{array}$ & $\begin{array}{l}\text { SAPS } \\
\text { II } \\
\text { Score }\end{array}$ & $\begin{array}{l}\text { SAPS } \\
\text { III } \\
\text { Score }\end{array}$ & $\begin{array}{l}\text { DIC } \\
\text { Score }\end{array}$ & $\begin{array}{l}\text { SIC } \\
\text { Score }\end{array}$ & $\begin{array}{c}\text { BMI } \\
(18.5-24.9 \\
\left.\mathrm{kg} / \mathrm{m}^{2}\right)\end{array}$ & Comorbidities & $\begin{array}{l}\mathrm{CRP}(\mathrm{mg} / \mathrm{L}) \\
(<5 \mathrm{mg} / \mathrm{L}) *\end{array}$ & $\begin{array}{c}\text { Fibrinogen } \\
(\mathrm{mg} / \mathrm{dL}) \\
(200-400 \\
\mathrm{mg} / \mathrm{dL}) *\end{array}$ & $\begin{array}{c}\text { D-Dimers } \\
(\mu \mathrm{g} / \mathrm{L})\end{array}$ & $\begin{array}{c}\text { Platelets } \\
\left(10^{3} / \mu \mathrm{L}\right) \\
(150-450 \times \\
\left.10^{3} / \mu \mathrm{L}\right) *\end{array}$ \\
\hline $\begin{array}{l}\text { Cordier et al. } \\
\text { France) [53] }\end{array}$ & TEG5000 & 24 & ICU & $\begin{array}{c}69 \\
(61-71) \\
\end{array}$ & 16 M: 8 F & $\mathrm{NP}$ & $\mathrm{NP}$ & $\begin{array}{c}45 \\
(33-53)\end{array}$ & $\mathrm{NP}$ & $\begin{array}{c}3 \\
(2-3) \\
\end{array}$ & $\mathrm{NP}$ & $\begin{array}{c}28.5 \\
(25.7-31) \\
\end{array}$ & $\mathrm{NP}$ & $\begin{array}{c}128 \\
(101-249)\end{array}$ & $\begin{array}{c}680 \\
(620-790) \\
\end{array}$ & $\begin{array}{c}3600(1960- \\
6490)\end{array}$ & $\begin{array}{c}220 \\
(173-294) \\
\end{array}$ \\
\hline $\begin{array}{l}\text { Hightower } \\
\text { et al. } \\
\text { (USA) [54] }\end{array}$ & TEG5000 & 5 & ICU & $\begin{array}{c}59(38- \\
69.5)\end{array}$ & $3 \mathrm{M}: 2 \mathrm{~F}$ & $\mathrm{NP}$ & $\mathrm{NP}$ & $\mathrm{NP}$ & $\mathrm{NP}$ & $\mathrm{NP}$ & $\mathrm{NP}$ & $34.4 \pm 3.9$ & Yes ${ }^{6}$ & $\mathrm{NP}$ & $658 \pm 93$ & $\begin{array}{c}10,672 \pm \\
7907\end{array}$ & $243 \pm 35$ \\
\hline $\begin{array}{l}\text { Maatman } \\
\text { et al. } \\
\text { (USA) [55] }\end{array}$ & TEG5000 & 109 & $\begin{array}{l}\text { ICU } \\
(\text { TEG } n \\
=12)\end{array}$ & $61 \pm 16$ & $62 \mathrm{M}: 47 \mathrm{~F}$ & $\mathrm{NP}$ & $\mathrm{NP}$ & $\mathrm{NP}$ & $\mathrm{NP}$ & $\mathrm{NP}$ & $\mathrm{NP}$ & $\begin{array}{c}34.8 \pm \\
11.8\end{array}$ & Yes $^{5}$ & $\begin{array}{c}146 \\
(101-227)\end{array}$ & $\begin{array}{c}535 \\
(435-651)\end{array}$ & $\begin{array}{c}506 \\
(321-973)\end{array}$ & $\begin{array}{c}207 \\
(152-255)\end{array}$ \\
\hline $\begin{array}{l}\text { Mortus et al. } \\
\text { (USA) [56] }\end{array}$ & TEG5000 & 21 & ICU & $68 \pm 11$ & $12 \mathrm{M}: 9$ F & $\mathrm{NP}$ & $\mathrm{NP}$ & $\mathrm{NP}$ & $\mathrm{NP}$ & $\mathrm{NP}$ & $\mathrm{NP}$ & $\mathrm{NP}$ & Yes (NS) & $\mathrm{NP}$ & $740 \pm 240$ & $\begin{array}{c}8300 \pm \\
7000\end{array}$ & $210 \pm 100$ \\
\hline $\begin{array}{l}\text { Sadd et al. } \\
\text { (USA) [57] }\end{array}$ & TEG5000 & 10 & ICU & $\begin{array}{c}58 \\
(49-70) \\
\end{array}$ & $8 \mathrm{M}: 2 \mathrm{~F}$ & $4(3-5)$ & $\mathrm{NP}$ & $\mathrm{NP}$ & $\mathrm{NP}$ & $\mathrm{NP}$ & $\mathrm{NP}$ & $35(30-39)$ & $\mathrm{Yes}^{3}$ & $20(13-25)$ & $\begin{array}{c}676 \\
(543-769) \\
\end{array}$ & $\begin{array}{l}3150(1000- \\
6620)\end{array}$ & $\begin{array}{c}291 \\
(224-408)\end{array}$ \\
\hline $\begin{array}{l}\text { Yuriditsky } \\
\text { et al. } \\
\text { (USA) [58] }\end{array}$ & TEG5000 & 64 & ICU & $\begin{array}{c}64 \\
(57-71)\end{array}$ & $46 \mathrm{M}: 18 \mathrm{~F}$ & $\mathrm{NP}$ & $\mathrm{NP}$ & $\mathrm{NP}$ & $\mathrm{NP}$ & $\mathrm{NP}$ & $\mathrm{NP}$ & $\mathrm{NP}$ & Yes $^{7}$ & $\begin{array}{c}104 \\
(35-158)\end{array}$ & $\begin{array}{c}669 \\
(451-838)\end{array}$ & $\begin{array}{c}2374 \\
(923-4820)\end{array}$ & $\begin{array}{c}244 \\
(176-321)\end{array}$ \\
\hline $\begin{array}{l}\text { Stattin et al. } \\
\text { (Sweden) } \\
\text { [60] }\end{array}$ & TEG6s & 31 & ICU & $\begin{array}{c}65 \\
(51-70)\end{array}$ & $25 \mathrm{M}: 6 \mathrm{~F}$ & $\mathrm{NP}$ & $\mathrm{NP}$ & $\mathrm{NP}$ & $\begin{array}{c}53 \\
(48- \\
60)\end{array}$ & $\mathrm{NP}$ & $\mathrm{NP}$ & $30(27-33)$ & Yes $^{5}$ & $\begin{array}{c}214 \\
(152-294)\end{array}$ & $\mathrm{NP}$ & $\begin{array}{c}2100 \\
(900-3200)\end{array}$ & $\begin{array}{c}227 \\
(163-248)\end{array}$ \\
\hline $\begin{array}{l}\text { Vlot et al. } \\
\text { (The Nether- } \\
\text { lands) } \\
\text { [61] }\end{array}$ & TEG6s & 16 & ICU & $\begin{array}{c}67 \\
(56-73)\end{array}$ & $12 \mathrm{M}: 4 \mathrm{~F}$ & $\mathrm{NP}$ & $\mathrm{NP}$ & $\mathrm{NP}$ & $\mathrm{NP}$ & $\mathrm{NP}$ & $\mathrm{NP}$ & $\mathrm{NP}$ & Yes $^{6}$ & $\mathrm{NP}$ & $\begin{array}{c}620 \\
(590-690)\end{array}$ & $\begin{array}{c}4425(1870- \\
5781)\end{array}$ & $\begin{array}{c}347 \\
(302-462)\end{array}$ \\
\hline $\begin{array}{c}\text { Patel et al. } \\
\text { (United } \\
\text { Kingdom) } \\
\text { [62] }\end{array}$ & TEG6s & 39 & ICU & $\begin{array}{c}52.5 \\
(29-79)\end{array}$ & $32 \mathrm{M}: 7 \mathrm{~F}$ & $8 \pm 2.5$ & $18.7 \pm 5$ & $\mathrm{NP}$ & $\mathrm{NP}$ & NP & $\mathrm{NP}$ & $31.3 \pm 6.1$ & Yes $^{5}$ & $305 \pm 101$ & $660 \pm 190$ & $\begin{array}{l}6440 \pm \\
10,434\end{array}$ & $272 \pm 77$ \\
\hline $\begin{array}{c}\text { Salem et al. } \\
\text { (United } \\
\text { Arab } \\
\text { Emirates) } \\
\text { [63] }\end{array}$ & TEG6s & 52 & ICU & $\begin{array}{c}53 \\
(39-62)\end{array}$ & $51 \mathrm{M}: 1 \mathrm{~F}$ & $\mathrm{NP}$ & $\mathrm{NP}$ & $\mathrm{NP}$ & $\mathrm{NP}$ & $\mathrm{NP}$ & $\mathrm{NP}$ & $\begin{array}{c}25.8 \\
(23-29.5)\end{array}$ & Yes $^{9}$ & $50(9-117)$ & $\begin{array}{c}400 \\
(270-600)\end{array}$ & $\begin{array}{l}4000(3300- \\
4000)\end{array}$ & $\begin{array}{c}228 \\
(137-292)\end{array}$ \\
\hline
\end{tabular}


Table 4. Cont.

\begin{tabular}{|c|c|c|c|c|c|c|c|c|c|c|c|c|c|c|c|c|c|}
\hline $\begin{array}{l}\text { First Author } \\
\text { (Country) }\end{array}$ & Device & $n$ & Ward & Age & M:F Ratio & $\begin{array}{l}\text { SOFA } \\
\text { Score }\end{array}$ & $\begin{array}{l}\text { APACHE } \\
\text { II Score }\end{array}$ & $\begin{array}{l}\text { SAPS } \\
\text { II } \\
\text { Score }\end{array}$ & $\begin{array}{l}\text { SAPS } \\
\text { III } \\
\text { Score }\end{array}$ & $\begin{array}{l}\text { DIC } \\
\text { Score }\end{array}$ & $\begin{array}{l}\text { SIC } \\
\text { Score }\end{array}$ & $\begin{array}{c}\text { BMI } \\
(18.5-24.9 \\
\left.\mathrm{kg} / \mathrm{m}^{2}\right)\end{array}$ & Comorbidities & $\begin{array}{l}\text { CRP }(\mathrm{mg} / \mathrm{L}) \\
(<5 \mathrm{mg} / \mathrm{L})^{*}\end{array}$ & $\begin{array}{l}\text { Fibrinogen } \\
(\mathrm{mg} / \mathrm{dL}) \\
(200-400 \\
\mathrm{mg} / \mathrm{dL})^{*}\end{array}$ & $\begin{array}{l}\text { D-Dimers } \\
(\mu \mathrm{g} / \mathrm{L})\end{array}$ & $\begin{array}{c}\text { Platelets } \\
\left(10^{3} / \mu \mathrm{L}\right) \\
(150-450 \times \\
\left.10^{3} / \mu \mathrm{L}\right)^{*}\end{array}$ \\
\hline $\begin{array}{l}\text { Shah et al. } \\
\text { (United } \\
\text { Kingdom) } \\
\text { [64] }\end{array}$ & TEG6s & 187 & $\begin{array}{l}\text { ICU } \\
(\text { TEG } n \\
=20)\end{array}$ & $\begin{array}{c}57 \\
(49-64)\end{array}$ & $\begin{array}{c}124 \text { M: } 63 \\
\text { F }\end{array}$ & NP & $\begin{array}{c}13 \\
(10-13)\end{array}$ & NP & NP & $\mathrm{NP}$ & $\mathrm{NP}$ & $28(25-32)$ & Yes ${ }^{10}$ & $\begin{array}{c}202 \\
(128-294)\end{array}$ & $\begin{array}{c}700(600- \\
1000)\end{array}$ & $\begin{array}{c}2587(950- \\
10,000)\end{array}$ & $\begin{array}{c}241 \\
(186-318)\end{array}$ \\
\hline $\begin{array}{c}\text { Fan et al. } \\
\text { (Singapore) } \\
\text { [65] }\end{array}$ & TEG6s & 1 & IMW & 39 & M & NP & NP & NP & $\mathrm{NP}$ & $\mathrm{NP}$ & NP & NP & $\mathrm{NP}$ & 136 & 770 & 2,55 & NP \\
\hline \multirow[b]{2}{*}{$\begin{array}{l}\text { Masi et al. } \\
\text { (France) [66] }\end{array}$} & \multirow[b]{2}{*}{ Quantra } & 17 & $\begin{array}{c}\text { ICU } \\
\text { COVID+ }\end{array}$ & $\begin{array}{c}48 \\
(42-58)\end{array}$ & $12 \mathrm{M}: 5 \mathrm{~F}$ & $12(9-17)$ & NP & $\begin{array}{c}52 \\
(43-63)\end{array}$ & NP & $0(0)$ & NP & $\begin{array}{c}31(28.8- \\
40.5)\end{array}$ & Yes $^{3}$ & $\begin{array}{c}136 \\
(92-315)\end{array}$ & $\begin{array}{c}710 \\
(490-790)\end{array}$ & $\begin{array}{c}8390(5330- \\
11,180)\end{array}$ & $\begin{array}{c}231 \\
(160-245)\end{array}$ \\
\hline & & 11 & $\begin{array}{c}\text { ICU } \\
\text { COVID- }\end{array}$ & $\begin{array}{c}34 \\
(28-55)\end{array}$ & $7 \mathrm{M}: 4 \mathrm{~F}$ & $9(7-17)$ & NP & $\begin{array}{c}57 \\
(37-81)\end{array}$ & NP & $4(36)$ & $\mathrm{NP}$ & $\begin{array}{c}29.3 \\
(26-35)\end{array}$ & NP & $\begin{array}{c}320 \\
(159-367)\end{array}$ & $\begin{array}{c}810 \\
(640-945)\end{array}$ & $\begin{array}{c}4640(3200- \\
20,000)\end{array}$ & $\begin{array}{c}262 \\
(224-334)\end{array}$ \\
\hline $\begin{array}{c}\text { Ranucci et al. } \\
\text { (Italy) [67] }\end{array}$ & Quantra & 16 & $\mathrm{ICU}$ & $\begin{array}{c}61 \\
(55-65)\end{array}$ & $15 \mathrm{M}: 1 \mathrm{~F}$ & NP & $\mathrm{NP}$ & NP & NP & $\mathrm{NP}$ & $\mathrm{NP}$ & $\begin{array}{c}26.4(23.9- \\
35.1)\end{array}$ & Yes $^{4}$ & NP & $\begin{array}{c}794 \\
(583-933)\end{array}$ & $\begin{array}{c}3500(2500- \\
6500)\end{array}$ & $\begin{array}{c}271 \\
(192-302)\end{array}$ \\
\hline $\begin{array}{c}\text { Bachler et al. } \\
\text { (Austria) } \\
\text { [24] }\end{array}$ & ClotPro & 20 & ICU & $\begin{array}{c}61.5 \\
(56.25- \\
68)\end{array}$ & $14 \mathrm{M}: 6 \mathrm{~F}$ & $\begin{array}{c}6.5 \\
(3-8.25)\end{array}$ & NP & NP & $\begin{array}{l}56 \\
(53- \\
64)\end{array}$ & NP & NP & $\begin{array}{c}28.8 \\
(24.3-31)\end{array}$ & Yes $^{1}$ & $\begin{array}{c}187.1(116.4- \\
275.7)\end{array}$ & $\begin{array}{c}600(553- \\
677.25)\end{array}$ & $\begin{array}{c}1554(1227- \\
9088)\end{array}$ & $\begin{array}{c}230(202.5- \\
297.25)\end{array}$ \\
\hline \multirow{3}{*}{$\begin{array}{c}\text { Zátroch et al. } \\
\text { (Hungary) } \\
\text { [68] }\end{array}$} & \multirow{3}{*}{ ClotPro } & 1 & & 62 & M & NP & NP & NP & $\mathrm{NP}$ & NP & NP & NP & \multirow{3}{*}{ Yes $^{2}$} & 21 & $\mathrm{NP}$ & $\mathrm{NP}$ & NP \\
\hline & & 1 & ICU & 80 & M & NP & NP & $\mathrm{NP}$ & $\mathrm{NP}$ & $\mathrm{NP}$ & $\mathrm{NP}$ & $\mathrm{NP}$ & & $176-221$ & 448 & 7370 & $\mathrm{NP}$ \\
\hline & & 1 & & 84 & F & NP & NP & NP & NP & $\mathrm{NP}$ & $\mathrm{NP}$ & NP & & $230-376$ & 544 & 10,600 & NP \\
\hline
\end{tabular}

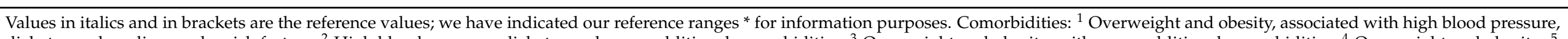

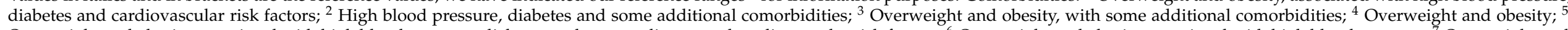

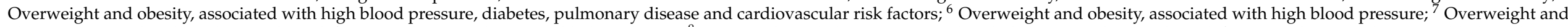

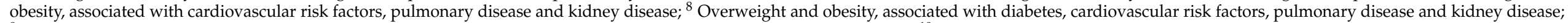

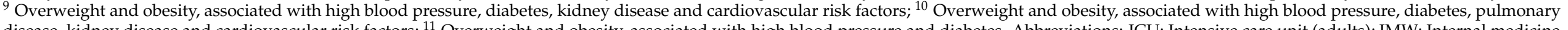

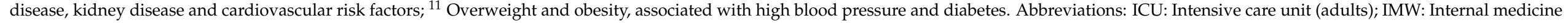

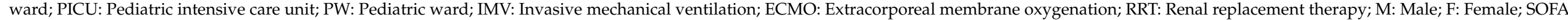

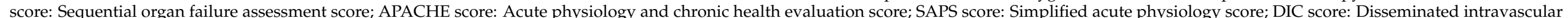

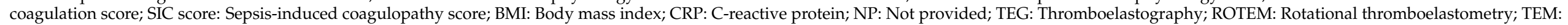
Thromboelastometry; tPA: tissue plasminogen activator. 
The number of COVID-19 patients with at least one VET performed in each article ranged from $1[26,38,65]$ to 64 [58]. Mean or median adult COVID-19 patients ages ranged from 39 [65] to 84 years [68]. Excluding case reports, the proportion of women among the studies reporting gender ranged from $0[40]$ to $50 \%[29,33,36]$.

Overall, most patients presented with overweight or obesity, associated with other additional co-morbidities such as diabetes or hypertension. Overall, COVID-19 patients were characterized by hyperfibrinogenemia, marked increased D-dimer levels, and increased C-reactive protein (CRP). The majority of patients received thromboprophylaxis either with unfractionated heparin (UFH) or low molecular weight heparin (LMWH) (at usual prophylactic doses or higher) according to published guidance [74-76] or local protocols. Thrombotic events (such as deep vein thrombosis, pulmonary embolism, ischemic stroke, or acute kidney injury) were reported as an outcome in 36 articles [24,26-29,31,33,34,3640,42-44,47-49,51,53-68].

\subsection{Results of the Viscoelastic Tests \\ 3.5.1. ROTEM}

ROTEM devices were used in 25 studies with a total of 708 patients, of whom 435 were ICU COVID-19 patients, most of them intubated and mechanically ventilated. Five studies compared results from COVID-19 patients versus non COVID-19 patients: one reported data from non-ICU patients [46], whereas the four other ones reported data from ICU patients $[32,35,36,45]$. Six studies reported data from both ICU and IMW COVID-19 patients $[28,32,33,39,41,48]$.

Data from ROTEM gamma, delta, and sigma were reported in one study, thirteen studies [28-40], and ten [41-50], respectively. One case report did not specify the device [26]. Results are displayed in Table 5 (EXTEM, INTEM, and FIBTEM assays), Table 6 (INTEM and HEPTEM assays), and Table 7 (EXTEM and TEP-tPA).

As a general rule, three assays were performed, mostly INTEM (19 studies), EXTEM (23 studies), and FIBTEM (23 studies). The great majority of the articles reported results from EXTEM assay with or without INTEM assay and associated with FIBTEM assay. Only four articles $[26,41,44,50]$ reported data from HEPTEM assay (Table 6), while almost all patients received anticoagulation by UFH or LMWH at least at a prophylactic dose. The APTEM assay results were only reported by one case report [26] and were consistent with the absence of hyperfibrinolysis. Two studies reported data from TEM-tPA (Table 7), an investigator-modified assay derived from EXTEM assay to investigate a potential hypofibrinolysis $[39,40]$.

Among the 18 articles reporting data from EXTEM, INTEM, and FIBTEM assays, $16[26,27,29,31,33,36,38,41,42,44-50]$ found an increase in "amplitude of the clot" in the three assays, and 2 only in EXTEM and FIBTEM assays [43], or in FIBTEM assay alone [28]. Among the four articles reporting data from EXTEM and FIBTEM only [30,34,35,37], EXTEM only [32], EXTEM and TEM-tPA only [40], and TEM-tPA only [39], an increased in the "amplitude of the clot" was also a common finding.

Besides the increased clot amplitude, other abnormalities were interpreted as suggesting a hypercoagulable state. First, a shortened CFT in EXTEM, INTEM, FIBTEM, and/or HEPTEM was evidenced in 14 studies [26,27,31-33,38,41-46,49,50] out of 18, whereas the others found no abnormalities or even a prolonged CFT $[28,29,35,37]$. Second, four studies $[32,38,39,50]$ out of five showed an increase in $\alpha$ angle in EXTEM or in TEM-tPA, whereas the last reported a normal or even a decrease one [37]. 
Table 5. Main findings of studies reporting ROTEM results (except APTEM and TEM-tPA assays).

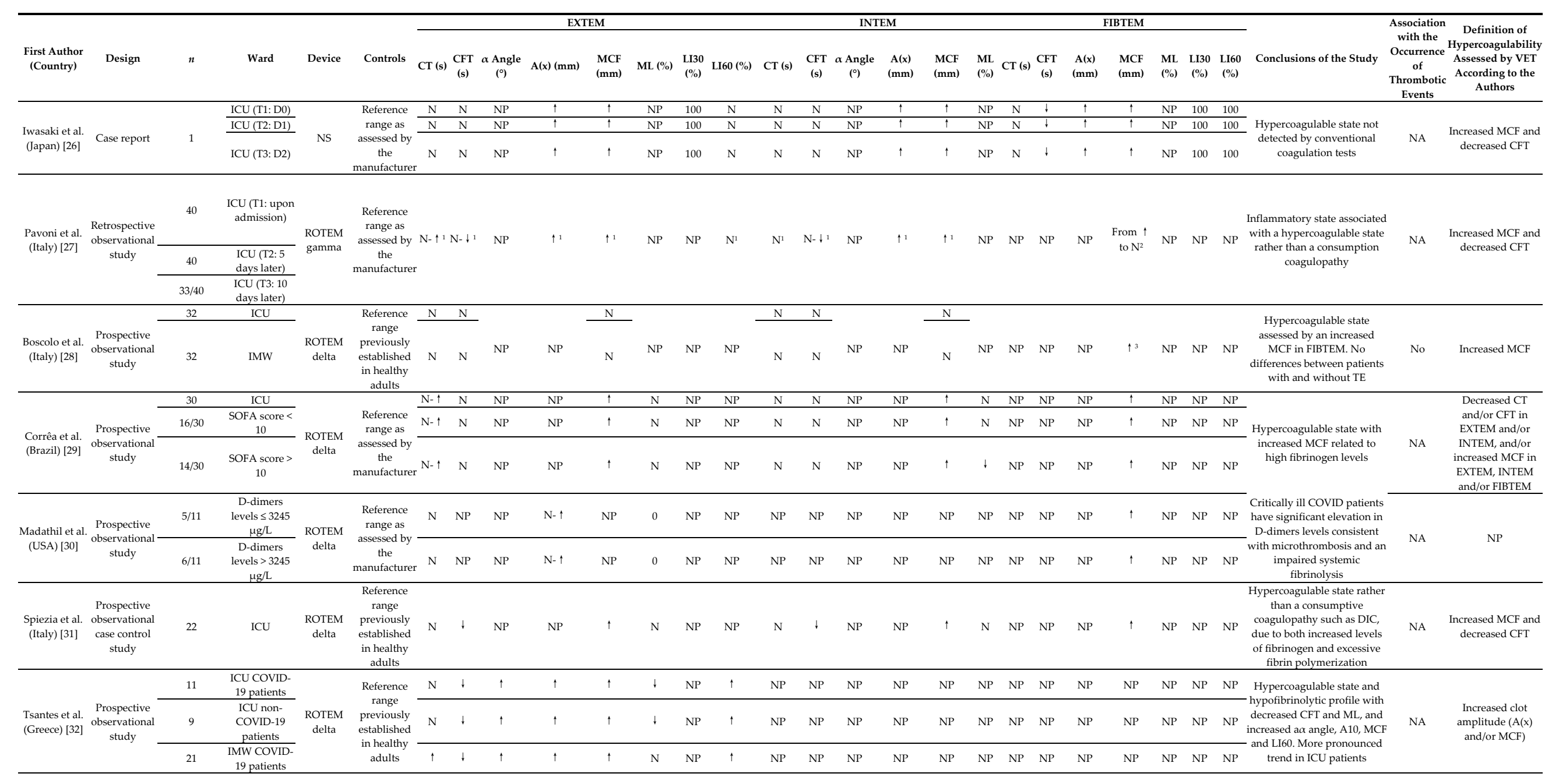


Table 5. Cont.

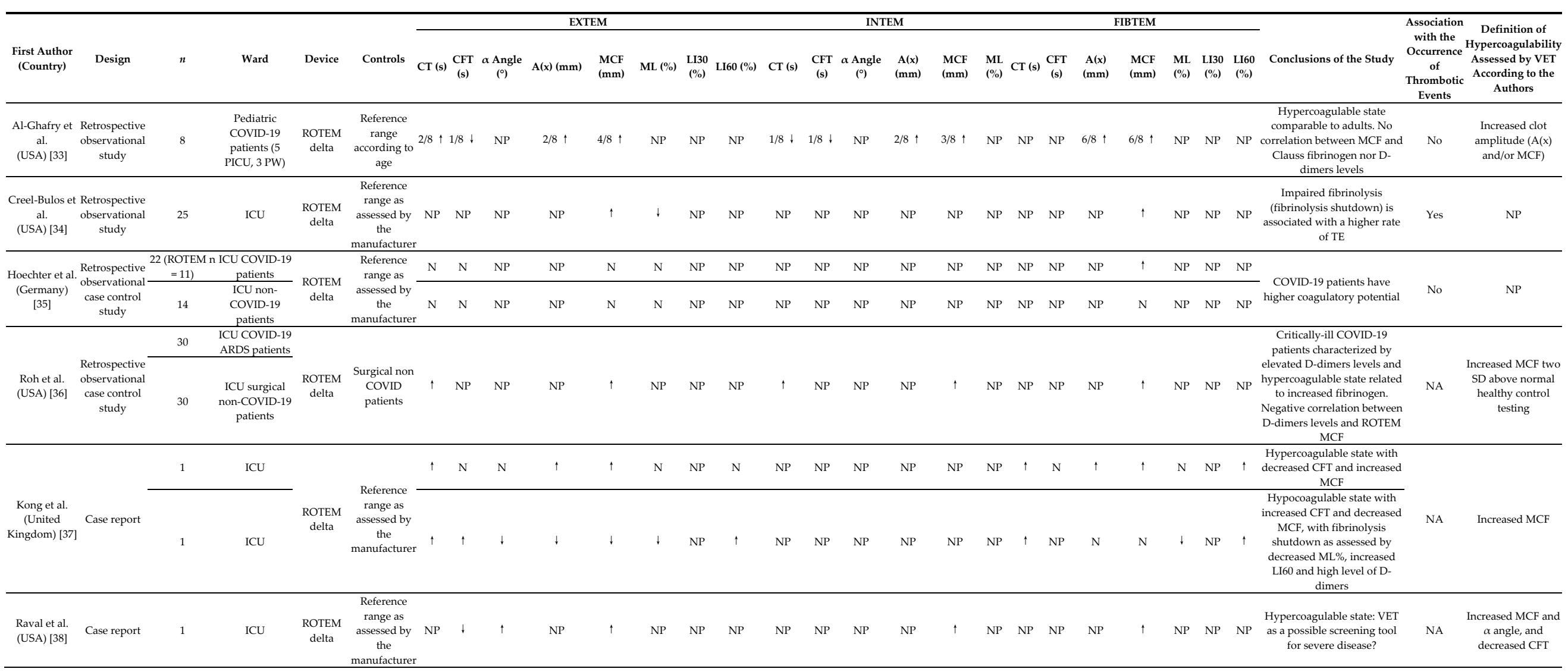


Table 5. Cont.

\begin{tabular}{|c|c|c|c|c|c|c|c|c|c|c|c|c|c|c|c|c|c|c|c|c|c|c|c|c|c|c|c|c|c|}
\hline \multirow[b]{2}{*}{$\begin{array}{l}\text { First Author } \\
\text { (Country) }\end{array}$} & \multirow[b]{2}{*}{ Design } & \multirow[b]{2}{*}{$n$} & \multirow[b]{2}{*}{ Ward } & \multirow[b]{2}{*}{ Device } & \multirow[b]{2}{*}{ Controls } & \multicolumn{9}{|c|}{ EXTEM } & \multicolumn{4}{|c|}{ INTEM } & \multicolumn{8}{|c|}{ FIBTEM } & \multirow{2}{*}{ Conclusions of the Study } & \multirow{2}{*}{$\begin{array}{c}\text { Association } \\
\text { with the } \\
\text { Occurrence } \\
\text { of } \\
\text { Thrombotic } \\
\text { Events } \\
\end{array}$} & \multirow{2}{*}{$\begin{array}{l}\text { Definition of } \\
\text { Hypercoagulability } \\
\text { Assessed by VET } \\
\text { According to the } \\
\text { Authors }\end{array}$} \\
\hline & & & & & & CT (s) & $\begin{array}{l}\text { CFT } \\
\text { (s) }\end{array}$ & $\underset{()^{\circ}}{\alpha \text { Angle }}$ & $\mathrm{A}(\mathrm{x})(\mathrm{mm})$ & $\begin{array}{l}\text { MCF } \\
(\mathrm{mm})\end{array}$ & ML (\%) & $\begin{array}{l}\text { LI30 } \\
(\%)\end{array}$ & LI60 (\%) & $\mathrm{CT}$ (s) & $\begin{array}{c}\text { CFT } \\
\text { (s) }\end{array}$ & $\underset{\left({ }^{\circ}\right)}{\alpha \text { Angle }}$ & $\begin{array}{l}\mathrm{A}(\mathrm{x}) \\
(\mathrm{mm})\end{array}$ & $\begin{array}{l}\text { MCF } \\
(\mathrm{mm})\end{array}$ & $\begin{array}{l}\text { ML } \\
(\%)\end{array}$ & CT (s) & $\begin{array}{l}\text { CFT } \\
\text { (s) }\end{array}$ & $\begin{array}{c}\mathrm{A}(\mathrm{x}) \\
(\mathrm{mm})\end{array}$ & $\begin{array}{l}\text { MCF } \\
(\mathrm{mm})\end{array}$ & $\begin{array}{l}\text { ML } \\
(\%)\end{array}$ & $\begin{array}{l}\mathrm{LI30} \\
(\%)\end{array}$ & $\begin{array}{l}\text { L160 } \\
(\%)\end{array}$ & & & \\
\hline $\begin{array}{l}\text { Weiss et al. } \\
\text { (France) [40] }\end{array}$ & $\begin{array}{l}\text { Prospective } \\
\text { observational } \\
\text { case control } \\
\text { study }\end{array}$ & 5 & ICU & $\begin{array}{l}\text { Modified } \\
\text { ROTEM } \\
\text { delta (TEM- } \\
\text { tPA) }\end{array}$ & $\begin{array}{l}\text { Reference } \\
\text { range } \\
\text { established } \\
\text { in healthy } \\
\text { adults }\end{array}$ & $\mathrm{NP}$ & $\mathrm{NP}$ & $\mathrm{NP}$ & NP & 1 & NP & $\mathrm{NP}$ & NP & $\mathrm{NP}$ & NP & $\mathrm{NP}$ & $\mathrm{NP}$ & $\mathrm{NP}$ & NP & $\mathrm{NP}$ & $\mathrm{NP}$ & $\mathrm{NP}$ & $\uparrow$ & $\mathrm{NP}$ & $\mathrm{NP}$ & $\mathrm{NP}$ & $\begin{array}{l}\text { No clot lysis after } 60 \text { min in } \\
\text { patients as compared to } \\
\text { healthy controls. Resistance } \\
\text { to clot lysis on tonly related } \\
\text { to high fibringogen levels: } \\
\text { dysregulation of the } \\
\text { fibrinolytic system? }\end{array}$ & $\mathrm{NA}$ & Increased MCF \\
\hline $\begin{array}{l}\text { Almskog et al. } \\
\text { (Sweden) [41] }\end{array}$ & $\begin{array}{c}\text { Prospective } \\
\text { observational } \\
\text { study }\end{array}$ & 20 & IMW & $\begin{array}{l}\text { ROTEM } \\
\text { sigma }\end{array}$ & $\begin{array}{l}\text { Reference } \\
\text { range } \\
\text { previously } \\
\text { established } \\
\text { in healthy } \\
\text { adults }\end{array}$ & 1 & 1 & $\mathrm{NP}$ & $1^{4}$ & $t^{3}$ & $\mathrm{NP}$ & 100 & $\mathrm{NP}$ & $t$ & $\mathrm{~N}$ & $\mathrm{NP}$ & $1^{4}$ & $t^{3}$ & $\mathrm{NP}$ & $\begin{array}{ll}\mathrm{NP} \\
\end{array}$ & $\mathrm{NP}$ & NP & $t^{3}$ & $\mathrm{NP}$ & $\mathrm{NP}$ & $\mathrm{NP}$ & $\begin{array}{l}\text { Association between MCF- } \\
\text { FIBTEM and Clauss } \\
\text { fibrinogen. Hypercoagulable } \\
\text { state as assessed by ROTEM } \\
\text { can be seen early after } \\
\text { admission, with a more } \\
\text { pronounced pattern in } \\
\text { patients with increased } \\
\text { disease severity: ROTEM } \\
\text { useful to predict TE and care } \\
\text { level? }\end{array}$ & $\mathrm{NA}$ & Increased MCF \\
\hline $\begin{array}{l}\text { Collett et al. } \\
\text { (Australia) } \\
\text { [422] }\end{array}$ & $\begin{array}{c}\text { Prospective } \\
\text { observational } \\
\text { study }\end{array}$ & 6 & ICU & $\begin{array}{c}\text { ROTEM } \\
\text { sigma } \\
\\
\end{array}$ & $\begin{array}{c}\text { Reference } \\
\text { range as } \\
\text { assessed by } \\
\text { the } \\
\text { manufacturer } \\
\end{array}$ & $\mathrm{NP}$ & $\begin{array}{l}\mathrm{N}-1 \\
2 / 6\end{array}$ & $\mathrm{NP}$ & $5 / 6 \uparrow$ & $15 / 6$ & $\mathrm{~N} 6 / 6$ & NP & $\mathrm{NP}$ & $\mathrm{NP}$ & $+5 / 6$ & NP & $\mathrm{NP}$ & $15 / 6$ & 0 & $\mathrm{NP}$ & $\mathrm{NP}$ & $6 / 6 \uparrow$ & $16 / 6$ & 0 & $\mathrm{NP}$ & $\mathrm{NP}$ & $\begin{array}{c}\text { Hypercoagulable state as } \\
\text { assessed by VET with } \\
\text { increased MCF, minimal } \\
\text { fibrinolysis and } \\
\text { hyperfibrinogenemia } \\
\end{array}$ & $\mathrm{NA}$ & $\begin{array}{l}\text { Increased clot } \\
\text { amplitude (A(x) } \\
\text { and/or MCF) }\end{array}$ \\
\hline $\begin{array}{l}\text { Ibañez et al. } \\
\text { (Spain) [43] }\end{array}$ & $\begin{array}{c}\text { Prospective } \\
\text { observational } \\
\text { study }\end{array}$ & 19 & ICU & $\begin{array}{c}\text { ROTEM } \\
\text { sigma }\end{array}$ & $\begin{array}{c}\text { Reference } \\
\text { range as } \\
\text { assessed by } \\
\text { the } \\
\text { manufacturer }\end{array}$ & $\mathrm{N}-\uparrow$ & $\mathrm{N}-\mathrm{t}$ & $\mathrm{NP}$ & NP & 1 & $\mathrm{NP}$ & 100 & 100 & $\mathrm{~N}$ & $\mathrm{~N}$ & $\mathrm{NP}$ & $\mathrm{NP}$ & $\mathrm{N}$ & $\mathrm{NP}$ & $\mathrm{NP}$ & $\mathrm{NP}$ & NP & $\uparrow$ & NP & 100 & 100 & $\begin{array}{l}\text { Hypercoagulable state mainly } \\
\text { characterized by decreased } \\
\text { fibrinolytic capacity } \\
\text { associated with a paradoxical } \\
\text { increase in D-dimers levels: } \\
\text { fibrinolysis shutdown? }\end{array}$ & $\mathrm{NA}$ & Increased MCF \\
\hline \multirow[b]{2}{*}{$\begin{array}{l}\text { Kruse et al. } \\
\text { (Germany) } \\
{[44]}\end{array}$} & \multirow[b]{2}{*}{$\begin{array}{c}\text { Prospective } \\
\text { observational } \\
\text { study }\end{array}$} & 40 & ICU & \multirow[b]{2}{*}{$\begin{array}{l}\text { ROTEM } \\
\text { sigma }\end{array}$} & \multirow[b]{2}{*}{$\begin{array}{c}\text { Reference } \\
\text { range as } \\
\text { assessed by } \\
\text { the } \\
\text { manufacturer }\end{array}$} & 1 & 1 & $\mathrm{NP}$ & $\mathrm{NP}$ & $t$ & $\frac{1}{15}$ & $\mathrm{NP}$ & $\mathrm{NP}$ & 1 & 1 & $\mathrm{NP}$ & $\mathrm{NP}$ & 1 & $\frac{1}{1}$ & $\mathrm{~N}$ & $\mathrm{~N}$ & $\mathrm{NP}$ & 1 & $\mathrm{NP}$ & $\mathrm{NP}$ & $\mathrm{NP}$ & \multirow[b]{2}{*}{$\begin{array}{l}\text { SP } \\
\text { Hypercoagulable state with } \\
\text { increased MCF related to } \\
\text { high fibininogen levels. } \\
\text { Hypofibrinolysis with } \\
\text { decreased ML\%. } \\
\text { Combination of ML\% with D- } \\
\text { Combimers levels revealed high } \\
\text { sensitivity and specificity of } \\
\text { TE risk prediction }\end{array}$} & \multirow[b]{2}{*}{ 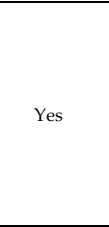 } & \multirow[b]{2}{*}{$\mathrm{NP}$} \\
\hline & & $17 / 40$ & no TE & & & $\begin{array}{l}1 \\
+1 \\
r\end{array}$ & 1 & $\mathrm{NP}$ & NP & 1 & $1^{5}$ & $\mathrm{NP}$ & $\mathrm{NP}$ & $1^{6}$ & 1 & $\mathrm{NP}$ & $\mathrm{NP}$ & 1 & $t^{5}$ & $\mathrm{~N}$ & $\mathrm{~N}$ & $\mathrm{NP}$ & 1 & $\mathrm{NP}$ & $\mathrm{NP}$ & $\mathrm{Nl}$ & & & \\
\hline
\end{tabular}


Table 5. Cont.

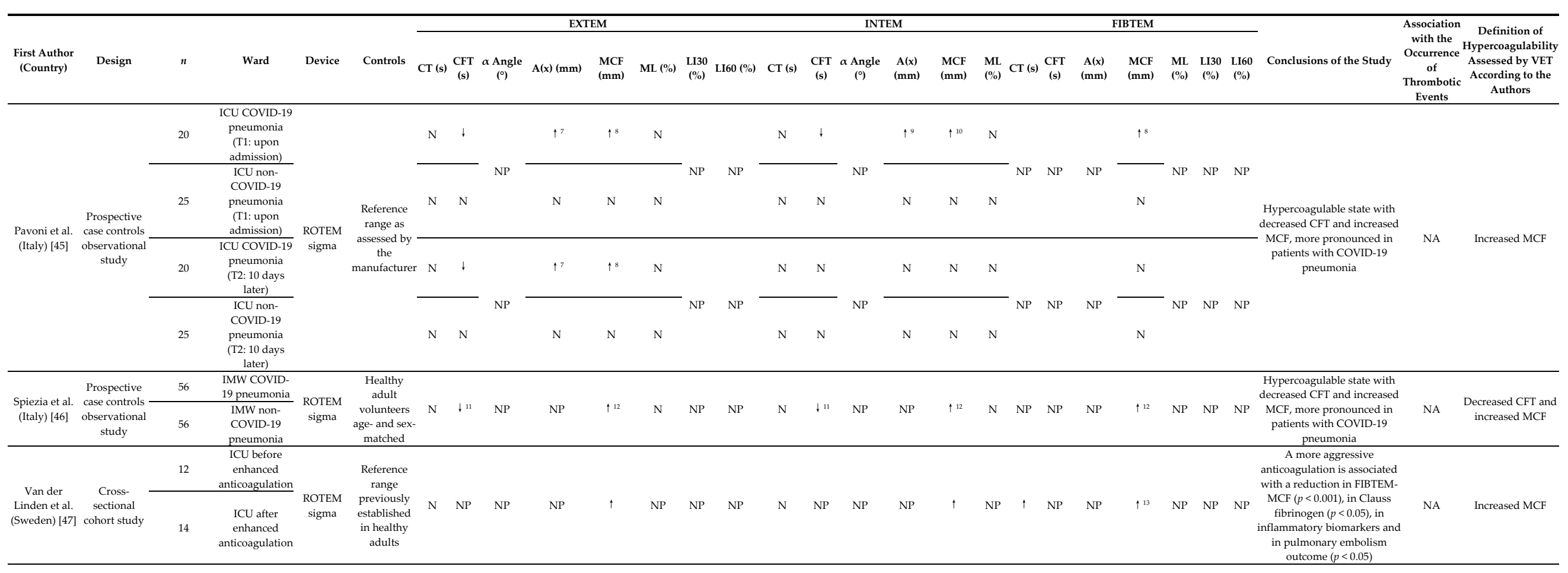


Table 5. Cont.

\begin{tabular}{|c|c|c|c|c|c|c|c|c|c|c|c|c|c|c|c|c|c|c|c|c|c|c|c|c|c|c|c|c|c|}
\hline \multirow[b]{2}{*}{$\begin{array}{l}\text { First Author } \\
\text { (Country) }\end{array}$} & \multirow[b]{2}{*}{ Design } & \multirow[b]{2}{*}{$n$} & \multirow[b]{2}{*}{ Ward } & \multirow[b]{2}{*}{ Device } & \multirow[b]{2}{*}{ Controls } & \multicolumn{9}{|c|}{$\begin{array}{l}\text { EXTEM } \\
\end{array}$} & \multicolumn{4}{|c|}{$\begin{array}{l}\text { INTEM } \\
\text { INT }\end{array}$} & \multicolumn{8}{|c|}{ FIBTEM } & \multirow{2}{*}{ Conclusions of the Study } & \multirow{2}{*}{\multicolumn{2}{|c|}{ 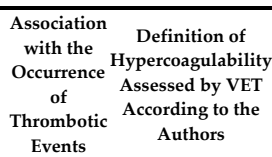 }} \\
\hline & & & & & & CT (s) & $\begin{array}{l}\text { CFT } \\
\text { (s) }\end{array}$ & $\begin{array}{c}\alpha \text { Angle } \\
()^{\circ}\end{array}$ & $\mathrm{A}(\mathrm{x})(\mathrm{mm})$ & $\begin{array}{l}\text { MCF } \\
(\mathrm{mm})\end{array}$ & ML (\%) & $\begin{array}{l}\mathrm{L} 130 \\
(\%)\end{array}$ & LI60 (\%) & $\mathrm{CT}(\mathrm{s})$ & $\begin{array}{l}\text { CFT } \\
\text { (s) }\end{array}$ & $\begin{array}{c}\alpha \text { Angle } \\
\left({ }^{\circ}\right)\end{array}$ & $\begin{array}{l}\mathrm{A}(\mathrm{x}) \\
(\mathrm{mm})\end{array}$ & $\begin{array}{l}\text { MCF } \\
(\mathrm{mm})\end{array}$ & $\begin{array}{l}\text { ML } \\
(\%)\end{array}$ & $\mathrm{CT}(\mathrm{s})$ & $\begin{array}{c}\text {, CFT } \\
\text { (s) }\end{array}$ & $\begin{array}{l}\mathrm{A}(\mathrm{x}) \\
(\mathrm{mm})\end{array}$ & $\begin{array}{l}\text { MCF } \\
(\mathrm{mm})\end{array}$ & $\begin{array}{l}\text { ML } \\
(\%)\end{array}$ & $\begin{array}{l}\text { LI30 } \\
(\%)\end{array}$ & $\begin{array}{l}\text { LI60 } \\
(\%)\end{array}$ & & & \\
\hline \multirow[b]{2}{*}{$\begin{array}{l}\text { Blasi et al. } \\
\text { (Spain) [48] }\end{array}$} & \multirow[b]{2}{*}{$\begin{array}{c}\text { Retrospective } \\
\text { observational } \\
\text { study }\end{array}$} & 12 & ICU & \multirow[b]{2}{*}{$\begin{array}{c}\text { ROTEM } \\
\text { sigma }\end{array}$} & \multirow[b]{2}{*}{$\begin{array}{l}\text { Reference } \\
\text { range as } \\
\text { assessed by } \\
\text { the } \\
\text { manufacturer }\end{array}$} & \multirow[b]{2}{*}{$\mathrm{N}$} & \multirow[b]{2}{*}{ NP } & \multirow[b]{2}{*}{ NP } & \multirow[b]{2}{*}{ NP } & \multirow[b]{2}{*}{$\mathrm{N}-1$} & \multirow[b]{2}{*}{$\mathrm{NP}$} & \multirow[b]{2}{*}{ NP } & 100 & $\mathrm{~N}-1$ & \multirow[b]{2}{*}{ NP } & \multirow[b]{2}{*}{ NP } & \multirow[b]{2}{*}{ NP } & \multirow[b]{2}{*}{$N-1$} & \multirow[b]{2}{*}{ NP } & \multirow[b]{2}{*}{$\mathrm{NP}$} & & \multirow[b]{2}{*}{$\mathrm{NP}$} & \multirow[b]{2}{*}{$\mathrm{N}-1$} & & & & Hypercoagulable state more & & \\
\hline & & 11 & IMW & & & & & & & & & & $\mathrm{N}$ & $\mathrm{N}$ & & & & & & & NP & & & $\mathrm{NP}$ & $\mathrm{NP}$ & NP & $\begin{array}{l}\text { pronounced in sicker patients } \\
\text { and related to } \\
\text { hyperfibrinogenemia and low } \\
\text { fibrinolysis despite } \\
\text { anticoagulation }\end{array}$ & s & Increased MCF \\
\hline Van & & 47 & ICU & & Reference - & 1 & $\begin{array}{ll}N-1 \\
\end{array}$ & $\mathrm{NP}$ & $\uparrow$ & 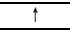 & $\mathrm{NP}$ & NP & NP & $\mathrm{N}$ & $t$ & $\mathrm{NP}$ & $t$ & 1 & $\mathrm{NP}$ & $\mathrm{NP}$ & $\mathrm{NP}$ & $\mathrm{NP}$ & 1 & $\mathrm{NP}$ & $\mathrm{NP}$ & NP & Hypercoagulable state with & & \\
\hline $\begin{array}{l}\text { Veenendaal et } \\
\text { al. (The } \\
\text { Netherlands) } \\
\text { [49] }\end{array}$ & $\begin{array}{l}t \text { Retrospective } \\
\text { observational } \\
\text { study }\end{array}$ & $37 / 47$ & no TE & $\begin{array}{c}\text { ROTEM } \\
\text { sigma }\end{array}$ & $\begin{array}{l}\text { Rererence } \\
\text { range as } \\
\text { assessed by } \\
\text { the } \\
\text { manufacturer }\end{array}$ & $\begin{array}{l}1 \\
\end{array}$ & $\frac{\mathrm{N}}{\mathrm{i}}$ & $\mathrm{NP}$ & $1^{14}$ & $\uparrow^{15}$ & $\mathrm{NP}$ & $\mathrm{NP}$ & $\mathrm{NP}$ & $\mathrm{N}$ & 16 & $\mathrm{NP}$ & $\uparrow^{15}$ & +1 & $\mathrm{NP}$ & $\mathrm{NP}$ & $\mathrm{NP}$ & NP & $\frac{1}{1}$ & $\mathrm{NP}$ & $\mathrm{NP}$ & NP & $\begin{array}{l}\text { decreased CFT and increased } \\
\text { MCF related to high } \\
\text { fibrinogen levels. Correlation } \\
\text { between increased CT and } \\
\text { prolonged aPTT and PT }\end{array}$ & 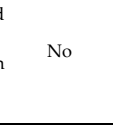 & $\begin{array}{l}\text { Decreased CFT and } \\
\text { increased MCF }\end{array}$ \\
\hline & & 1 & IMW & ROTEM & Local & $\mathrm{N}$ & $i$ & 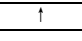 & 1 & $t$ & $\mathrm{~N}$ & $\mathrm{NP}$ & $\mathrm{NP}$ & $\mathrm{N}$ & $\mathrm{N}$ & $\mathrm{N}$ & $t$ & $t$ & $\mathrm{~N}$ & $\mathrm{~N}$ & $\mathrm{NP}$ & i & 1 & $\mathrm{~N}$ & NP & NP & & & \\
\hline 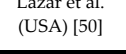 & Case report & 1 & IMW & sigma & $\begin{array}{c}\text { reference } \\
\text { range }\end{array}$ & + & $\mathrm{N}$ & $\mathrm{N}$ & $\mathrm{N}-1$ & $\uparrow$ & $\mathrm{N}$ & $\mathrm{NP}$ & $\mathrm{NP}$ & 1 & $\mathrm{~N}$ & $\mathrm{~N}$ & $\mathrm{~N}$ & $\mathrm{~N}$ & $\mathrm{~N}$ & $\mathrm{~N}$ & NP & $\uparrow$ & $\uparrow$ & $\mathrm{N}$ & $\mathrm{NP}$ & $\mathrm{NP}$ & $\begin{array}{l}\text { present early in the clinical } \\
\text { course of the disease }\end{array}$ & $\mathrm{NA}$ & Increased MCF \\
\hline
\end{tabular}

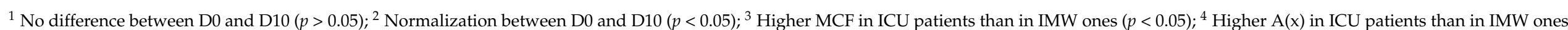

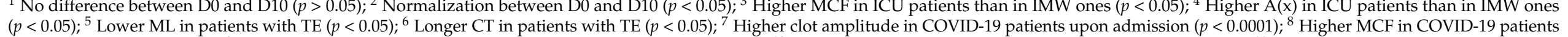

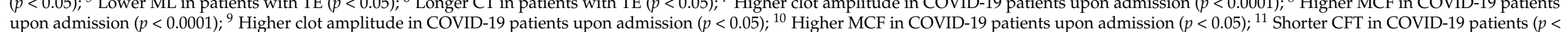

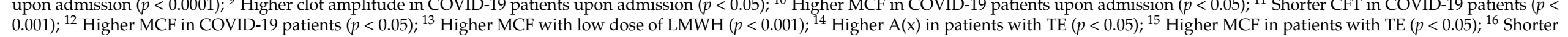

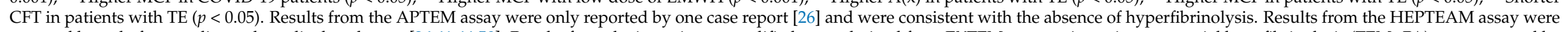

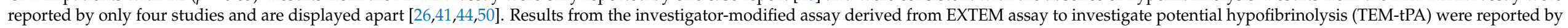

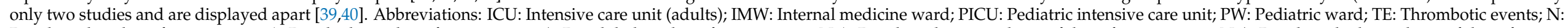

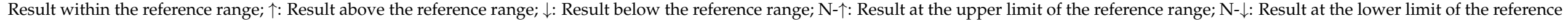
range; NP: Not provided; NA: Not assessed; tPA: tissue plasminogen activator. 
Table 6. Main findings of studies reporting results from the HEPTEM assay (ROTEM).

\begin{tabular}{|c|c|c|c|c|c|c|c|c|c|c|c|c|c|c|c|c|c|c|c|}
\hline \multirow[b]{2}{*}{$\begin{array}{l}\text { First Author } \\
\text { (Country) }\end{array}$} & \multirow[b]{2}{*}{ Design } & \multirow[b]{2}{*}{$n$} & \multirow[b]{2}{*}{ Ward } & \multirow[b]{2}{*}{ Device } & \multirow[b]{2}{*}{ Controls } & \multicolumn{6}{|c|}{ INTEM } & \multicolumn{5}{|c|}{ HEPTEM } & \multirow[b]{2}{*}{ Conclusions of the Study } & \multirow{2}{*}{$\begin{array}{c}\text { Associatio } \\
\text { n with the } \\
\text { Occurrence } \\
\text { of } \\
\text { Thromboti } \\
\text { c Events } \\
\end{array}$} & \multirow{2}{*}{$\begin{array}{c}\text { Definition of } \\
\text { Hypercoagulability } \\
\text { Assessed by VET } \\
\text { According to the } \\
\text { Authors }\end{array}$} \\
\hline & & & & & & $\begin{array}{l}\text { CT } \\
\text { (s) }\end{array}$ & CFT (s) & $\underset{\left({ }^{\circ}\right)}{\alpha \text { Angle }}$ & $\begin{array}{l}\mathrm{A}(\mathrm{x}) \\
(\mathrm{mm})\end{array}$ & $\begin{array}{l}\text { MCF } \\
(\mathrm{mm})\end{array}$ & ML (\%) & $\begin{array}{l}\text { CT } \\
\text { (s) }\end{array}$ & CFT (s) & $\begin{array}{c}\alpha \\
\text { Angle } \\
\left({ }^{\circ}\right)\end{array}$ & $\begin{array}{l}\text { MCF } \\
(\mathrm{mm})\end{array}$ & $\begin{array}{l}\mathrm{ML} \\
(\%)\end{array}$ & & & \\
\hline \multirow{3}{*}{$\begin{array}{l}\text { Iwasaki et al. } \\
\text { (Japan) [26] }\end{array}$} & \multirow{3}{*}{ Case report } & \multirow{3}{*}{1} & ICU (T1: D0) & & & $\mathrm{N}$ & $\mathrm{N}$ & $\mathrm{NP}$ & 1 & 1 & $\mathrm{NP}$ & $\mathrm{NP}$ & $\mathrm{NP}$ & $\mathrm{NP}$ & $\mathrm{NP}$ & $\mathrm{NP}$ & \multirow{3}{*}{$\begin{array}{l}\text { Hypercoagulable state not } \\
\text { detected by conventional } \\
\text { coagulation tests }\end{array}$} & \multirow{3}{*}{$\mathrm{NA}$} & \multirow{3}{*}{$\begin{array}{l}\text { Increased MCF and } \\
\text { decreased CFT }\end{array}$} \\
\hline & & & ICU (T2: D1) & NS & $\begin{array}{l}\text { Reference } \\
\text { range as } \\
\text { assessed by } \\
\text { the }\end{array}$ & $\mathrm{N}$ & $\mathrm{N}$ & $\mathrm{NP}$ & 1 & 1 & $\mathrm{NP}$ & $\mathrm{N}$ & $\mathrm{N}$ & $\mathrm{NP}$ & $\mathrm{N}$ & $\mathrm{NP}$ & & & \\
\hline & & & ICU (T3: D2) & & & $\mathrm{N}$ & $\mathrm{N}$ & $\mathrm{NP}$ & $\uparrow$ & 1 & $\mathrm{NP}$ & $\mathrm{N}$ & $\mathrm{N}$ & $\mathrm{NP}$ & $\mathrm{N}$ & $\mathrm{NP}$ & & & \\
\hline
\end{tabular}

\begin{tabular}{|c|c|c|c|c|c|c|c|c|c|c|c|c|c|c|c|c|c|c|c|}
\hline $\begin{array}{l}\text { Almskog et } \\
\text { al. } \\
\text { (Sweden) [41] }\end{array}$ & $\begin{array}{c}\text { Prospective } \\
\text { observational } \\
\text { study }\end{array}$ & 20 & ICU & $\begin{array}{l}\text { ROTEM } \\
\text { sigma }\end{array}$ & $\begin{array}{l}\text { Reference } \\
\text { range } \\
\text { previously } \\
\text { established in } \\
\text { healthy adults }\end{array}$ & 1 & r & $\mathrm{NP}$ & $1^{4}$ & $1^{3}$ & NP & 1 & $\mathrm{NP}$ & $\mathrm{NP}$ & NP & $\mathrm{NP}$ & $\begin{array}{l}\text { Association between MCF- } \\
\text { FIBTEM and Clauss } \\
\text { fibrinogen. } \\
\text { Hypercoagulable state as } \\
\text { assessed by ROTEM can be } \\
\text { seen early after admission, } \\
\text { with a more pronounced } \\
\text { pattern in patients with } \\
\text { increased disease severity: } \\
\text { ROTEM useful to predict } \\
\text { TE and care level? }\end{array}$ & $\mathrm{NA}$ & Increased MCF \\
\hline & & 40 & IMW & & & 1 & $\mathrm{~N}$ & NP & 1 & 1 & $\mathrm{NP}$ & 1 & $\mathrm{NP}$ & NP & NP & $\mathrm{NP}$ & & & \\
\hline \multirow{3}{*}{ 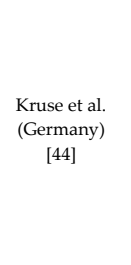 } & \multirow{3}{*}{$\begin{array}{l}\text { Prospective } \\
\text { observational } \\
\text { study }\end{array}$} & 40 & ICU & \multirow{3}{*}{$\begin{array}{l}\text { ROTEM } \\
\text { sigma }\end{array}$} & \multirow{3}{*}{$\begin{array}{l}\text { Reference } \\
\text { range as } \\
\text { assessed by } \\
\text { the } \\
\text { manufacturer }\end{array}$} & 1 & r & $\mathrm{NP}$ & $\mathrm{NP}$ & 1 & r & $\mathrm{N}$ & r & $\mathrm{NP}$ & $i$ & $\mathrm{NP}$ & \multirow{3}{*}{$\begin{array}{l}\text { Hypercoagulable state with } \\
\text { increased MCF related to } \\
\text { high hibrinogen levels. } \\
\text { Hypofibrinolysis with } \\
\text { decreased ML\%. } \\
\text { Combination of ML\% with } \\
\text { D-dimers levels revealed } \\
\text { high sensitivity and } \\
\text { specificity of TE risk } \\
\text { prediction }\end{array}$} & \multirow{3}{*}{ Yes } & \multirow{3}{*}{$\mathrm{NP}$} \\
\hline & & $23 / 40$ & $\geq 1 \mathrm{TE}$ & & & 1 & b & $\mathrm{NP}$ & $\mathrm{NP}$ & 1 & i & $\mathrm{N}$ & i & $\mathrm{NP}$ & 1 & NP & & & \\
\hline & & $17 / 40$ & no TE & & & 1 & i & & & 1 & $\mathrm{~N}$ & $\mathrm{~N}$ & & & 1 & & & & \\
\hline \multirow{2}{*}{$\begin{array}{l}\text { Lazar et al. } \\
\text { (USA) [50] }\end{array}$} & \multirow{2}{*}{ Case report } & 1 & IMW & \multirow{2}{*}{$\begin{array}{l}\text { ROTEM } \\
\text { sigma }\end{array}$} & \multirow{2}{*}{$\begin{array}{l}\text { Local } \\
\text { reference } \\
\text { range }\end{array}$} & $\mathrm{N}$ & $\mathrm{N}$ & $\mathrm{N}$ & 1 & 1 & $\mathrm{~N}$ & $\mathrm{~N}$ & $\mathrm{~N}$ & $\mathrm{~N}$ & 1 & $\mathrm{~N}$ & \multirow{2}{*}{$\begin{array}{l}\text { Hypercoagulable state } \\
\text { present early in the clinical } \\
\text { course of the disease }\end{array}$} & \multirow{2}{*}{ NA } & \multirow{2}{*}{ Increased MCF } \\
\hline & & 1 & IMW & & & $\uparrow$ & $\mathrm{N}$ & $\mathrm{N}$ & $\mathrm{N}$ & $\mathrm{N}$ & $\mathrm{N}$ & $\mathrm{N}$ & $\mathrm{N}$ & $\mathrm{N}$ & $\mathrm{N}$ & $\mathrm{N}$ & & & \\
\hline
\end{tabular}

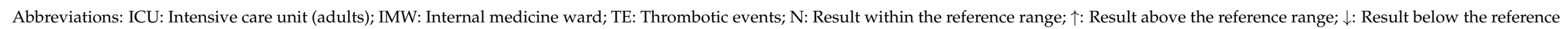
range; NP: Not provided; NA: Not assessed; tPA: tissue plasminogen activator. 
Table 7. Main findings of studies reporting results from the TEM-tPA assay (ROTEM).

\begin{tabular}{|c|c|c|c|c|c|c|c|c|c|c|c|c|c|c|c|c|c|c|c|}
\hline \multirow[b]{2}{*}{$\begin{array}{l}\text { First author } \\
\text { (Country) }\end{array}$} & \multirow[b]{2}{*}{ Design } & \multirow[b]{2}{*}{$n$} & \multirow[b]{2}{*}{ Ward } & \multirow[b]{2}{*}{ Device } & \multirow[b]{2}{*}{ Controls } & \multirow[b]{2}{*}{$\begin{array}{l}\mathrm{CT} \\
\text { (s) }\end{array}$} & \multirow[b]{2}{*}{$\begin{array}{l}\text { CFT } \\
\text { (s) }\end{array}$} & \multicolumn{3}{|c|}{ EXTEM Assay } & \multirow[b]{2}{*}{$\begin{array}{l}\text { ML } \\
(\%)\end{array}$} & \multirow[b]{2}{*}{$\begin{array}{l}\mathrm{LI30} \\
(\%)\end{array}$} & \multicolumn{4}{|c|}{ TEM-tPA Assay } & \multirow[b]{2}{*}{ Conclusions } & \multirow{2}{*}{$\begin{array}{l}\text { Association with } \\
\text { the Occurrence of } \\
\text { Thrombotic } \\
\text { Events Outcomes }\end{array}$} & \multirow{2}{*}{$\begin{array}{l}\text { Definition of Hy- } \\
\text { percoagulability } \\
\text { Assessed by VET } \\
\text { According to the } \\
\text { Authors } \\
\end{array}$} \\
\hline & & & & & & & & $\underset{\left({ }^{\circ}\right)}{\alpha}$ & $\begin{array}{l}\mathrm{A}(\mathrm{x}) \\
(\mathrm{mm})\end{array}$ & $\begin{array}{l}\text { MCF } \\
(\mathrm{mm})\end{array}$ & & & $\begin{array}{l}\text { LI60 } \\
(\%)\end{array}$ & $\begin{array}{l}\mathrm{MCF} \\
(\mathrm{mm})\end{array}$ & $\begin{array}{l}\text { LI30 } \\
(\%)\end{array}$ & $\begin{array}{l}\mathrm{ML} \\
(\%)\end{array}$ & & & \\
\hline $\begin{array}{l}\text { Nougier } \\
\text { et al. } \\
\text { (France) [39] }\end{array}$ & $\begin{array}{c}\text { Prospective } \\
\text { observational } \\
\text { case control study }\end{array}$ & 19 & ICU & $\begin{array}{l}\text { Modified } \\
\text { ROTEM delta } \\
\text { (TEM-tPA) }\end{array}$ & $\begin{array}{l}\text { Reference range } \\
\text { previously established } \\
\text { in healthy adults }\end{array}$ & NP & $\mathrm{NP}$ & $\mathrm{NP}$ & $\mathrm{NP}$ & $\mathrm{NP}$ & $\mathrm{NP}$ & $\mathrm{NP}$ & $\mathrm{NP}$ & $\uparrow^{1}$ & $\uparrow^{2}$ & $\mathrm{NP}$ & $\begin{array}{l}\text { Hypercoagulable state associated with } \\
\text { impaired fibrinolysis leading to a high } \\
\text { thrombin generation despite adequate } \\
\text { antithrombotic therapy }\end{array}$ & $\mathrm{NA}$ & Increased MCF \\
\hline $\begin{array}{l}\text { Weiss et al. } \\
\text { (France) [40] }\end{array}$ & $\begin{array}{c}\text { Prospective } \\
\text { observational } \\
\text { case control study }\end{array}$ & 5 & ICU & $\begin{array}{c}\text { Modified } \\
\text { ROTEM delta } \\
\text { (TEM-tPA) }\end{array}$ & $\begin{array}{l}\text { Reference range } \\
\text { established in healthy } \\
\text { adults }\end{array}$ & NP & NP & NP & NP & $\uparrow$ & NP & $\mathrm{NP}$ & NP & $\uparrow$ & NP & $\downarrow$ & $\begin{array}{l}\text { No clot lysis after } 60 \text { min in patients as } \\
\text { compared to healthy controls. } \\
\text { Resistance to clot lysis not only related } \\
\text { to high fibrinogen levels: dysregulation } \\
\text { of the fibrinolytic system? }\end{array}$ & $\mathrm{NA}$ & Increased MCF \\
\hline
\end{tabular}

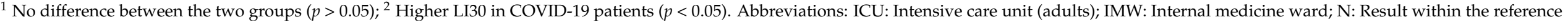
range; $\uparrow:$ Result above the reference range; $\downarrow$ : Result below the reference range; NP: Not provided; NA: Not assessed; tPA: tissue plasminogen activator. 
Some articles also reported a reduced or absent fibrinolysis, better evidenced with added plasminogen activator (tissue plasminogen activator, tPA) [39,40] than without [26,30,32,34,37,42-44,46,48], whereas others did not report any abnormality $[27,31,35,45,46,50]$. Few articles studied fibrinolysis over time and found it persistently defective [26,29]. Fibrinolysis was weaker in ICU COVID-19 patients than in non-ICU COVID-19 patients $(p<0.05[32,39,48])$, and among ICU patients in those with SOFA score $>10(p=0.004$ [29] $)$ or with thrombotic events $(p=0.001$ [44]). However, there was no difference between ICU COVID-19 patients and ICU non COVID-19 patients $(p>0.05$ [32]).

Among the five studies comparing results from COVID-19 patients versus non-COVID19 (surgical or suffering from pneumonia or ARDS) patients $[32,35,36,45,46]$, three reported a hypercoagulable pattern only in COVID-19 patients $(p<0.05[35,36,45])$, a finding which could be explained by a fibrinogen level remaining within the reference range for nonCOVID-19 patients [45]. The other two [32,46] showed a similar hypercoagulable pattern in COVID-19 and non-COVID-19 patients as compared with healthy controls $(p<0.001)$, however with a more pronounced one $(p<0.05)$ in COVID-19 patients despite a similar fibrinogen level [46].

Among the five studies reporting data from COVID-19 adult patients both in an ICU and an IMW [28,32,39,41,48], one showed a similar hypercoagulable profile (increased maximum clot firmness) for both groups ( $p>0.05$ [48]), whereas the four others showed a similar hypercoagulable pattern (increased "amplitude of the clot" or maximum clot firmness with or without a decreased CFT) for both groups compared with healthy controls or manufacturer's reference range; however, the hypercoagulable pattern was more pronounced for ICU patients ( $p<0.05$ between both groups).

Results reported in children [33] showed a hypercoagulable pattern comparable to adults with an increased in MCF in INTEM, EXTEM, and FIBTEM assays and a slightly decreased CFT.

Overall, the authors concluded from those described reports that COVID-19 patients exhibit a hypercoagulable profile characterized by an increased fibrinogen component of clot mechanical strength reflected by an increase in clot amplitude $(\mathrm{A}(\mathrm{x}))$ and /or maximum clot firmness (MCF), sometimes associated with a shorter clot formation time CFT $[26,27,31-33,38,41-46,49,50]$, or an increased $\alpha$ angle $[32,38,39,50]$. This pattern was often associated with an impaired or absent fibrinolysis [26,30,32,34,37,39,40,42-44,46,48].

In summary, four points are worthy of consideration. First, the hypercoagulable profile defined just above was observed early in the clinical course of the disease [41,50]. Second, it was observed in both ICU and non-ICU COVID-19 patients [28,32,39,41,48]. Third, it persisted over time from admission up to 10 to 14 days later $[26,27,29,45]$. Fourth, it was observed even in the absence of heparin neutralization and despite higher therapeutic intensity anticoagulation administration [26,47]. Of note, only six studies [28,33-35,44,49] gathering 195 patients examined the potential association with thrombotic events occurring, and only two $[34,44]$ reported that patients with thromboembolic complications exhibited low or even absent fibrinolysis.

\subsubsection{TEG}

A total of 403 patients, of whom 402 were COVID-19 ICU patients, had at least one VET performed with TEG. Most of them were intubated and mechanically ventilated. They almost all received anticoagulation by UFH or LMWH, at least at prophylactic dose.

Among the 15 TEG studies, two versions of the device were used: the TEG5000 $(n=7)$ [52-58] and the brand-new version TEG6s $(n=7)$ [59-65]. One article reported data without specification of the device [51]. Results are summarized in Table 8.

Kaolin TEG with heparinase ( $\mathrm{CKH})$ was the most used assay, as heparin is neutralized, and most patients received heparin. Among the 14 studies using this assay [51-60,62-65], an increase in maximum clot amplitude was reported, but this finding needs to be tempered for the following reasons. With patients' values higher than reference $[51,54,57,58,60]$ or 
locally established $[52,53,56]$ values, MA was considered abnormally increased, while in other studies MA was found at the upper limit of normal $[59,62,64,65]$ or increased only in certain patients $[55,63]$. For reaction time (R), 5 studies found decreased values from reference ranges [57] or from healthy volunteers [52,53,55,58], 4 reported decreased kinetics reaction $\mathrm{K}$ parameter as compared with healthy volunteers $[52,53,55,58]$, and 11 reported increased $\alpha$ angle as compared with reference ranges $(42,45-48,52,53)$ or healthy volunteers $[54,57-60,64,65]$. Impaired fibrinolysis was found in eleven studies, with 'fibrinolytic activity' at 30 min after maximum amplitude (LY30) reduced as compared with reference ranges in healthy volunteers [52,53], or even undetectable [51,54,57-60,62-65].

TEG Functional Fibrinogen (CFF) was assessed in four studies [59,61,62,65], showing an increase in maximum clot amplitude with a median CFF-MA ranging from 41 to $56 \mathrm{~mm}$ for all patients as compared with manufacturer's reference range (15 to $32 \mathrm{~mm})$, and with a negative skewness coefficient of -0.37 [59].

Increased fibrinogen component of clot strength was considered as the hallmark of hypercoagulability, associated with at least one of the following: a shorter reaction time R $[52,53,55,57,58]$, a shorter kinetic time $\mathrm{K}[52,53,55,58]$, and an increased $\alpha$ angle $[52-60,64,65]$. This pattern was often associated with an impaired $[52,53]$ or absent fibrinolysis [51,54,57-60,62-65]. 
Table 8. Main findings of studies reporting TEG results.

\begin{tabular}{|c|c|c|c|c|c|c|c|c|c|c|c|c|c|c|c|c|c|c|c|c|c|c|c|c|c|c|c|}
\hline \multirow[b]{2}{*}{$\begin{array}{l}\text { First Author } \\
\text { (Country) }\end{array}$} & \multirow[b]{2}{*}{ Design } & \multirow[b]{2}{*}{$n$} & \multirow[b]{2}{*}{ Ward } & \multirow[b]{2}{*}{ Device } & \multirow[b]{2}{*}{ Controls } & \multicolumn{6}{|c|}{ CRT Assay/Rapid-TEG } & \multicolumn{5}{|c|}{ CK Assay } & \multicolumn{5}{|c|}{ CKH Assay } & \multicolumn{3}{|c|}{ CFF Assay } & \multirow[b]{2}{*}{ Conclusions of the Study } & \multirow[b]{2}{*}{$\begin{array}{l}\text { Association with the } \\
\text { Occurrence of } \\
\text { Thrombotic Events }\end{array}$} & \multirow{2}{*}{$\begin{array}{c}\text { Definition of } \\
\text { Hypercoagulability } \\
\text { Assessed by VET } \\
\text { According to the } \\
\text { Authors } \\
\end{array}$} \\
\hline & & & & & & $\begin{array}{l}\text { TEG- } \\
\text { ACT }\end{array}$ & $\underset{(\min )(\mathrm{n}}{\mathrm{R}}$ & $\underset{(\min )}{\mathrm{K}}{ }^{\alpha}$ & $\begin{array}{l}x \text { angle } \\
\left({ }^{\circ}\right)\end{array}$ & $\begin{array}{l}\mathrm{A} 10 \\
(\mathrm{~mm})\end{array}$ & $\begin{array}{c}\text { MA } \\
(\mathrm{mm})\end{array}$ & $\begin{array}{l}\text { LY30 } \\
(\%)\end{array}$ & $\underset{(\min )(\mathrm{m}}{\mathrm{R}}$ & $\begin{array}{c}\mathrm{K} \\
\min )\end{array}$ & $\begin{array}{c}\alpha \text { angle } \\
\left({ }^{\circ}\right)\end{array}$ & $\begin{array}{c}\mathrm{MA} \\
(\mathrm{mm})\end{array}$ & $\begin{array}{l}\mathrm{LY} 30 \\
(\%)\end{array}$ & $\stackrel{\mathrm{R}}{(\min )(1}$ & $\underset{(\min )}{\mathrm{K}}$ & $\begin{array}{c}\alpha \text { angle } \\
\left({ }^{\circ}\right)\end{array}$ & $\begin{array}{l}\mathrm{MA} \\
(\mathrm{mm})\end{array}$ & $\begin{array}{l}\text { LY30 } \\
(\%)\end{array}$ & $\begin{array}{l}\text { A10 } \\
\text { (mm) }\end{array}$ & $\begin{array}{c}\mathrm{MA} \\
(\mathrm{mm})\end{array}$ & & & \\
\hline $\begin{array}{l}\text { Wright et al. } \\
\text { (USA) [51] }\end{array}$ & $\begin{array}{l}\text { Retrospective } \\
\text { observational } \\
\text { study }\end{array}$ & 44 & ICU & $\mathrm{NP}$ & $\begin{array}{l}\text { Reference } \\
\text { range as } \\
\text { assessed by } \\
\text { the } \\
\text { manufacturer }\end{array}$ & NP & NP & $\mathrm{NP}$ & $\mathrm{NP}$ & NP & NP & NP & $\mathrm{NP} N$ & NP & NP & NP & $\mathrm{NP}$ & $\mathrm{N}$ & $\mathrm{NP}$ & $\mathrm{N}$ & $i$ & 0 & NP & NP & $\begin{array}{l}\text { Fibrinolysis shutdown, as evidenced by } \\
\text { elevated D-dimers levels and complete } \\
\text { failure of clot lysis at } 30 \text { min on } \\
\text { thromboelastography predicts } \\
\text { thromboembolic events and need for } \\
\text { hemodialysis in critically ill patients } \\
\text { with COVID-19. }\end{array}$ & $\begin{array}{l}\text { Yes: higher rate of TE } \\
(p<0.05) \text {, shorter time } \\
\text { to } \mathrm{TE}(p=0.001)\end{array}$ & $\begin{array}{l}\text { Increased MA despite } \\
\text { appropriate } \\
\text { prophylatcic } \\
\text { anticoagulation }\end{array}$ \\
\hline $\begin{array}{l}\text { Panigada et al. } \\
\text { (Italy) [52] }\end{array}$ & $\begin{array}{l}\text { Prospective } \\
\text { observational } \\
\text { study }\end{array}$ & 24 & ICU & TEG5000 & $\begin{array}{c}\text { Reference } \\
\text { range } \\
\text { previously } \\
\text { established } \\
\text { in healthy } \\
\text { adults } \\
\end{array}$ & $\mathrm{NP}$ & NP & $\mathrm{NP}$ & NP & NP & NP & NP & NP $N$ & NP & $\mathrm{NP}$ & NP & $\mathrm{NP}^{1}$ & $\begin{array}{l}12 / 242 \\
!\end{array}$ & $\begin{array}{c}22 / 24 \\
+\end{array}$ & $18 / 24 \uparrow$ & $21 / 24 \uparrow$ & $\stackrel{24 / 24}{!}$ & NP & NP & $\begin{array}{l}\text { Hypercoagulable state assessed by a } \\
\text { shortened K, decrease II30 and } \\
\text { increase MA and } \alpha \text { angle }\end{array}$ & $\mathrm{NA}$ & $\begin{array}{l}\text { Decreased R, K or } \\
\text { LY30 as well as } \\
\text { increased } \alpha \text { angle or } \\
\text { MA }\end{array}$ \\
\hline $\begin{array}{l}\text { Cordier et al. } \\
\text { (France) [53] }\end{array}$ & $\begin{array}{l}\text { Retrospective } \\
\text { observational } \\
\text { study }\end{array}$ & $10 / 24$ & $\begin{array}{c}\text { ICU (T1: upon } \\
\text { admission) }\end{array}$ & TEG5000 & $\begin{array}{l}\text { Reference } \\
\text { range } \\
\text { previously } \\
\text { established } \\
\text { in healthy } \\
\text { adults }\end{array}$ & NP & NP & $\mathrm{NP}$ & NP & NP & NP & $\mathrm{NP}$ & $\mathrm{NP} N$ & NP & NP & NP & NP & $b^{1}$ & t1 & $1^{1}$ & $1^{2}$ & 0 & NP & NP & $\begin{array}{l}\text { Hypercoagulable state which persists } \\
\text { even in case of favorable clinical } \\
\text { evolutiton. No differencebe between obese } \\
\text { and non-obese patients. No difference } \\
\text { between according to the severity of CT } \\
\text { lesions. No difference between patients } \\
\text { who developed TE and those who did } \\
\text { not. No difference between patients } \\
\text { who died and those who survived }\end{array}$ & 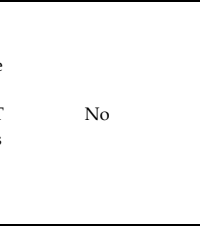 & $\begin{array}{l}\text { Decreased R, K or } \\
\text { LY30 as well as } \\
\text { increased } \alpha \text { angle or } \\
\text { MA }\end{array}$ \\
\hline $\begin{array}{l}\text { Hightower et al. } \\
\text { (USA) [54] }\end{array}$ & $\begin{array}{l}\text { Retrospective } \\
\text { observational } \\
\text { study }\end{array}$ & 5 & ICU & TEG5000 & $\begin{array}{c}\text { Reference } \\
\text { range as } \\
\text { assessed by } \\
\text { the } \\
\text { manufacturer } \\
\end{array}$ & NP & NP & $\mathrm{NP}$ & NP & $\mathrm{NP}$ & NP & NP & $\mathrm{NP} N$ & NP & $\mathrm{NP}$ & NP & $\mathrm{NP}$ & $\mathrm{N}$ & $\mathrm{N}$ & 1 & 1 & 0 & NP & NP & $\begin{array}{l}\text { Hypercoagulable state with impaired } \\
\text { fibrinolysis }\end{array}$ & $\mathrm{NA}$ & $\begin{array}{l}\text { Decreased R or Kas } \\
\text { well as increased } \alpha \\
\text { angle or MA }\end{array}$ \\
\hline \multirow[b]{3}{*}{$\begin{array}{l}\text { Maatman et al. } \\
\text { (USA) [55] }\end{array}$} & & $\begin{array}{c}109 \text { (TEG } n \\
=12 \text { ) }\end{array}$ & ICU & \multirow[b]{3}{*}{ TEG5000 } & \multirow{3}{*}{$\begin{array}{c}\text { Reference } \\
\text { range } \\
\text { previously } \\
\text { established } \\
\text { in healthy } \\
\text { adults }\end{array}$} & NP & NP $\mathrm{I}$ & NP & $\mathrm{NP}$ & NP & $\mathrm{NP}$ & $\mathrm{NP}$ & $\mathrm{NP} N$ & NP & $\mathrm{NP}$ & NP & $\mathrm{NP}$ & $\begin{array}{c}8 / 12 \\
1 \\
\end{array}$ & $\begin{array}{l}5 / 12 \\
!\end{array}$ & $5 / 12 \uparrow$ & $5 / 12 \uparrow$ & $\mathrm{NP}$ & $\mathrm{NP}$ & $\mathrm{NP}$ & & \multirow{3}{*}{\multicolumn{2}{|c|}{$\begin{array}{l}\text { At the parameters } \\
\text { level: decreased R or K } \\
\text { as well as increased } \alpha \\
\text { angle or MA. At the } \\
\text { thromboelastography } \\
\text { level : two or more } \\
\text { parameters beyond } \\
\text { one SD of the age- and } \\
\text { gender-matched } \\
\text { controls } \\
\end{array}$}} \\
\hline & Retrospective & $\frac{78 / 109}{31109}$ & $\begin{array}{l}\text { no } \mathrm{TE} \\
\geq 1 \mathrm{TE}\end{array}$ & & & $\frac{\mathrm{NP}}{\mathrm{NP}}$ & $\frac{\mathrm{NP} P}{\mathrm{NP} 1}$ & $\frac{\mathrm{NP}}{\mathrm{NP}}$ & $\frac{\mathrm{NP}}{\mathrm{NP}}$ & $\frac{\mathrm{NP}}{\mathrm{NP}}$ & $\frac{\mathrm{NP}}{\mathrm{NP}}$ & $\frac{\mathrm{NP}}{\mathrm{NP}}$ & $\frac{\mathrm{NP} N}{\mathrm{NP} N}$ & $\frac{N P}{N P}$ & $\frac{\mathrm{NP}}{\mathrm{NP}}$ & $\begin{array}{l}\mathrm{NP} \\
\mathrm{NP}\end{array}$ & $\begin{array}{ll}N P & 5 \\
N P & 3\end{array}$ & $\frac{5 / 8+3 /}{3 /+2}$ & $\frac{3 / 8 \downarrow}{2 / 4 !}$ & $\frac{3 / 8 \uparrow}{2 / 4 \uparrow}$ & $\frac{3 / 8 \uparrow}{2 / 4 \uparrow}$ & $\frac{N P}{N P}$ & $\frac{N P}{N P}$ & $\frac{N P}{N P}$ & - raised MA and an absent fibrinolysis, & & \\
\hline & $\begin{array}{l}\text { multi-center } \\
\text { observational } \\
\text { study }\end{array}$ & $31 / 109$ & & & & $\mathrm{~N}$ & $\mathrm{~N}$ & $\mathrm{NP}$ & $N P$ & $\mathrm{NP}$ & 1 & $\mathrm{~N}$ & $\mathrm{NP}^{2} \mathrm{~N}$ & $\mathrm{~N}$ & $\mathrm{~N}$ & $\mathrm{~N}$ & $\mathrm{NIT}$ & 8 & $\mathrm{~N}$ & $\mathrm{~N}$ & 1 & $\mathrm{NP}$ & $\mathrm{NP}$ & $\uparrow$ & $\begin{array}{l}\text { - despite at least prophylactic dose of } \\
\text { LWMH or HNF. However, no } \\
\text { systematic association between } \\
\text { hypercoagulable state as assessed by } \\
\text { TEG and TE outcomes }\end{array}$ & & \\
\hline
\end{tabular}


Table 8. Cont.

\begin{tabular}{|c|c|c|c|c|c|c|c|c|c|c|c|c|c|c|c|c|c|c|c|c|c|c|c|c|c|c|c|}
\hline \multirow[b]{2}{*}{$\begin{array}{l}\text { First Author } \\
\text { (Country) }\end{array}$} & \multirow[b]{2}{*}{ Design } & \multirow[b]{2}{*}{$n$} & \multirow[b]{2}{*}{ Ward } & \multirow[b]{2}{*}{ Device } & \multirow[b]{2}{*}{ Controls } & \multicolumn{7}{|c|}{ CRT Assay /Rapid-TEG } & \multicolumn{4}{|c|}{ CK Assay } & \multicolumn{5}{|c|}{ CKH Assay } & & \multicolumn{2}{|c|}{ CFF Assay } & \multirow[b]{2}{*}{ Conclusions of the Study } & \multirow[b]{2}{*}{$\begin{array}{l}\text { Association with the } \\
\text { Occurrence of } \\
\text { Thrombotic Events }\end{array}$} & \multirow{2}{*}{$\begin{array}{c}\text { Definition of } \\
\text { Hypercoagulability } \\
\text { Assessed by VET } \\
\text { According to the } \\
\text { Authors }\end{array}$} \\
\hline & & & & & & $\begin{array}{l}\text { TEG- } \\
\text { ACT }\end{array}$ & $\underset{(\min )(}{\mathbf{R}}$ & $\underset{(\min )}{\mathbf{K}}{ }^{a}$ & $\begin{array}{c}\alpha \text { angle } \\
\left({ }^{\circ}\right)\end{array}$ & $\begin{array}{l}\mathrm{A} 10 \\
(\mathrm{~mm})\end{array}$ & $\begin{array}{c}\mathrm{MA} \\
(\mathrm{mm})\end{array}$ & $\begin{array}{l}\text { LY30 } \\
(\%)\end{array}$ & $\underset{(\min )(\mathbf{m}}{\mathbf{R}}$ & $\underset{(\min )}{\mathbf{K}} \alpha$ & $\begin{array}{c}\alpha \text { angle } \\
\left({ }^{\circ}\right)\end{array}$ & $\begin{array}{l}\mathrm{MA} \\
(\mathrm{mm})\end{array}$ & $\begin{array}{l}\mathrm{LY} 30 \\
(\%)\end{array}$ & $\underset{(\min )(\mathrm{r}}{\mathrm{R}}$ & $\underset{(\min )}{\mathrm{K}}{ }^{\circ}$ & $\begin{array}{c}\alpha \text { angle } \\
{ }_{(\circ)}^{\circ}\end{array}$ & $\begin{array}{c}\mathrm{MA} \\
(\mathrm{mm})\end{array}$ & $\begin{array}{l}\text { LY30 } \\
(\%)\end{array}$ & $\begin{array}{l}\text { A10 } \\
(\mathrm{mm})\end{array}$ & $\begin{array}{l}\mathrm{MA} \\
(\mathrm{mm})\end{array}$ & & & \\
\hline \multirow[b]{3}{*}{$\begin{array}{l}\text { Mortus et al. } \\
\text { (USA) [56] }\end{array}$} & \multirow[b]{3}{*}{$\begin{array}{l}\text { Retrospective } \\
\text { cohort study }\end{array}$} & 21 & ICU & \multirow[b]{3}{*}{ TEG5000 } & \multirow[b]{3}{*}{$\begin{array}{l}\text { Reference } \\
\text { range } \\
\text { previously } \\
\text { established } \\
\text { in healthy } \\
\text { adults }\end{array}$} & NP & $\begin{array}{ll}\mathrm{NP} \\
\mathrm{NP}\end{array}$ & $\mathrm{NP}$ & $\mathrm{NP}$ & $\mathrm{NP}$ & $\mathrm{NP}$ & $\mathrm{NP}$ & $1 \quad N$ & $\mathrm{NP}$ & $\mathrm{N}$ & $t$ & $\mathrm{~N}$ & $\begin{array}{lll}\mathrm{N} \quad \mathrm{N} \\
\end{array}$ & $\mathrm{NP}$ & $\mathrm{N}-1$ & 1 & $\mathrm{~N}$ & $\mathrm{NP}$ & $\mathrm{NP}$ & \multirow{3}{*}{$\begin{array}{l}\text { Innate TEG MA provides 100\% } \\
\text { sensitivity and 100\% negative } \\
\text { predictive value to discriminate } \\
\text { between patients with high rate of TE } \\
\text { and those with low rate. }\end{array}$} & \multirow{3}{*}{$\begin{array}{l}\text { Yes: Innate TEG MA } \\
\text { provides } 100 \% \\
\text { sensitivity and } 100 \% \\
\text { negative predictive } \\
\text { value to discriminate } \\
\text { between patients with } \\
\text { high rate of TE and } \\
\text { those with low rate. }\end{array}$} & \multirow[b]{3}{*}{$\begin{array}{l}\alpha \text { angle }>73^{\circ} \text { and/or } \\
\text { MA }>65 \text { mm after } \\
\text { heparinase correction }\end{array}$} \\
\hline & & $11 / 21$ & $\leq 1 \mathrm{TE}$ & & & $\mathrm{NP}$ & $\mathrm{NP}$ & $\mathrm{NP}$ & $\mathrm{NP}$ & $\mathrm{NP}$ & $\mathrm{NP}$ & $\mathrm{NP}$ & $1 \quad N$ & $\mathrm{NP}$ & $\mathrm{N}$ & $\mathrm{N}$ & $\mathrm{N}$ & $\mathrm{N}$ & $\mathrm{NP}$ & $\mathrm{N}-1$ & & $\mathrm{~N}$ & $\mathrm{NP}$ & $\mathrm{NP}$ & & & \\
\hline & & $10 / 21$ & $\geq 2 \mathrm{TE}$ & & & NP & NP & NP & $\mathrm{NP}$ & $\mathrm{NP}$ & $\mathrm{NP}$ & $\mathrm{NP}$ & $N-1 \mathrm{~N}$ & $\mathrm{NP}$ & $\mathrm{N}$ & 1 & $\mathrm{~N}-1$ & $\mathrm{~N}$ & $\mathrm{NP}$ & 1 & 1 & $\mathrm{~N}$ & $\mathrm{NP}$ & NP & & & \\
\hline \multirow{3}{*}{$\begin{array}{l}\text { Sadd et al. } \\
\text { (USA) [57] }\end{array}$} & \multirow{3}{*}{$\begin{array}{l}\text { Retrospective } \\
\text { observational } \\
\text { cohort study }\end{array}$} & 10 & ICU & \multirow{3}{*}{ TEG5000 } & \multirow{3}{*}{$\begin{array}{c}\text { Reference } \\
\text { range as } \\
\text { assessed by } \\
\text { the } \\
\text { manufacturer }\end{array}$} & $\mathrm{NP}$ & $\mathrm{NP}$ & $\mathrm{NP}$ & $\mathrm{NP}$ & $\mathrm{NP}$ & $\mathrm{NP}$ & $\mathrm{NP}$ & $\mathrm{N} \quad \mathrm{N}$ & $\mathrm{NP}$ & $\mathrm{NP}$ & $\mathrm{NP}$ & $\mathrm{NP}$ & 1 & $\mathrm{~N}$ & 1 & 1 & 0 & $\mathrm{NP}$ & NP & \multirow{3}{*}{$\begin{array}{l}\text { Hypercoagulable state with impaired } \\
\text { fibrinolysis }\end{array}$} & \multirow{3}{*}{ NA } & \multirow{3}{*}{ NP } \\
\hline & & 4/10 & $\begin{array}{c}\geq 1 \mathrm{TE} \text { and after } \\
\text { tPA } \\
\text { thrombolysis } \\
\end{array}$ & & & NP & $\mathrm{NP}$ & $\mathrm{NP}$ & $\mathrm{NP}$ & $\mathrm{NP}$ & $\mathrm{NP}$ & $\mathrm{NP}$ & $\mathrm{N} N$ & $\mathrm{NP}$ & $\mathrm{NP}$ & $\mathrm{NP}$ & $\mathrm{NP}$ & $\mathrm{N}$ & $\mathrm{N}$ & $N-1$ & $\mathrm{~N}$ & 0 & $\mathrm{NP}$ & $\mathrm{NP}^{\mathrm{H}}$ & & & \\
\hline & & $6 / 10$ & No TE & & & $\mathrm{NP}$ & $\mathrm{NP}$ & $\mathrm{NP}$ & $\mathrm{NP}$ & $\mathrm{NP}$ & $\mathrm{NP}$ & $\mathrm{NP}$ & $\frac{\mathrm{NP} N}{10 / 44}$ & $\mathrm{NP}$ & $\mathrm{NP}$ & $\mathrm{NP}$ & $\mathrm{NP}$ & NP $\quad 1$ & $\frac{\mathrm{NP}}{2864}$ & $\mathrm{NP}$ & NP & $\mathrm{NP}$ & $\mathrm{NP}$ & $\mathrm{NP}$ & & & \\
\hline \multirow[b]{2}{*}{$\begin{array}{l}\text { Yuriditsky et al. }{ }^{\mathrm{F}}{ }_{\mathrm{o}} \\
\text { (USA) [58] }\end{array}$} & & 64 & ICU & & Reference & $\mathrm{NP}$ & $\mathrm{NP}$ & $\mathrm{NP}$ & $\mathrm{NP}$ & $\mathrm{NP}$ & $\mathrm{NP}$ & $\mathrm{NP}$ & $\underset{\uparrow}{19 / 64} \mathrm{~N}$ & $\mathrm{NP}$ & $\mathrm{NP}$ & $\mathrm{NP}$ & $\mathrm{NP}^{2}$ & $\begin{array}{c}28 / 64 \\
!\end{array}$ & $\begin{array}{c}28 / 64 \\
1\end{array}$ & $45 / 64 \uparrow$ & $38 / 64 \uparrow$ & $\mathrm{N}$ & $\mathrm{NP}$ & $\mathrm{NP}$ & & & \\
\hline & $\begin{array}{l}\text { Retrospective- } \\
\text { observational } \\
\text { study }\end{array}$ & $38 / 64$ & $\begin{array}{c}\text { D-dimers levels } \\
\leq 2000 \mu \mathrm{g} / \mathrm{L} \\
\begin{array}{c}\text { D-dimers levels } \\
>2000 \mu \mathrm{g} / \mathrm{L}\end{array} \\
\end{array}$ & TEG5000 & $\begin{array}{c}\text { range as - } \\
\text { assessed by } \\
\text { the } \\
\text { manufacturer }\end{array}$ & NP & $\mathrm{NP}$ & NP & NP & NP & $\mathrm{NP}$ & $\mathrm{NP}$ & $\mathrm{N}^{3} \mathrm{~N}$ & $\mathrm{NP}$ & $\mathrm{NP}$ & $\mathrm{NP}$ & $\mathrm{NP}$ & $\frac{\mathrm{N}}{b^{4}}$ & $\mathrm{~N}^{3}$ & $1^{3}$ & $1^{3}$ & $\mathrm{~N}^{3}$ & $\mathrm{NP}$ & NP & $\begin{array}{l}\text { No correlation between D-dimers } \\
\text { levels and LYY0, no association } \\
\text { between TEG variables and TE }\end{array}$ & No & $\begin{array}{c}\mathrm{R}<5 \mathrm{mn}, \mathrm{K}<1 \mathrm{mn} \\
\quad \mathrm{MA}>70 \mathrm{~mm}\end{array}$ \\
\hline & & $\begin{array}{ll}40 \\
26 / 40 \\
\end{array}$ & 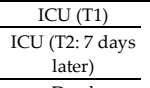 & & $\begin{array}{l}\text { Reference } \\
\text { range as }\end{array}$ & $N-\downarrow^{5}$ & $\mathrm{~N}^{5}$ & $\mathrm{~N}^{5}$ & $\uparrow^{5}$ & $\uparrow^{5}$ & $\uparrow^{5}$ & 0 & $\begin{array}{ll}\mathrm{N}^{5} & \mathrm{~N} \\
\end{array}$ & $\mathrm{~N}^{5}$ & $\mathrm{~N}^{5}$ & $\mathrm{NP}$ & 0 & $\mathrm{~N}^{5}$ & $\mathrm{~N}^{5}$ & $N-1^{5}$ & $\mathrm{~N}-\uparrow^{5}$ & 0 & $\uparrow^{5}$ & $1^{5}$ & $\begin{array}{l}\text { Hypercoagulable state as assessed by } \\
\text { an increased } \alpha \text { angle and clot } \\
\text { amplitude, associated with an absent }\end{array}$ & & \\
\hline $\begin{array}{l}\text { Boccie tal. } \\
\text { (Italy) [59] }\end{array}$ & $\begin{array}{l}\text { observational__ } \\
\text { study }\end{array}$ & $23 / 40$ & Dead & TEG6s & $\begin{array}{l}\text { assessed by } \\
\text { the } \\
\text { manufacturer }\end{array}$ & $\mathrm{N}-t^{3}$ & $N^{3} N$ & $\mathrm{~N}-+^{3}$ & $\uparrow^{3}$ & $1^{3}$ & $\mathrm{~N}-\uparrow^{3}$ & 0 & $\mathrm{~N}^{3} \mathrm{~N}$ & $\mathrm{~N}^{3}$ & $\mathrm{~N}^{3}$ & $\mathrm{NP}$ & 0 & $\mathrm{~N}^{3}$ & $\mathrm{~N}^{3}$ & $\mathrm{~N}-\uparrow^{3}$ & $\mathrm{~N}-\uparrow^{3}$ & 0 & $1^{3}$ & $1^{3} \mathrm{c}$ & $\begin{array}{l}\text { lysis of the clot at } 30 \text { min but no } \\
\text { correlation with the occurrence of } T E \text {. } \\
\text { No difference between D0 and D7, nor } \\
\text { between patients who survived and } \\
\text { those not }\end{array}$ & . & $\mathrm{NP}$ \\
\hline $\begin{array}{l}\text { Stattin et al. } \\
\text { (Sweden) [60] }\end{array}$ & $\begin{array}{l}\text { Prospective } \\
\text { observational } \\
\text { study }\end{array}$ & $11 / 31$ & $\begin{array}{c}\text { ICU (T1: within } \\
4 \text { days after } \\
\text { admission) } \\
\text { ICU (T2: } \\
\text { between D4 and } \\
\text { D7) } \\
\text { ICU (T3: } 7 \text { days } \\
\text { later) }\end{array}$ & TEG6s & $\begin{array}{l}\text { Reference } \\
\text { range as } \\
\text { assessed by } \\
\text { the } \\
\text { manufacturer }\end{array}$ & $\mathrm{NP}$ & $\mathrm{NP}$ & NP & $\mathrm{NP}$ & $\mathrm{NP}$ & $\mathrm{NP}$ & NP & $\begin{array}{lll}N^{5} & N \\
\end{array}$ & $\mathrm{NP}$ & $\mathrm{NP}$ & $\mathrm{NP}$ & NP & $\mathrm{N}^{5} \mathrm{~N}$ & $\mathrm{NP}$ & $\mathrm{N}-\uparrow^{5}$ & $1^{5}$ & 0 & $\mathrm{NP}$ & NP & $\begin{array}{l}\text { Hypercoagulable state as assessed by } \\
\text { MA on TEG with insufficient effect of } \\
\text { standard doses of LMWH. Neither } \\
\text { anti-Xa levels nor TEG can reliably } \\
\text { determine the effect of LMWH in } \\
\text { patients with COVID-19. }\end{array}$ & No & Increased MA \\
\hline & & $\begin{array}{l}5 / 31 \\
26 / 31\end{array}$ & $\begin{array}{l}\geq 1 \mathrm{TE} \\
\text { No TE }\end{array}$ & & & $\mathrm{NP}$ & $\mathrm{NP}$ & $\mathrm{NP}$ & $\mathrm{NP}$ & $\mathrm{NP}$ & $\mathrm{NP}$ & NP & $\mathrm{N}^{3} \mathrm{~N}$ & $\mathrm{NP}$ & NP & NP & $\mathrm{NP}$ & $\mathrm{N}^{3} \quad \mathrm{~N}$ & NP & $\mathrm{N}-\uparrow^{3}$ & $1^{3}$ & 0 & $\mathrm{NP}$ & $\mathrm{NP}$ & & & \\
\hline
\end{tabular}


Table 8. Cont.

\begin{tabular}{|c|c|c|c|c|c|c|c|c|c|c|c|c|c|c|c|c|c|c|c|c|c|c|c|c|c|c|c|}
\hline \multirow[b]{2}{*}{$\begin{array}{l}\text { First Author } \\
\text { (Country) }\end{array}$} & \multirow[b]{2}{*}{ Design } & \multirow[b]{2}{*}{$n$} & \multirow[b]{2}{*}{ Ward } & \multirow[b]{2}{*}{ Device } & \multirow[b]{2}{*}{ Controls } & \multicolumn{6}{|c|}{ CRT Assay/Rapid-TEG } & \multicolumn{5}{|c|}{ CK Assay } & \multicolumn{5}{|c|}{ CKH Assay } & \multicolumn{3}{|c|}{ CFF Assay } & \multirow[b]{2}{*}{ Conclusions of the Study } & \multirow[b]{2}{*}{$\begin{array}{l}\text { Association with the } \\
\text { Occurrence of } \\
\text { Thrombotic Events }\end{array}$} & \multirow{2}{*}{$\begin{array}{c}\text { Definition of } \\
\text { Hypercoagulability } \\
\text { Assessed by VET } \\
\text { According to the } \\
\text { Authors }\end{array}$} \\
\hline & & & & & & $\begin{array}{l}\text { TEG- } \\
\text { ACT }\end{array}$ & $\underset{(\min )(\mathrm{r}}{\mathrm{R}}$ & $\underset{(\min )}{\mathrm{K}}{ }^{a}$ & $\begin{array}{c}\alpha \text { angle } \\
{ }_{\left({ }^{\circ}\right)}\end{array}$ & $\begin{array}{c}\mathrm{A} 10 \\
(\mathrm{~mm})\end{array}$ & $\begin{array}{c}\mathrm{MA} \\
(\mathrm{mm})\end{array}$ & $\begin{array}{c}\mathrm{LY}_{30} \\
(\%)\end{array}$ & & $\underset{(\min )}{\mathrm{K}}$ & $\underset{\left({ }^{\circ}\right)}{\alpha \text { angle }}$ & $\begin{array}{c}\text { MA } \\
(\mathrm{mm})\end{array}$ & $\begin{array}{l}\text { LY30 } \\
(\%)\end{array}$ & $\underset{(\min )(\mathrm{r}}{\mathrm{R}}$ & $\underset{(\min )}{\mathrm{K}}$ & $\begin{array}{c}\alpha \text { angle } \\
\left({ }^{\circ}\right)\end{array}$ & $\begin{array}{c}\mathrm{MA} \\
(\mathrm{mm})\end{array}$ & $\begin{array}{l}\text { LY30 } \\
(\%)\end{array}$ & $\begin{array}{c}\mathrm{A} 10 \\
(\mathrm{~mm})\end{array}$ & $\begin{array}{l}\text { MA } \\
(\mathrm{mm})\end{array}$ & & & \\
\hline $\begin{array}{l}\text { Vlot et al. } \\
\text { (The } \\
\text { Netherlands) } \\
\text { [61] }\end{array}$ & $\begin{array}{l}\text { Prospective } \\
\text { observational } \\
\text { study }\end{array}$ & 16 & $\begin{array}{l}\mathrm{ICU}(\mathrm{T} 1) \\
\mathrm{ICU}(\mathrm{T} 2)\end{array}$ & \multirow{2}{*}{ TEG6s } & $\begin{array}{c}\text { Reference } \\
\text { range as } \\
\text { assessed by } \\
\text { the } \\
\text { manufacturer } \\
\end{array}$ & NP & NP & NP & $\mathrm{NP}$ & $\mathrm{NP}$ & NP & NP & $\mathrm{NP}$ & $\mathrm{N}-\mathrm{t}$ & NP & 1 & $\mathrm{NP}$ & $\mathrm{NP}$ & NP & $\mathrm{NP}$ & $\mathrm{NP}$ & NP & $\mathrm{NP}$ & + & $\begin{array}{l}\text { Despite anti-Xa levels within the target } \\
\text { range of pharmacodynamic endpoint, } \\
\text { VET still demonstrates a procoagulant } \\
\text { pattern with a clot strength dominated } \\
\text { by the fibrinogen component } \\
\end{array}$ & $\mathrm{NA}$ & $\mathrm{NP}$ \\
\hline $\begin{array}{l}\text { Patel et al. } \\
\text { (United } \\
\text { Kingdom) [62] }\end{array}$ & $\begin{array}{l}\text { Retrospective } \\
\text { observational } \\
\text { study }\end{array}$ & 39 & ICU & & $\begin{array}{l}\text { Reference } \\
\text { range as } \\
\text { assessed by } \\
\text { the } \\
\text { manufacturer } \\
\end{array}$ & $\mathrm{NP}$ & $\mathrm{NP}$ & $\mathrm{NP}$ & $\mathrm{NP}$ & NP & $\mathrm{NP}$ & $\mathrm{NP}$ & $\mathrm{NP}$ & NP & NP & $\mathrm{NP}$ & $\mathrm{NP}$ & $\mathrm{NP}$ & NP & NP & $21 / 39 \uparrow$ & 0 & NP & 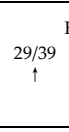 & $\begin{array}{l}\text { Hypercoagulable state as assessed by a } \\
\text { raised MA and an absent fibrinolysis, } \\
\text { despite at least prophylactic dose of } \\
\text { LWMH or HNF } \\
\end{array}$ & NA & $\begin{array}{l}\text { Increased MA and } \\
\text { particularly in CFF } \\
\text { assay }\end{array}$ \\
\hline \multirow[b]{3}{*}{$\begin{array}{l}\text { Salem et al. } \\
\text { (United Arab } \\
\text { Emirates) [63] }\end{array}$} & \multirow[b]{3}{*}{$\begin{array}{l}\text { Retrospective- } \\
\text { observational } \\
\text { study }\end{array}$} & 52 & $\mathrm{ICU}$ & \multirow[b]{3}{*}{ TEG6s } & \multirow{3}{*}{$\begin{array}{c}\text { Reference } \\
\text { range as } \\
\text { assessed by } \\
\text { the } \\
\text { manufacturer }\end{array}$} & $\mathrm{NP}$ & $\mathrm{NP}$ & $\mathrm{NP}$ & $\mathrm{NP}$ & $\mathrm{NP}$ & $\mathrm{NP}$ & $\mathrm{NP}$ & $\mathrm{NP}$ & $\mathrm{NP}$ & $\mathrm{NP}$ & $\mathrm{NP}$ & $\mathrm{NP}$ & $\mathrm{N}$ & $\mathrm{N}$ & $\mathrm{N}$ & $\mathrm{N}$ & 0 & NP & $\mathrm{NP}$ & & & \\
\hline & & $\begin{array}{l}14 / 52 \\
38 / 52 \\
\end{array}$ & $\begin{array}{l}\geq 1 \mathrm{TE} \\
\text { No TE } \\
\end{array}$ & & & $\mathrm{NP}$ & $\mathrm{NP}$ & $\mathrm{NP}$ & $\mathrm{NP}$ & $\mathrm{NP}$ & $\mathrm{NP}$ & NP & $\mathrm{NP}$ & $\mathrm{NP}$ & $\mathrm{NP}$ & $\mathrm{NP}$ & $\mathrm{NP}$ & $\mathrm{N}^{3}$ & $\mathrm{~N}^{3}$ & $\mathrm{~N}^{3}$ & $\mathrm{~N}^{3}$ & 0 & $\mathrm{NP}$ & $\mathrm{NP}$ & & & \\
\hline & & $\begin{array}{l}16 / 52 \\
36 / 52 \\
\end{array}$ & $\begin{array}{c}\frac{\begin{array}{c}\text { hypercoagulable } \\
\text { profile }\end{array}}{\text { non }} \\
\begin{array}{c}\text { hypercoagulable } \\
\text { profile }\end{array} \\
\end{array}$ & & & NP & $\mathrm{NP}$ & NP & NP & NP & $\mathrm{NP}$ & $\mathrm{NP}$ & \multicolumn{2}{|c|}{ NP NP } & NP & $\mathrm{NP}$ & NP & $\mathrm{N}^{3}$ & $\mathrm{~N}^{3}$ & $N-\uparrow^{3}$ & $1^{6}$ & 0 & NP & $\overline{\mathrm{NP}}{ }^{\mathrm{T}}$ & $\begin{array}{l}\text { Hyp not associated with the occurrence } \\
\text { of TE }\end{array}$ & No & $\begin{array}{l}R<4.3 \min , K<0.8 \\
\text { min, MA } \mathrm{A} 69 \mathrm{~mm}, \alpha \\
\text { angle }>77^{\circ}\end{array}$ \\
\hline Shah et al. & $\begin{array}{l}\text { Multicenter } \\
\text { retrospective- }\end{array}$ & $\begin{array}{c}187 \text { (TEG } n \\
=20 \text { ) }\end{array}$ & ICU & & $\begin{array}{c}\text { Reference } \\
\text { range as }\end{array}$ & NP & NP & NP & NP & $\mathrm{NP}$ & NP & NP & NP & $\mathrm{NP}$ & NP & NP & $\mathrm{NP}$ & $\mathrm{N}$ & NP & $\mathrm{N}-1$ & $\uparrow$ & 0 & NP & 1 & $\begin{array}{l}\text { Hypercoagulable state as assesses by } \\
\text { VET, but with no discrimination }\end{array}$ & & $\begin{array}{l}\alpha \text { angle and } \mathrm{MA} \geq \text { the } \\
\text { upper limit of the }\end{array}$ \\
\hline $\begin{array}{l}\text { (United } \\
\text { Kingdom) [64] }\end{array}$ & $\begin{array}{l}\text { observational- } \\
\text { study }\end{array}$ & $\begin{array}{l}81 / 187 \\
106 / 187\end{array}$ & $\begin{array}{l}\geq 1 \mathrm{TE} \\
\text { No TE }\end{array}$ & TEG6s & $\begin{array}{l}\text { assessed by } \\
\text { the } \\
\text { manufacturer }\end{array}$ & NP & NP & $\mathrm{NP}$ & $\mathrm{NP}$ & $\mathrm{NP}$ & $\mathrm{NP}$ & $\mathrm{NP}$ & $\mathrm{NP}$ & $\mathrm{NP}$ & $\mathrm{NP}$ & $\mathrm{NP}$ & $\mathrm{NP}$ & $\mathrm{N}^{3}$ & $\mathrm{NP}$ & $\mathrm{N}-1^{3}$ & $1^{3}$ & 0 & $\mathrm{NP}$ & $\hat{1}^{3}$ & $\begin{array}{l}\text { between patients who will undergo TE } \\
\text { and patients who won't }\end{array}$ & No & $\begin{array}{l}\text { reference range, } \\
\text { extremely low LY30 }\end{array}$ \\
\hline $\begin{array}{l}\text { Fan et al. } \\
\text { (Singapore) [65] }\end{array}$ & Case report & 1 & IMW & TEG6s & $\begin{array}{c}\text { Reference } \\
\text { range as } \\
\text { assessed by } \\
\text { the } \\
\text { manufacturer }\end{array}$ & $\mathrm{N}$ & $\mathrm{N}$ & $\mathrm{N}$ & 1 & $\mathrm{NP}$ & 1 & $\mathrm{~N}$ & $\mathrm{~N}$ & $\mathrm{~N}$ & $\mathrm{~N}$ & $\mathrm{~N}$ & $\mathrm{~N}$ & $\mathrm{~N}$ & $\mathrm{~N}$ & $\mathrm{~N}$ & $\mathrm{~N}-1$ & $\mathrm{NP}$ & $\mathrm{NP}$ & $\frac{1}{1}$ & $\begin{array}{l}\text { Hypercoagulable state assessed by VET } \\
\text { with an excessive fibrinogen } \\
\text { component to clot strength }\end{array}$ & $\mathrm{NA}$ & Increased MA \\
\hline
\end{tabular}

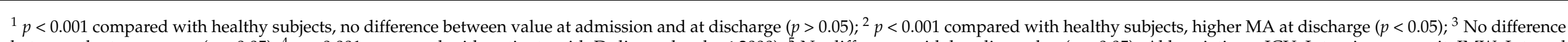

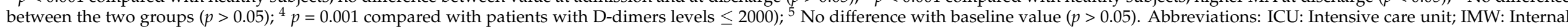

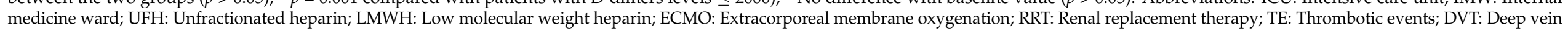

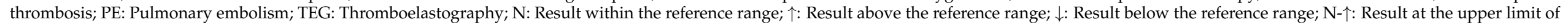
the reference range; $\mathrm{N}-\downarrow$ : Result at the lower limit of the reference range; NP: Not provided; NS: Not specified; NA: Not assessed. 
In summary, three points are worthy of attention. First, the hypercoagulable pattern defined as just above was observed in both ICU and non-ICU COVID-19 patients [65]. Second, it was observed despite UFH or LMWH anticoagulation at prophylactic doses or higher, and an anti-Xa activity within the target range without heparin neutralization (TEG, CK assay) [49]; and third it persisted over time [53,59-61]. However, the association between the observed pattern and the occurrence of thrombotic events remains a matter of debate. One study including 21 patients reported that an increase in MA provides 100\% sensitivity and $100 \%$ negative predictive value to discriminate between patients with high or low rate of thrombotic events (44), but only a few patients were reported. Another study (44 patients) reported that no evidence of clot lysis at $30 \mathrm{~min}$ (LY30) associated with high D-dimers levels $(>2600 \mu \mathrm{g} / \mathrm{L})$ could predict thromboembolic events $(p=0.008)$ and need for hemodialysis in critically ill patients $(p=0.004)$ with COVID-19 [51]. However, seven other studies $[53,55,58-60,63,64]$ comprising 243 patients did not find an association between the VET parameters and the occurrence of thrombotic events.

\subsubsection{Quantra}

The Quantra device was used in two studies [66,67], both prospective, one of them comparing data from ICU non-COVID-19 patients with ICU COVID-19 patients [66]. The two studies included 44 ARDS intubated and mechanically ventilated ICU patients, of whom 33 were COVID-19 positive. All patients received anticoagulation according to local protocols or guidelines [74]. Tests were performed using the QPlus Cartridge, which contains heparinase in the CTH channel and polybrene in the CS and FCS channels to neutralize heparin. Results are summarized in Table 9.

Both studies suggested a hypercoagulable pattern associated with preserved thrombin generation, assessed by prothrombin fragments $1+2$ and thrombin-antithrombin complex levels [66] and despite UFH or LMWH anticoagulation at a minimum of prophylactic dosing. However, the VET hypercoagulable pattern tended to normalize [67] after a $50 \%$ increase in thromboprophylaxis dosing and based on the body weight. However, the association between the documented hypercoagulable pattern and thrombotic event occurrence was not studied.

\subsubsection{ClotPro}

ClotPro was used in a retrospective study in Austria [24] and in three cases in Hungary [68] of ICU patients who received anticoagulation at prophylactic doses or greater. VET assays were performed using four reagents and channels (Table A7), namely EX-test, IN-test, Fib-test, and tPA-test. Results are summarized in Table 10.

Results from the tPA-test showed a hypercoagulable pattern (increased maximum clot firmness) associated with impaired fibrinolysis; the latter was assessed either by a decreased lysis capacity of the clot in presence of tPA as compared with manufacturer's reference values, followed few days later by a normalization with still marked elevated D-dimers levels [68], or by an increased clot lysis time as compared with healthy controls with a $p$-value $<0.01$ [24]. However, these findings do not appear to be associated with the occurrence of thrombotic events [24]. 
Table 9. Main findings of studies reporting Quantra results using the QPlus cartridge.

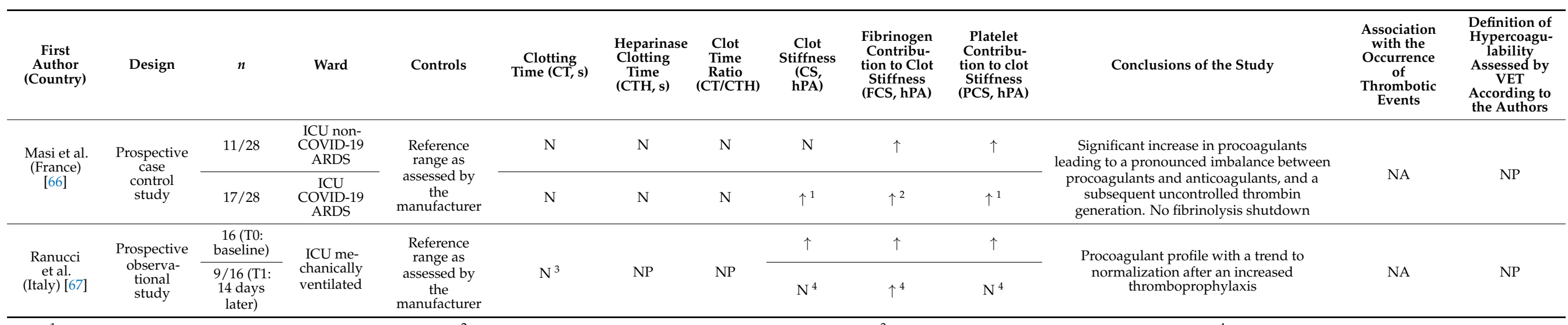

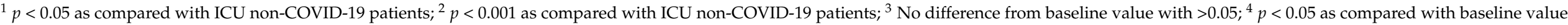

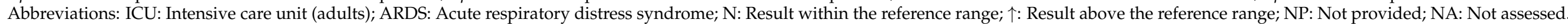


Table 10. Main findings of studies reporting ClotPro results.

\begin{tabular}{|c|c|c|c|c|c|c|c|c|c|c|c|c|c|c|c|c|c|c|c|c|c|c|c|c|}
\hline \multirow{2}{*}{$\begin{array}{l}\text { First } \\
\text { Author } \\
\text { (COUN- } \\
\text { TRY) }\end{array}$} & \multirow[b]{2}{*}{ Design } & \multirow[b]{2}{*}{$n$} & \multirow[b]{2}{*}{ Ward } & \multirow[b]{2}{*}{ Controls } & \multicolumn{5}{|c|}{ EX-Test } & \multicolumn{5}{|c|}{ IN-Test } & \multicolumn{3}{|c|}{ FIB-Test } & \multicolumn{4}{|c|}{ tPA-Test } & \multirow[b]{2}{*}{ Conclusions } & \multirow{2}{*}{$\begin{array}{l}\text { Association with } \\
\text { the Occurrence } \\
\text { of Thrombotic } \\
\text { Events Outcomes }\end{array}$} & \multirow{2}{*}{$\begin{array}{l}\text { Definition of } \\
\text { Hypercoagulability } \\
\text { Assessed by VET } \\
\text { According to the Authors }\end{array}$} \\
\hline & & & & & $\begin{array}{l}\mathrm{CT} \\
\text { (s) }\end{array}$ & $\begin{array}{l}\text { CFT } \\
(\mathrm{s})\end{array}$ & $\begin{array}{l}\mathrm{A}(\mathrm{x}) \\
(\mathrm{mm})\end{array}$ & $\begin{array}{l}\text { MCF } \\
(\mathrm{mm})\end{array}$ & $\begin{array}{l}\text { ML } \\
(\%)\end{array}$ & $\begin{array}{l}\mathrm{CT} \\
\text { (s) }\end{array}$ & $\begin{array}{l}\text { CFT } \\
\text { (s) }\end{array}$ & $\begin{array}{l}\mathrm{A}(\mathrm{x}) \\
(\mathrm{mm})\end{array}$ & $\begin{array}{l}\text { MCF } \\
(\mathrm{mm})\end{array}$ & $\begin{array}{l}\text { ML } \\
(\%)\end{array}$ & $\begin{array}{l}\mathrm{CT} \\
(\mathrm{s})\end{array}$ & $\begin{array}{c}\mathrm{A}(\mathrm{x}) \\
(\mathrm{mm})\end{array}$ & $\begin{array}{l}\text { MCF } \\
(\mathrm{mm})\end{array}$ & $\begin{array}{l}\mathrm{CT} \\
(\mathrm{s})\end{array}$ & $\begin{array}{l}\text { MCF } \\
(\mathrm{mm})\end{array}$ & ML (\%) & $\begin{array}{l}\mathrm{LT} \\
\text { (s) }\end{array}$ & & & \\
\hline \multirow{2}{*}{$\begin{array}{l}\text { Bachler } \\
\text { et al. } \\
\text { (Austria) } \\
\text { [24] }\end{array}$} & \multirow{2}{*}{$\begin{array}{l}\text { Retrospective } \\
\text { study }\end{array}$} & 20 & ICU & \multirow{2}{*}{$\begin{array}{c}\text { Reference } \\
\text { range es- } \\
\text { tablished } \\
\text { in } \\
\text { healthy } \\
\text { adults }\end{array}$} & $\mathrm{N}$ & NP & $\uparrow^{1}$ & $\uparrow^{1}$ & $\mathrm{~N}$ & $\mathrm{~N}$ & $\mathrm{NP}$ & $\uparrow^{1}$ & $\uparrow^{1}$ & $\mathrm{~N}$ & $\mathrm{~N}$ & $\uparrow^{1}$ & $\uparrow^{1}$ & $\mathrm{~N}$ & $\uparrow^{1}$ & $\mathrm{~N}$ & $\begin{array}{l}\uparrow \\
1\end{array}$ & \multirow{2}{*}{$\begin{array}{l}\text { Hypercoagulable } \\
\text { pattern assessed by } \\
\text { increased clot } \\
\text { amplitude and MCF } \\
\text { in all assays. No } \\
\text { difference in TE } \\
\text { outcomes between } \\
\text { patients with } \\
\text { impaired fibrinolysis } \\
\text { (assessed by a } \\
\text { prolonged clot lysis } \\
\text { time in tPA assay) } \\
\text { and patients with } \\
\text { normal clot lysis time }\end{array}$} & \multirow{2}{*}{ No } & \multirow{2}{*}{$\begin{array}{l}\text { Increased MCF. Definition } \\
\text { not relying on VET } \\
\text { =difficulties in reaching } \\
\text { the anti-Xa target range } \\
\text { despite high doses of } \\
\text { LMWH or elevated } \\
\text { D-dimer leveleds } \\
2000 \mu \mathrm{L} / \mathrm{L}\end{array}$} \\
\hline & & $6 / 20$ & $\begin{array}{c}\text { ICU } \\
\text { with LT } \\
\leq 393 \mathrm{~s} \\
\end{array}$ & & $\mathrm{~N}^{2}$ & NP & $\mathrm{N}$ & $\mathrm{N}$ & $\mathrm{N}$ & $\mathrm{N}$ & NP & $\mathrm{N}$ & $\mathrm{N}$ & $\mathrm{N}$ & $\mathrm{N}$ & $\uparrow$ & $\uparrow$ & $\mathrm{N}$ & $\mathrm{N}$ & $\mathrm{N}$ & $\mathrm{N}$ & & & \\
\hline \multirow{3}{*}{$\begin{array}{c}\text { Zátroch } \\
\text { et al. } \\
\text { (Hun- } \\
\text { gary) } \\
\text { [68] }\end{array}$} & \multirow[b]{3}{*}{ Case report } & 1 & ICU & \multirow{3}{*}{$\begin{array}{c}\text { Reference } \\
\text { range as } \\
\text { assessed } \\
\text { by the } \\
\text { manufac- } \\
\text { turer }\end{array}$} & $\mathrm{N}$ & $\mathrm{N}$ & $\mathrm{N}$ & $\mathrm{N}$ & $\mathrm{N}$ & $\mathrm{N}$ & $\mathrm{N}$ & $\mathrm{N}$ & $\mathrm{N}$ & $\mathrm{N}$ & $\mathrm{N}$ & $\uparrow$ & $\uparrow$ & $\mathrm{N}$ & $\uparrow$ & $\mathrm{N}$ & NP & \multirow{3}{*}{$\begin{array}{l}\text { Procoagulation, } \\
\text { hypercoagulation and } \\
\text { fibrinolysis shutdown }\end{array}$} & \multirow[b]{3}{*}{ NA } & \multirow{3}{*}{$\begin{array}{l}\text { Procoagulability: } \\
\text { decreased CT } \\
\text { Hypercoagulability: } \\
\text { Increased MCF }\end{array}$} \\
\hline & & 1 & ICU & & $\uparrow$ & $\mathrm{N}$ & $\uparrow$ & $\uparrow$ & $\mathrm{N}$ & $\mathrm{N}$ & $\downarrow$ & $\uparrow$ & $\uparrow$ & $\mathrm{N}$ & $\uparrow$ & $\uparrow$ & $\uparrow$ & $\mathrm{N}$ & $\uparrow$ & $\mathrm{N}$ & $\mathrm{NP}$ & & & \\
\hline & & 1 & ICU & & $\uparrow$ & $\mathrm{N}$ & $\uparrow$ & $\uparrow$ & $\mathrm{NP}$ & $\uparrow$ & $\mathrm{N}$ & $\uparrow$ & $\uparrow$ & $\mathrm{N}$ & $\uparrow$ & $\uparrow$ & $\uparrow$ & $\mathrm{N}$ & $\uparrow$ & $\begin{array}{l}\downarrow \text { then } \\
\text { normal- } \\
\text { ization } \\
\text { few } \\
\text { days later }\end{array}$ & NP & & & \\
\hline
\end{tabular}

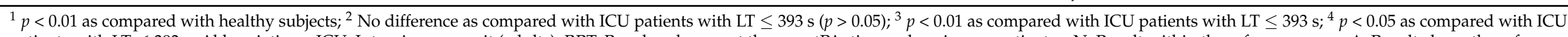

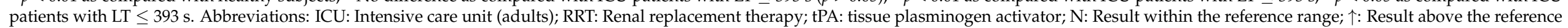
range; $\downarrow$ : Result below the reference range; NP: Not provided; NA: Not assessed. 


\section{Discussion}

Although all of the studies share the common viscoelastometric testing concept in evaluating COVID 19 patients' hemostasis, the differences in the testing systems and reagents, resultant data and implications, and variability of the patients' severity of illness make interpretation difficult. The association with thrombotic events is not very well established, and might largely depend on the actual VET used. We will more specifically discuss whether VETs provide clinically relevant information about fibrinogen in a COVID19 patient, and we will discuss its use regarding potential anticoagulation with heparins.

\subsection{Methodological Issues in VET Studies}

There are numerous methodological differences among the 44 studies using VETs to assess the hemostasis in COVID-19 patients we have retrieved and analyzed, explaining why results were not consistent through studies, or sometimes even conflicting. This was already raised by previously published reviews $[70,71]$.

First, the design was heterogeneous among studies with 19 prospective studies [2832,39-46,52,59-61,66,67], 19 retrospective ones [24,27,33-36,47-49,51,53-58,62-64], and 6 case reports $[26,37,38,50,65,68]$ with no randomized controlled trial (VET versus no VET). Studies also differed on the timing of the sampling for VET assay (ranging from admission $[27,29-31,36-38,44-46,50,53,56,66]$ to a median of 18 (13-29) days after admission [47]), the number of studied patients (ranging from 5 excepted case-reports $[40,54]$ to 64 [58]), the anticoagulation regimen, and the diagnosis of thrombotic events (solely based upon clinical signs, based upon a systematic screening by imaging or based upon clinical signs and confirmed by imaging). There is variability how the authors defined hypercoagulable patterns in VETs based on the parameters used and the reference values considered. Some studies used reference range from local healthy subjects $[24,28,31-33,39-41,46,47,50,52,53,55,56]$, while most of the reference values were manufacturer determined and could not be fully adapted to the local population and settings [1,3].

Second, there was also heterogeneity among the patients' characteristics concerning age, severity of the disease, gender distribution, and comorbidities. In addition to the lack of power to evidence a statistically significant association between the VET patterns and thrombotic events, this heterogeneity could explain the differences between the studies results, at least in part.

One important consideration is different monitoring devices were used. Even though they share the same objective of viscoelastic clot properties evaluation, they present substantial differences from technological and methodological viewpoints. First, they rely on different technologies to monitor clot formation, clot strength, and clot lysis (i.e., thromboelastometry, thromboelastography, and sonorheometry). Second, there are some differences in the way the tests are carried out and the sample and reagents are delivered to perform the assay, specifically the activators. While in the most recent versions of the instruments (TEG6s, ROTEM sigma, Quantra, ClotPro) the reagents are already included in reaction cartridges or in tips and require only the addition of the blood sample, the previous versions (ROTEM gamma and delta, TEG5000) required manual or semi-automated pipetting of reagents and samples, resulting in very high inter- and intra-operator coefficients of variation for some parameters $[77,78]$. Third, the composition of the reagents differs from one manufacturer to another, especially for the assay aiming to assess the fibrinogen component of clot strength, also called functional fibrinogen. Briefly, clot strength is mainly due to the interaction between fibrin network (containing activated factor XIII), platelets [7], neutrophil extracellular traps [79], and red blood cells [80,81]. Platelets are an important contributor to the clot strength, and the MA (TEG), MCF (ROTEM and ClotPro), and CS (Quantra) parameters reflect both platelet count and function [9,82], as well as fibrin contribution. To assess functional fibrinogen, platelet contribution must be inhibited, and two different approaches are used that include abciximab (GpIIb-IIIa inhibitor, TEG and Quantra), cytochalasin D (cytoskeleton inhibitor, ROTEM), or a combination of both (ClotPro). Some studies [83-85] compared the fibrinogen contribution to clot mechanical 
strength measured with VET using either a GpIIb-IIIa inhibitor or cytochalasin D and showed that the latter was more efficient: functional fibrinogen assessment with TEG or Quantra could lead to an overestimation of fibrinogen levels as compared with ROTEM. However, cytochalasin D alone may not completely remove the platelet contribution, especially with a high platelet count, and a combination of a GpIIb-IIIa inhibitor and cytochalasin D seems to provide more accurate results [83-85].

Therefore, we can reasonably doubt that the results obtained from the different devices and studies are interchangeable, as previously noted in non-COVID-19 patients [3,86]. There may even be differences in results between different versions of the same device (as between ROTEM-delta and ROTEM-sigma for example [15,87], or between TEG5000 and TEGS6s [17-19]), but overall the devices show good correlations for the main parameters evaluated $[14,86,88,89]$. To our knowledge, there have not been previous comparisons in COVID-19 patients. Studies on VET have always been plagued by those issues, unfortunately still unresolved.

\subsection{Definition of a Hypercoagulable State by VET and Association with Thrombotic Events}

The conventional clotting time corresponds to the 'reaction time' $\mathrm{R}$ for TEG, and the 'clotting time' CT for ROTEM, ClotPro, and Quantra. Extended fibrin polymerization is described as the kinetics time $\mathrm{K}$ and $\alpha$ angle for TEG and CFT and $\alpha$ angle for ROTEM and ClotPro. The clot strength is defined as maximal mechanical strength (maximal amplitude MA for TEG, maximal clot firmness MCF for ROTEM and ClotPro, and clot stiffness CS for Quantra).

Beyond a purely biological definition, for which there is no consensus or appropriate term, sometimes 'procoagulant' or hypercoagulable, what matters is the association with the patient's thrombotic risk. Outside the COVID-19 setting, two systematic reviews and a subsequent meta-analysis involving 1285 patients with solid tumors or hematopoietic malignancies [90] or 8944 surgical patients [91] showed that the occurrence of thrombotic events was associated with features consistent with hypercoagulability: acceleration of fibrin polymerization (increase in $\alpha$ angle in both ROTEM and TEG, shortened CFT in ROTEM and shortened $\mathrm{K}$ time in TEG) and increased clot mechanical strength (increase in MCF for ROTEM and in MA for TEG). However, another meta-analysis of 1081 patients in a variety of clinical settings [92] showed that ROTEM and TEG had a moderate ability to discriminate between patients who developed a thrombotic event and those who did not, with a diagnostic odds-ratio of 3.6, a low sensitivity (56\%) but a somewhat better specificity $(76 \%)$. It is noteworthy that the performance in the prediction of thrombotic events depends both on the type of device (with a better performance for ROTEM with a diagnostic odds-ratio of 6.3 against 3.2 for TEG), and on the type of thrombotic event (with a sensitivity of $67 \%$, a specificity of $72 \%$, and a diagnostic odds-ratio of 6.4 for arterial thrombotic events, contrasting with a sensitivity of $41 \%$, a specificity of $70 \%$, and an oddsratio diagnosis of 3.1 for venous thrombotic events). Why VET findings should be more associated with arterial thrombotic events than with venous ones is obscure, though.

Regarding the 44 studies we examined, all authors concluded that COVID-19 patients displayed a hypercoagulable pattern characterized by an increased clot mechanical strength (assessed by CS in Quantra, MA in TEG and MCF in ROTEM and ClotPro) basically due to an excessive fibrin(ogen) component (assessed by FCS in Quantra, CFF-MA in TEG, FIBTEM-MCF in ROTEM and MCF from FIB-test in ClotPro), associated with a shortening of clot initiation (decreased $\mathrm{K}$ in TEG and CFT in ROTEM and ClotPro) in 18 studies $[26,27,31-33,38,41-46,49,50,52,53,55,58]$, an acceleration of fibrin polymerization (increased $\alpha$ angle in TEG, ROTEM and ClotPro) in 15 studies [32,38,39,50,52-60,64,65], and an impaired or reduced fibrinolysis in 26 studies [24,26,30,32,34,37,39,40,42-44,46,48,51$54,57-60,62-65,68]$. It is crucial to note however that an association between that pattern and thrombotic events was evidenced by only one study [56] out of the sixteen addressing the issue $[24,31,33-35,44,49,51,53,55,56,58-60,63,64]$ : an increase in the maximum clot amplitude (MA) provides $100 \%$ sensitivity and $100 \%$ negative predictive value to discriminate 
between patients with a high or low rate of thrombotic events, but confidence intervals were not reported [56]. This raises doubts about the clinical significance of the 'so called' hypercoagulability identified by VET and its potential clinical implications (e.g., thrombotic risk stratification or adjustment of thromboprophylaxis).

\subsection{Ability of VETs to Detect Hypofibrinolysis State and Association with Thrombotic Events}

Fibrinolysis is monitored at a specific time $\mathrm{x}$ minutes after MA was reached for TEG (LY(x) parameter), and by maximal lysis ML (reduction in clot firmness after MCF in relation to MCF) or lysis of the clot at a given time $\mathrm{x}$ minutes after $\mathrm{CT}$ was reached $(\mathrm{LI}(\mathrm{x}))$ parameter for ROTEM and ClotPro. The diminution in clot maximum amplitude was thought to be due to both fibrinolysis and potentially platelet-mediated clot retraction [4-6,93]. However, as no change in clot mechanical strength after the maximum was reached was reported in many studies in COVID-19 patients, platelet-mediated clot retraction does not seem to play a significant role here.

Usually VETs are used to detect major hyperfibrinolytic states [94] that occur in the most severe, advanced stages of hemostasis derangements in clinical settings such as trauma and perioperative hemorrhage. However, could they be used to assess hypofibrinolysis? VETs have shown potential usefulness in sepsis-induced coagulopathy [10] and trauma-induced coagulopathy [11] to detect low levels of fibrinolysis and to identify patients for whom the administration of tranexamic acid should be avoided. Endogenous systemic fibrinolysis is usually weak because of low or even no circulating levels of free plasminogen activators, which are fully complexed to PAI-1 and thus inactive. Normal lysis of a whole blood clot is therefore a slow phenomenon [95], and its visualization on a VET trace recorded during one hour or two seems unlikely. Furthermore, as the zero value belongs to the manufacturer's reference range, speaking about a reduced or an absent fibrinolysis seems awkward if there is no control group for comparison. Among the 25 studies reporting a reduced or absent fibrinolysis, only $8[24,32,39,40,44,48,52,53]$ made this assessment by comparison with a control group.

Several ROTEM and TEG modifications have been reported adding urokinase plasminogen activator (uPA) or tissue plasminogen activator (tPA) to demonstrate hypofibrinolysis. A brief literature search revealed multiple protocols for modified ROTEM and TEG including addition of a plasminogen activator. Although they show evidence of hypofibrinolysis in different clinical settings, they all share the same methodological issues and limitations. First, there is a lack of standardization concerning tissue factor concentrations, as low levels added to the sample produce non-reproducible results and often a weak clot $[96,97]$. Second, there is also a lack of standardization in tPA concentrations studied ranging from 50 to $625 \mathrm{ng} / \mathrm{mL}$ [96-98], and similar results for modified VET with uPA $[99,100]$, with an 'optimal concentration of uPA' differing from subject to subject, and a wide interindividual variation in lysis parameters [99].

Among the 44 studies analyzed in this review, only four investigated the effect of adding tPA to standard VET. Two used the ClotPro device [24,68] and its ready-to-use tPA-test reagents, which are now CE-marked, whereas the two others [39,40] used an in-house ROTEM assay with two different tPA concentrations (named TEM-tPA), making a comparison between them problematic. No study has investigated a defective fibrinolysis using the Quantra device into the COVID-19 context, whereas a new dedicated reagent cartridge is now available [23]. The four articles share the same conclusion that increased clot maximum amplitude and decreased lysis index reflect an increase in clot strength and a decreased fibrinolytic capacity, results that need to be confirmed with a larger cohort. Further, the TEM-tPA assay needs to be standardized and validated [101], although it seemed to show good intra- and inter-assay precision in healthy controls [39].

Association between impaired fibrinolysis assessed with VETs and clinical outcomes is a matter of debate. Some studies failed to find an association $[24,53,55,58,59]$, while others suggested that impaired fibrinolysis was associated with a higher rate [34] and a shorter time to the occurrence of thrombotic events [51], and together with D-dimer levels 
it could predict thrombotic events $[44,51]$ and the need for hemodialysis in critically ill patients with COVID-19 [51].

\subsection{Correlation between Clauss Fibrinogen and Functional Fibrinogen Assessed by VETs}

Outside of the COVID-19 context, the ROTEM FIBTEM is the most studied point of care fibrinogen level assay with numerous studies in trauma, cardiac surgery, liver transplantation, and obstetrics. The correlation between Clauss fibrinogen and FIBTEMMCF or fibrinogen-related TEG parameters was reported as variable with $R^{2}$ values ranging from 0.44 to 0.94 for ROTEM [102] and from 0 [103] to at least 0.80 [102] for TEG. The clinical experience with the Quantra device is limited, with only few published studies to date, but the correlation between Clauss fibrinogen and FCS ranged from moderate to very good, with $R^{2}$ values ranging from 0.55 to 0.88 , with a huge variability between studies $[14,22,104,105]$. To our knowledge, data concerning correlation between Clauss fibrinogen and clot amplitude and maximum clot firmness provided by the ClotPro FIB-test assay is not yet available.

Among the 44 studies dealing with VETs and COVID-19 patients, only a few ones $[33,41,53,58]$ investigated the correlation between Clauss fibrinogen and 'functional fibrinogen' assessed by VETs. For ROTEM®(FIBTEM), one report noted a good correlation (Pearson's correlation coefficient $r=0.84$ ) [41], while another showed no correlation $(p=0.130)$ in children [33]. Two studies explored TEG in this regard and reported a moderate to good association (Pearson's correlation coefficient $r=0.453$ [58] and 0.74 [53]). These limited results due to low COVID-19 patient numbers and different assays suggest more studies are required.

Further, whether VET characteristics are unique to hyperfibrinogenemia alone is an important question, as almost all COVID-19 patients also present with hyperfibrinogenemia. Patients with hyperfibrinogenemia may exhibit a 'functional fibrinogen' (VET parameter) in the reference range $[35,37,66]$, while other reports of fibrinogen levels within reference ranges exhibit increased functional fibrinogen $[26,28,48]$.

The authors of a previously published review [69] highlighted the potential usefulness of VET in accurately assessing plasma fibrinogen levels in COVID-19 patients receiving direct thrombin inhibitors (DTI) through the assessment of the clot amplitude of the functional fibrinogen assay. Indeed, evaluation of fibrinogen levels by the Clauss method could lead to an underestimation due to the inhibition of the thrombin included in the reagent by the DTI [106,107], ranging from 23 to $96 \%$ according to the reagent used [107].

\subsection{Impact of Differences in Anticoagulation Regimens (Type (UFH, LMWH) and Dosage)}

Most currently studied COVID-19 patients receive heparin (LMWH or UFH), either with prophylactic or therapeutic regimens according to local protocol or guidelines $[74-76,108]$. Some studies specifically noted when blood samples for VETs were drawn in heparinized patients, but the timing of administration was often missing as well as anti-Xa levels. While for TEG, heparinase reagents were frequently used (14 studies of 15 [51-60,62-65]), this was not the case for ROTEM: only a few ones (4 of 25) generated data with HEPTEM assay, together with INTEM assay. Among these four latter studies, only one [26] reported different results from the two assays, whereas the three others showed similar results with both assays $[41,44,50]$. This raises questions that include (i) the effect of heparin, particularly at low doses, on VET results, (ii) whether heparinase or polybrene added to heparinized blood completely neutralized circulating heparin, and (iii) whether VETs can be used to guide heparin therapy. These questions were not raised by the previously published reviews [69-72].

The effect of heparin (UFH and LMWH) on VETs (performed without heparin neutralization) seems, according to the literature, to depend mainly on the heparin dose and the VETs used. Two trends have emerged for prophylactic or therapeutic concentrations (anti-Xa up to $1.5 \mathrm{IU} / \mathrm{mL}$ ). First, with TEG, anti-Xa levels and $\mathrm{R}$ and $\mathrm{K}$ parameters (clot initiation) seemed to correlate, while an inverse correlation between anti-Xa levels and $\alpha$ 
angle and MA is observed (fibrin polymerization), sometimes leading to a 'flat line' with the highest anti-Xa levels [109-112]. Second, fewer data are available for ROTEM, but there seems to be a correlation only between anti-Xa levels and CT parameter from the INTEM assay (clot initiation) [112-114].

In the setting of cardiac surgery with cardiopulmonary bypass, VETs have been increasingly used, and manufacturers have adapted testing to neutralize circulating heparin by the addition of heparinase or polybrene in order to differentiate between insufficient heparin neutralization in patients with protamine from underlying post-bypass coagulopathy. Few data are available, however, on whether this neutralization is complete. In an in vitro study performed with TEG and coated cups with heparinase [109], results were similar between native samples and samples spiked with heparin (UFH or LMWH) or danaparoid, but tested concentrations were too low $(0.005$ to $0.05 \mathrm{IU} / \mathrm{mL})$ to be clinically relevant. Another in vitro study performed with ROTEM and heparinase [113] showed similar results between native samples and samples spiked with increasing heparin (HNF) concentrations ranging from 0.1 to $1 \mathrm{IU} / \mathrm{mL}$.

Among the 44 COVID studies we retrieved, several mentioned a considerably high incidence of thrombotic events despite thromboprophylaxis, in line with most reports, and raising the potential interest of increasing anticoagulant doses. Could VETs then be useful to identify patients who will benefit from a higher dose of thrombosis anticoagulant prophylaxis? This remains a matter of debate. According to the authors, VETs seem able to detect coagulation abnormalities advocating for a hypercoagulable prothrombotic state in a broad sense, including procoagulable state (with a decreased clot formation time), hypercoagulable state (with an increased clot strength), and impaired fibrinolysis (with a reduced or absent clot lysis) early in the course of the disease, and even if conventional coagulation tests remain in the reference ranges. Second, as reduced or absent fibrinolysis was associated with an increased risk of thrombotic events outcome despite anticoagulation $[34,42-44,51,54,57,63,64]$, we could assume that VET results might be used to adapt level of anticoagulation. Five studies $[26,47,59,61,67]$ have reported VET parameters from ICU COVID-19 patients before and after an intensification of thromboprophylaxis, but results were inconsistent. Two of them showed a decrease in clot mechanical strength and in functional fibrinogen level [47,67], and even in the rate of thrombotic events [47], and the three others $[26,59,61]$ did not find any significant difference. However, if VETs still demonstrate a hypercoagulable pattern despite anticoagulation at least with a prophylactic dose and even an anti-Xa level within the target range [60,61], it was not always associated with thrombotic outcomes, although there was no systematic VTE screening either $[28,35,58,63]$. Third, three studies have shown an exaggerated thrombin generation despite anticoagulation, at least with a prophylactic dose $[39,48,66]$, advocating for a new way to monitor efficiency of thromboprophylaxis.

Rather than VETs, the study of thrombin generation could be more interesting to adjust anticoagulant therapy as heparin inhibits thrombin generation by multiple pathways as reviewed elsewhere [115]. Several methods exist to study thrombin generation, either with biomarkers such as prothrombin fragment $1+2$ or thrombin-antithrombin complexes [116] (thrombin generation in vivo), or in vitro by assessment of the levels of thrombin over time (through the use of a chromogenic or fluorogenic substrate) in response to initiation of coagulation. Regarding the latter, several commercial devices and assays are available $[117,118]$. Of note, thrombin generation assays (TGAs) are highly sensitive to preanalytical aspects [119]. So far, some in vitro studies have reported that there was a heparin concentration dependent decrease in thrombin generation $[120,121]$. Studies showed that COVID-19 patients had a higher endogenous thrombin potential [31,39,48,66,122-127] than manufacturer's reference range, healthy controls or patients with sepsis, sometimes despite UFH or LMWH anticoagulation at a minimum of prophylactic dosing. Few studies found a heparin dose-dependent decrease in thrombin generation [125,127] as described in vitro. Interestingly, one study showed that a persisting thrombin burst despite anticoagulation correlated with non-survival [123], whereas another found no difference between noncriti- 
cal and critically ill COVID-19 patients [124]. Further studies are needed to evaluate the clinical value in this context of the in vitro study of thrombin generation, and particularly with the new automated ST Genesia device [118], as already mentioned elsewhere [128]. A potential issue could be the non-availability of such device and the high turn-around-time for a result There is also an unmet need regarding the exploration of fibrin polymerization and lysis [95] with good and convenient assays.

\subsection{Summary of the Conclusions of the Previously Published Reviews}

Conclusions of the previously published reviews are summarized in Table 11. Overall, the four reviews reported the same findings as we do: COVID-19 patients displayed an abnormal VET pattern [69-72], but further studies are needed for various reasons. Moreover, we challenge the idea that such a pattern represents hypercoagulability; one main reason is that inhibitory systems are not at all taken into account, in sharp contrast with TGAs.

Of note, except the systematic review about the potential usefulness of TEG [71], no consistent association between the abnormal VET pattern and clinical outcome could have been demonstrated. Interestingly, one review [69] pointed out the potential usefulness of VETs in accurately assessing plasma fibrinogen levels in COVID-19 patients receiving DTI (see Section 4.4). 
Table 11. Conclusions of the previously published reviews.

\begin{tabular}{|c|c|c|c|c|}
\hline First Author (VET Devices) & Type of the Review & Aim of the Review & Number and Type of Studies Included & Conclusions of the Authors \\
\hline $\begin{array}{l}\text { Görlinger et al. [69] } \\
\text { (ROTEM, TEG and Quantra) }\end{array}$ & Narrative review & $\begin{array}{l}\text { Review of coagulation } \\
\text { abnormalities and } \\
\text { inflammatory response } \\
\text { associated with COVID-19, } \\
\text { as well as highlight of } \\
\text { what we still do not know } \\
\text { about COVID-19 } \\
\text { associated coagulopathy }\end{array}$ & 8 studies ( 5 prospective, 3 retrospective) & $\begin{array}{l}\text { VETs can detect the presence of hypercoagulability in } \\
\text { critically ill COVID-19 patients, but further studies } \\
\text { are needed to define the role of viscoelastometric } \\
\text { testing in the management of patients } \\
\text { VETs can be used to assess fibrinogen levels of } \\
\text { COVID-19 patients receiving direct thrombin } \\
\text { inhibitors (such as argatroban and bivalirudin) } \\
\text { through functional fibrinogen measurement }\end{array}$ \\
\hline $\begin{array}{l}\text { Tsantes et al. [70] } \\
\text { (ROTEM, TEG and Quantra) }\end{array}$ & Narrative review & $\begin{array}{l}\text { Evaluation of the } \\
\text { usefulness of VETs in } \\
\text { clinical practice to guide } \\
\text { anticoagulant treatments } \\
\text { or predict prognosis }\end{array}$ & 13 studies ( 8 prospective, 5 retrospective) & $\begin{array}{l}\text { VETs can detect the presence of hypercoagulability in } \\
\text { critically ill COVID-19 patients, but further studies } \\
\text { are needed to establish reference ranges for each } \\
\text { viscoelastic test, to define the common cut-off values } \\
\text { of hypo- and hypercoagulability or threshold values } \\
\text { to predict prognosis, or to guide anticoagulant, } \\
\text { antiplatelet or fibrinolytic therapy }\end{array}$ \\
\hline $\begin{array}{l}\text { Hartmann et al. [71] } \\
\qquad \text { (TEG) }\end{array}$ & Systematic review & $\begin{array}{c}\text { Evaluation of the } \\
\text { usefulness of TEG in } \\
\text { clinical practice to identify } \\
\text { and manage } \\
\text { hypercoagulation } \\
\text { associated with COVID-19 }\end{array}$ & $\begin{array}{c}15 \text { studies (5 prospective, } 9 \text { retrospective and } \\
\text { one case report) }\end{array}$ & $\begin{array}{l}\text { TEG can detect a hypercoagulable state in patients } \\
\text { with COVID-19, and provides differential diagnostic } \\
\text { insights alongside the ability to risk-stratify patients } \\
\text { at elevated risk for complications such as VTE or } \\
\text { kidney failure } \\
\text { Further studies are needed to elucidate the optimal } \\
\text { use of TEG to maximize patient benefit }\end{array}$ \\
\hline $\begin{array}{l}\text { Słomka et al. [72] } \\
\text { (ROTEM and TEG) }\end{array}$ & Systematic review & $\begin{array}{l}\text { Evaluation of the } \\
\text { performance of TEG and } \\
\text { TEM in the assessment of } \\
\text { blood coagulation and } \\
\text { fibrinolysis in patients } \\
\text { with COVID-19 }\end{array}$ & 10 studies ( 2 prospective, 8 retrospective) & $\begin{array}{l}\text { VETs can detect a hypercoagulable state and } \\
\text { fibrinolysis shutdown in COVID-19 patients, and } \\
\text { might be used to identify patients with high } \\
\text { prothrombotic risk for whom an antithrombotic } \\
\text { therapy would be benefic }\end{array}$ \\
\hline
\end{tabular}




\section{Conclusions}

VETs are now well established in acute settings to assist in bleeding management and transfusion practices, with convenient, fully automated devices and ready-to-use reagents. Since the beginning of the pandemic, they were used to characterize hemostasis abnormalities in critically ill COVID-19 patients. As already reported in previous reviews [69-72], almost all the studies we analyzed reported increased clot strength, considered to be a hallmark of the 'hypercoagulable state', often associated with impaired fibrinolysis (with the analytical limitations we have emphasized)—globally referred to as 'prothrombotic pattern', but there was no consistent association with clinical outcomes. Indeed, few studies suggested an association with the occurrence of thrombotic events, as well as with the need for hemodialysis $[34,44,51,56]$. However, lack of power (low number of studied patients), retrospective design, and no standardized study protocol are of concern.

In the COVID-19 setting, the appraisal of (high) fibrinogen levels through VET as opposed to the Clauss method in the laboratory is not an obvious asset. As already pointed out however [69], VET could be of interest for accurately assessing plasma fibrinogen levels in COVID-19 patients receiving DTI through the assessment of the clot amplitude in functional fibrinogen assay. Modified VETs (with addition of a plasminogen activator) to detect, quantify, and monitor hypofibrinolysis in whole blood (with the advantage for instance to integrate the PAI-1 released by platelets) could be of clinical relevance $[24,39,40,68]$.

Three different types of studies would be needed. First, prospective ones comparing the results from the different available devices are needed. Second, as it was already highlighted by previously published reviews [69-72], further prospective studies are needed, ideally randomized, to highlight the added-value of VET in predicting the clinical course of the disease, addressing patients to the appropriate ward according to their risk stratification, and identifying which patients would benefit from intensified anticoagulant treatment and those who would show clot resistance to fibrinolysis. Third, prospective randomized controlled trials are needed to evaluate the usefulness of VET and TGA in monitoring and adapting thromboprophylaxis.

Supplementary Materials: The following are available online at https: / www.mdpi.com/article/10 .3390/jcm10081740/s1, Data S1: Search strategy, Data S2: PRISMA summary table, Data S3: Quality assessment of the retrieved studies.

Author Contributions: Conceptualization, T.L. and F.M.; methodology, M.B.; data curation, M.B.; writing-original draft preparation, M.B.; writing—review and editing, T.L., F.M.; review and editing, M.H., J.D., S.R., D.L., J.H.L., A.S., S.S., C.F.; English editing: J.H.L.; supervision, T.L. and F.M. All authors have read and agreed to the published version of the manuscript.

Funding: This research received no external funding.

Institutional Review Board Statement: Not applicable.

Informed Consent Statement: Not applicable.

Data Availability Statement: Data can be provided by contacting the authors.

Conflicts of Interest: The authors declare no conflict of interest. 


\section{Appendix A. ROTEM ${ }^{\circledR}$ Reagents and Parameters}

Table A1. ROTEM®reagents.

\begin{tabular}{|c|c|c|c|}
\hline Assay & Reagent & Description & Heparin Neutralization \\
\hline INTEM & Ellagic acid & \multirow{2}{*}{$\begin{array}{c}\text { Intrinsic pathway screening test } \\
\text { Intrinsic pathway screening test with } \\
\text { heparinase }\end{array}$} & No \\
\hline HEPTEM & Ellagic acid + Heparinase & & Yes $^{1}$ \\
\hline EXTEM & Tissue factor + Polybrene & $\begin{array}{c}\text { Rapid overview of the coagulation } \\
\text { process }\end{array}$ & Yes $^{2}$ \\
\hline APTEM & Tissue factor + Aprotinin + Polybrene & $\begin{array}{l}\text { Exploration of the fibrinolysis by } \\
\text { comparison with the EXTEM results }\end{array}$ & Yes $^{2}$ \\
\hline FIBTEM & Tissue factor + Cytochalasin D + Polybrene & $\begin{array}{c}\text { Functional detection of the fibrinogen } \\
\text { level after platelet inhibition by } \\
\text { cytochalasin D }\end{array}$ & Yes $^{2}$ \\
\hline
\end{tabular}

${ }^{1} \mathrm{Up}$ to $7 \mathrm{IU} / \mathrm{mL}$ according to the manufacturer; ${ }^{2} \mathrm{Up}$ to $5 \mathrm{IU} / \mathrm{mL}$ according to the manufacturer.

Table A2. ROTEM®parameters.

\begin{tabular}{cc}
\hline Parameter & Description \\
\hline $\mathrm{CT}(\mathrm{s})$ & Clotting time: time interval from the start of the run until a $2 \mathrm{~mm}$ clot forms \\
$\mathrm{CFT}(\mathrm{s})$ & Clot formation time: time interval from CT until a clot amplitude of 20 mm is reached \\
$\alpha$ angle $\left({ }^{\circ}\right)$ & Rate of clot formation \\
$\mathrm{A}(\mathrm{x})(\mathrm{mm})$ & Amplitude of the oscillation due to clotting $\mathrm{x}$ minutes after CT \\
$\mathrm{MCF}(\mathrm{mm})$ & Maximum clot firmness: maximum clot amplitude \\
$\mathrm{LI}(\mathrm{x})(\%)$ & Clot lysis index: ratio between $\mathrm{MCF}$ and amplitude of the clot $\mathrm{x}$ minutes after CT \\
$\mathrm{ML}(\%)$ & Maximum lysis: maximum fibrinolysis detected during the observation period, expressed as a percentage of MCF \\
\hline
\end{tabular}

\section{Appendix B. TEG ${ }^{\circledR}$ Reagents and Parameters (Haemonetics Corporation, Boston, MA, USA)}

Table A3. TEG®reagents.

\begin{tabular}{|c|c|c|c|c|}
\hline Assay & Reagents for TEG5000 & Reagents for TEG6s & Description & $\begin{array}{c}\text { Heparin } \\
\text { Neutralization }\end{array}$ \\
\hline RapidTEG (CRT) & $\begin{array}{c}\text { Tissue factor }+ \text { Kaolin }+ \\
\text { Heparinase if heparinase } \\
\text { cups are used }\end{array}$ & Tissue factor + Kaolin & $\begin{array}{l}\text { Rapid overview of the } \\
\text { coagulation process }\end{array}$ & $\begin{array}{l}\text { Yes (if heparinase cups } \\
\text { were used for } \\
\text { TEG5000), otherwise no }\end{array}$ \\
\hline Kaolin TEG (CK) & Kaolin & Kaolin & $\begin{array}{l}\text { Intrinsic pathway } \\
\text { screening test }\end{array}$ & No \\
\hline $\begin{array}{l}\text { Kaolin TEG with } \\
\text { heparinase }(\mathrm{CKH})\end{array}$ & $\begin{array}{l}\text { Kaolin + Heparinase } \\
\text { (heparinase cup) }\end{array}$ & Kaolin + Heparinase & $\begin{array}{l}\text { Intrinsic pathway } \\
\text { screening test with } \\
\text { heparinase }\end{array}$ & Yes \\
\hline $\begin{array}{l}\text { TEG Functional } \\
\text { Fibrinogen (CFF) }\end{array}$ & $\begin{array}{c}\text { Tissue factor }+ \text { Abciximab }+ \\
\text { Heparinase if heparinase } \\
\text { cups are used }\end{array}$ & $\begin{array}{l}\text { Tissue factor }+ \\
\text { Abciximab }\end{array}$ & $\begin{array}{l}\text { Functional detection of } \\
\text { the fibrinogen level } \\
\text { after platelet inhibition } \\
\text { by abciximab }\end{array}$ & $\begin{array}{l}\text { Yes (if heparinase cups } \\
\text { were used for } \\
\text { TEG5000), otherwise no }\end{array}$ \\
\hline
\end{tabular}

Table A4. TEG®parameters.

\begin{tabular}{cc}
\hline Parameter & Description \\
\hline $\mathrm{R}(\mathrm{min})$ & Reaction time: time to initial fibrin formation \\
$\mathrm{K}(\mathrm{min})$ & Kinetics time: time to clot formation \\
$\alpha$ angle $\left(^{\circ}\right)$ & Rate of clot formation \\
$\mathrm{MA}(\mathrm{mm})$ & Maximum amplitude: absolute clot strength \\
$\mathrm{LY} 30(\%)$ & Fibrinolytic activity 30 min after maximum amplitude was reached \\
\hline
\end{tabular}




\section{Appendix C. Quantra ${ }^{\circledR}$ Reagents and Parameters (HemoSonics, LLC, Charlottesville, VA, USA)}

Table A5. Quantra®QPlus cartridge and parameters.

\begin{tabular}{|c|c|c|c|c|}
\hline Parameter & Reagents & Description & Heparin Neutralization & $\begin{array}{l}\text { Manufacturer's } \\
\text { Reference Range }\end{array}$ \\
\hline $\mathrm{CT}(\mathrm{s})$ & Kaolin (channel 1) & $\begin{array}{l}\text { Clotting time after } \\
\text { addition of kaolin }\end{array}$ & No & $113-164 \mathrm{~s}$ \\
\hline $\mathrm{CTH}(\mathrm{s})$ & $\begin{array}{c}\text { Kaolin + Heparinase } \\
\text { (channel 2) }\end{array}$ & $\begin{array}{c}\text { Clotting time with } \\
\text { heparinase after addition } \\
\text { of kaolin }\end{array}$ & Yes & $103-153 \mathrm{~s}$ \\
\hline $\mathrm{CT} / \mathrm{CTH}$ & $\begin{array}{l}\text { None, calculated as the } \\
\text { ratio of CT (channel 1) } \\
\text { over CTH (channel 2) }\end{array}$ & Clot time ratio & $\mathrm{NA}^{1}$ & $<1.4$ \\
\hline CS (hPA) & $\begin{array}{l}\text { Thromboplastin + } \\
\text { Polybrene (channel 3) }\end{array}$ & Clot stiffness & Yes & $13-33.2 \mathrm{hPa}$ \\
\hline FCS (hPA) & $\begin{array}{c}\text { Thromboplastin }+ \\
\text { Abciximab + Polybrene } \\
\text { (channel 4) }\end{array}$ & $\begin{array}{l}\text { Fibrinogen contribution } \\
\text { to overall clot stiffness } \\
\text { after platelet inhibition } \\
\text { with abciximab }\end{array}$ & Yes & $1-3.7 \mathrm{hPa}$ \\
\hline PCS (hPA) & $\begin{array}{c}\text { None, calculated as the } \\
\text { difference between CS } \\
\text { (channel 3) and FCS } \\
\text { (channel 4) }\end{array}$ & $\begin{array}{l}\text { Platelet contribution to } \\
\text { clot stiffness }\end{array}$ & Yes & $11.9-29.8 \mathrm{hPa}$ \\
\hline
\end{tabular}

${ }^{1}$ NA: not applicable.

Table A6. Quantra®QStat cartridge and parameters.

\begin{tabular}{|c|c|c|c|c|}
\hline Parameter & Reagents & Description & Heparin Neutralization & $\begin{array}{l}\text { Manufacturer's } \\
\text { Reference Range }\end{array}$ \\
\hline $\mathrm{CT}(\mathrm{s})$ & Kaolin & $\begin{array}{l}\text { Clotting time after } \\
\text { addition of kaolin }\end{array}$ & No & $113-164 \mathrm{~s}$ \\
\hline $\mathrm{CS}(\mathrm{hPA})$ & Thromboplastin + Polybrene & Clot stiffness & Yes & $13-33.2 \mathrm{hPa}$ \\
\hline CSL $(\%)$ & $\begin{array}{l}\text { None, calculated as the } \\
\text { normalized difference } \\
\text { between the clot stiffness } \\
\text { change after maximum clot } \\
\text { stiffness in the absence of } \\
\text { tranexamic acid and the } \\
\text { corresponding clot stiffness } \\
\text { change in the presence of } \\
\text { tranexamic acid }\end{array}$ & Clot stability to lysis & Yes & $93-100 \%$ \\
\hline FCS (hPA) & $\begin{array}{c}\text { Thromboplastin }+ \\
\text { Abciximab + Polybrene }\end{array}$ & $\begin{array}{l}\text { Fibrinogen contribution } \\
\text { to overall clot stiffness } \\
\text { after platelet inhibition } \\
\text { with abciximab }\end{array}$ & Yes & $1-3.7 \mathrm{hPa}$ \\
\hline PCS (hPA) & $\begin{array}{c}\text { None, calculated as the } \\
\text { difference between CS and } \\
\text { FCS }\end{array}$ & $\begin{array}{l}\text { Platelet contribution to } \\
\text { clot stiffness }\end{array}$ & Yes & $11.9-29.8 \mathrm{hPa}$ \\
\hline
\end{tabular}




\section{Appendix D. ClotPro®Reagents and Parameters (enicor GmbH, Munich, Germany)}

Table A7. ClotPro®reagents.

\begin{tabular}{|c|c|c|c|}
\hline Assay & Reagent & Description & Heparin Neutralization \\
\hline IN-test & Ellagic acid & $\begin{array}{c}\text { Intrinsic pathway screening } \\
\text { test }\end{array}$ & No \\
\hline HI-test & Ellagic acid + Heparinase & $\begin{array}{l}\text { Intrinsic pathway screening } \\
\text { test with heparinase }\end{array}$ & Yes \\
\hline EX-test & $\begin{array}{l}\text { Recombinant tissue factor }+ \\
\text { Polybrene }\end{array}$ & $\begin{array}{l}\text { Rapid overview of the } \\
\text { coagulation process }\end{array}$ & Yes \\
\hline AP-test & $\begin{array}{c}\text { Tissue factor }+ \text { Aprotinin }+ \\
\text { Polybrene }\end{array}$ & $\begin{array}{l}\text { Exploration of the fibrinolysis } \\
\text { by comparison with the } \\
\text { EX-test results }\end{array}$ & Yes \\
\hline tPA-test & $\begin{array}{l}\text { Recombinant tissue factor }+ \\
\text { Recombinant } \mathrm{tPA}+\text { Polybrene }\end{array}$ & $\begin{array}{l}\text { Exploration of the fibrinolysis } \\
\text { by comparison with the } \\
\text { EX-test results }\end{array}$ & Yes \\
\hline FIB-test & $\begin{array}{l}\text { Recombinant tissue factor }+ \\
\text { Cytolochalasin D + Abciximab } \\
+ \text { Polybrene }\end{array}$ & $\begin{array}{l}\text { Functional detection of the } \\
\text { fibrinogen level after dual } \\
\text { platelet inhibition by } \\
\text { cytochalasin D and abciximab }\end{array}$ & Yes \\
\hline RVV-test & $\begin{array}{c}\text { Reagent derived from Russell } \\
\text { viper venom }\end{array}$ & $\begin{array}{c}\text { Detection of factor Xa } \\
\text { inhibitors (LMWH, DOAC) }\end{array}$ & No \\
\hline ECA-test & Ecarin + Polybrene & $\begin{array}{l}\text { Detection of direct thrombin } \\
\text { antagonists }\end{array}$ & Yes \\
\hline NA-test & None & $\begin{array}{l}\text { Non-activated test for the } \\
\text { exploration of non-activated } \\
\text { coagulation in citrated blood }\end{array}$ & No \\
\hline
\end{tabular}

Abbreviations: LMWH: Low molecular weight heparin; UFH: unfractionated heparin; DOAC: Direct oral anticoagulant.

Table A8. ClotPro®parameters.

\begin{tabular}{cc}
\hline Parameter & Description \\
\hline $\mathrm{CT}(\mathrm{s})$ & Clotting time: time interval from the start of the run until a $2 \mathrm{~mm}$ amplitude of oscillations due to clotting was \\
reached & Clot formation time: time interval from CT until a clot amplitude of 20 mm is reached \\
$\mathrm{CFT}(\mathrm{s})$ & Amplitude of the oscillation due to clotting $\mathrm{x}$ minutes after $\mathrm{CT}$ \\
$\mathrm{A}(\mathrm{x})(\mathrm{mm})$ & Maximum clot firmness: maximum clot amplitude \\
$\mathrm{MCF}(\mathrm{mm})$ & Maximum lysis: maximum fibrinolysis detected during the observation period, expressed as a percentage of MCF \\
$\mathrm{ML}(\%)$ &
\end{tabular}

\section{References}

1. Hans, G.A.; Besser, M.W. The place of viscoelastic testing in clinical practice. Br. J. Haematol. 2016, 173, 37-48. [CrossRef] [PubMed]

2. Roullet, S.; de Maistre, E.; Ickx, B.; Blais, N.; Susen, S.; Faraoni, D.; Garrigue, D.; Bonhomme, F.; Godier, A.; Lasne, D.; et al. Position of the French Working Group on Perioperative Haemostasis (GIHP) on viscoelastic tests: What role for which indication in bleeding situations? Anaesth. Crit. Care Pain Med. 2019, 38, 539-548. [CrossRef] [PubMed]

3. Curry, N.S.; Davenport, R.; Pavord, S.; Mallett, S.V.; Kitchen, D.; Klein, A.A.; Maybury, H.; Collins, P.W.; Laffan, M. The use of viscoelastic haemostatic assays in the management of major bleeding: A British Society for Haematology Guideline. Br. J. Haematol. 2018, 182, 789-806. [CrossRef] [PubMed]

4. Katori, N.; Tanaka, K.A.; Szlam, F.; Levy, J.H. The Effects of Platelet Count on Clot Retraction and Tissue Plasminogen ActivatorInduced Fibrinolysis on Thrombelastography. Anesth. Analg. 2005, 100, 1781-1785. [CrossRef] [PubMed]

5. Ganter, M.T.; Hofer, C.K. Coagulation Monitoring: Current Techniques and Clinical Use of Viscoelastic Point-of-Care Coagulation Devices. Anesth. Analg. 2008, 106, 1366-1375. [CrossRef] [PubMed]

6. Arnolds, D.E.; Scavone, B.M. Thromboelastographic Assessment of Fibrinolytic Activity in Postpartum Hemorrhage: A Retrospective Single-Center Observational Study. Anesth. Analg. 2020, 131, 1373-1379. [CrossRef]

7. Solomon, C.; Ranucci, M.; Hochleitner, G.; Schöchl, H.; Schlimp, C.J. Assessing the Methodology for Calculating Platelet Contribution to Clot Strength (Platelet Component) in Thromboelastometry and Thrombelastography. Anesth. Analg. 2015, 121, 868-878. [CrossRef] 
8. Ranucci, M.; Baryshnikova, E. Sensitivity of Viscoelastic Tests to Platelet Function. J. Clin. Med. 2020, 9, 189. [CrossRef]

9. Ranucci, M.; Di Dedda, U.; Baryshnikova, E. Platelet Contribution to Clot Strength in Thromboelastometry: Count, Function, or Both? Platelets 2020, 31, 88-93. [CrossRef]

10. Scarlatescu, E.; Juffermans, N.P.; Thachil, J. The current status of viscoelastic testing in septic coagulopathy. Thromb. Res. 2019, 183, 146-152. [CrossRef]

11. Moore, H.B.; Gando, S.; Iba, T.; Kim, P.Y.; Yeh, C.H.; Brohi, K.; Hunt, B.J.; Levy, J.H.; Draxler, D.F.; Stanworth, S.; et al. Defining trauma-induced coagulopathy with respect to future implications for patient management: Communication from the SSC of the ISTH. J. Thromb. Haemost. 2020, 18, 740-747. [CrossRef] [PubMed]

12. Moore, H.B.; Moore, E.E. Temporal Changes in Fibrinolysis following Injury. Semin. Thromb. Hemost. 2020, 46, 189-198. [CrossRef] [PubMed]

13. Moher, D.; Liberati, A.; Tetzlaff, J.; Altman, D.G.; for the PRISMA Group. Preferred reporting items for systematic reviews and meta-analyses: The PRISMA statement. BMJ 2009, 339, b2535. [CrossRef]

14. Huffmyer, J.L.; Fernandez, L.G.; Haghighian, C.; Terkawi, A.S.; Groves, D.S. Comparison of SEER Sonorheometry with Rotational Thromboelastometry and Laboratory Parameters in Cardiac Surgery. Anesth. Analg. 2016, 123, 1390-1399. [CrossRef]

15. Schenk, B.; Görlinger, K.; Treml, B.; Tauber, H.; Fries, D.; Niederwanger, C.; Oswald, E.; Bachler, M. A comparison of the new ROTEM ${ }^{\circledR}$ sigma with its predecessor, the ROTEM delta: ROTEM sigma reference intervals. Anaesthesia 2019, 74, 348-356. [CrossRef]

16. Görlinger, K.; Pérez-Ferrer, A.; Dirkmann, D.; Saner, F.; Maegele, M.; Calatayud, Á.A.P.; Kim, T.Y. The role of evidence-based algorithms for rotational thromboelastometry-guided bleeding management. Korean J. Anesthesiol. 2019, 72, 297-322. [CrossRef]

17. Gurbel, P.A.; Bliden, K.P.; Tantry, U.S.; Monroe, A.L.; Muresan, A.A.; Brunner, N.E.; Lopez-Espina, C.G.; Delmenico, P.R.; Cohen, E.; Raviv, G.; et al. First report of the point-of-care TEG: A technical validation study of the TEG-6S system. Platelets 2016, 27, 642-649. [CrossRef]

18. Lloyd-Donald, P.; Churilov, L.; Zia, F.; Bellomo, R.; Hart, G.; McCall, P.; Mårtensson, J.; Glassford, N.; Weinberg, L. Assessment of agreement and interchangeability between the TEG5000 and TEG6S thromboelastography haemostasis analysers: A prospective validation study. BMC Anesth. 2019, 19, 45. [CrossRef]

19. Wong, Q.; Byrne, K.P.; Robinson, S.C. Clinical agreement and interchangeability of TEG5000 and TEG6s during cardiac surgery. Anaesth. Intensive Care 2020, 48, 43-52. [CrossRef] [PubMed]

20. Viola, F.; Kramer, M.D.; Lawrence, M.B.; Oberhauser, J.P.; Walker, W.F. Sonorheometry: A noncontact method for the dynamic assessment of thrombosis. Ann. Biomed. Eng. 2004, 32, 696-705. [CrossRef] [PubMed]

21. Viola, F.; Mauldin, F.W.; Lin-Schmidt, X.; Haverstick, D.M.; Lawrence, M.B.; Walker, W.F. A novel ultrasound-based method to evaluate hemostatic function of whole blood. Clin. Chim. Acta Int. J. Clin. Chem. 2010, 411, 106-113. [CrossRef] [PubMed]

22. Ferrante, E.A.; Blasier, K.R.; Givens, T.B.; Lloyd, C.A.; Fischer, T.J.; Viola, F. A Novel Device for the Evaluation of Hemostatic Function in Critical Care Settings. Anesth. Analg. 2016, 123, 1372-1379. [CrossRef] [PubMed]

23. Michelson, E.A.; Cripps, M.W.; Ray, B.; Winegar, D.A.; Viola, F. Initial clinical experience with the Quantra QStat System in adult trauma patients. Trauma Surg. Acute Care Open 2020, 5, e000581. [CrossRef]

24. Bachler, M.; Bösch, J.; Stürzel, D.P.; Hell, T.; Giebl, A.; Ströhle, M.; Klein, S.J.; Schäfer, V.; Lehner, G.F.; Joannidis, M.; et al. Impaired fibrinolysis in critically ill COVID-19 patients. Br. J. Anaesth. 2020. [CrossRef]

25. Oberladstätter, D.; Voelckel, W.; Schlimp, C.; Zipperle, J.; Ziegler, B.; Grottke, O.; Schöchl, H. A prospective observational study of the rapid detection of clinically-relevant plasma direct oral anticoagulant levels following acute traumatic injury. Anaesthesia 2021, 76, 373-380. [CrossRef] [PubMed]

26. Iwasaki, Y.; Shiga, T.; Konno, D.; Saito, K.; Aoyagi, T.; Oshima, K.; Kanamori, H.; Baba, H.; Tokuda, K.; Yamauchi, M. Screening of COVID-19-associated hypercoagulopathy using rotational thromboelastometry. J. Clin. Anesth. 2020, 67. [CrossRef] [PubMed]

27. Pavoni, V.; Gianesello, L.; Pazzi, M.; Stera, C.; Meconi, T.; Frigieri, F.C. Evaluation of coagulation function by rotation thromboelastometry in critically ill patients with severe COVID-19 pneumonia. J. Thromb. Thrombolysis 2020, 50, 281-286. [CrossRef] [PubMed]

28. Boscolo, A.; Spiezia, L.; Correale, C.; Sella, N.; Pesenti, E.; Beghetto, L.; Campello, E.; Poletto, F.; Cerruti, L.; Cola, M.; et al. Different Hypercoagulable Profiles in Patients with COVID-19 Admitted to the Internal Medicine Ward and the Intensive Care Unit. Thromb. Haemost. 2020, 120, 1474-1477. [CrossRef]

29. Corrêa, T.D.; Cordioli, R.L.; Campos Guerra, J.C.; Caldin da Silva, B.; dos Reis Rodrigues, R.; de Souza, G.M.; Midega, T.D.; Campos, N.S.; Carneiro, B.V.; Campos, F.N.D.; et al. Coagulation profile of COVID-19 patients admitted to the ICU: An exploratory study. PLoS ONE 2020, 15, e0243604. [CrossRef]

30. Madathil, R.J.; Tabatabai, A.; Rabin, J.; Menne, A.R.; Henderson, R.; Mazzeffi, M.; Scalea, T.M.; Tanaka, K. Thromboelastometry and D-Dimer Elevation in Coronavirus-2019. J. Cardiothorac. Vasc. Anesth. 2020. [CrossRef] [PubMed]

31. Spiezia, L.; Boscolo, A.; Poletto, F.; Cerruti, L.; Tiberio, I.; Campello, E.; Navalesi, P.; Simioni, P. COVID-19-Related Severe Hypercoagulability in Patients Admitted to Intensive Care Unit for Acute Respiratory Failure. Thromb. Haemost. 2020, 120, 998-1000. [CrossRef] [PubMed]

32. Tsantes, A.E.; Frantzeskaki, F.; Tsantes, A.G.; Rapti, E.; Rizos, M.; Kokoris, S.I.; Paramythiotou, E.; Katsadiotis, G.; Karali, V.; Flevari, A.; et al. The haemostatic profile in critically ill COVID-19 patients receiving therapeutic anticoagulant therapy: An observational study. Medicine 2020, 99, e23365. [CrossRef] [PubMed] 
33. Al-Ghafry, M.; Aygun, B.; Appiah-Kubi, A.; Vlachos, A.; Ostovar, G.; Capone, C.; Sweberg, T.; Palumbo, N.; Goenka, P.; Wolfe, L.W.; et al. Are children with SARS-CoV-2 infection at high risk for thrombosis? Viscoelastic testing and coagulation profiles in a case series of pediatric patients. Pediatr. Blood Cancer 2020, 67, e28737. [CrossRef] [PubMed]

34. Creel-Bulos, C.; Auld, S.C.; Caridi-Scheible, M.; Barker, N.; Friend, S.; Gaddh, M.; Kempton, C.L.; Maier, C.L.; Nahab, F.; Sniecinski, R. Fibrinolysis Shutdown and Thrombosis in A COVID-19 ICU. Shock 2020, 55, 316-320. [CrossRef] [PubMed]

35. Hoechter, D.J.; Becker-Pennrich, A.; Langrehr, J.; Bruegel, M.; Zwissler, B.; Schaefer, S.; Spannagl, M.; Hinske, L.C.; Zoller, M. Higher procoagulatory potential but lower DIC score in COVID-19 ARDS patients compared to non-COVID-19 ARDS patients. Thromb. Res. 2020, 196, 186-192. [CrossRef] [PubMed]

36. Roh, D.J.; Eiseman, K.; Kirsch, H.; Yoh, N.; Boehme, A.; Agarwal, S.; Park, S.; Connolly, E.S.; Claassen, J.; Wagener, G. Brief Report: Hypercoagulable viscoelastic blood clot characteristics in critically-ill COVID-19 patients and associations with thrombotic complications. J. Trauma Acute Care Surg. 2021, 90, e7-e12. [CrossRef]

37. Kong, R.; Hutchinson, N.; Görlinger, K. Hyper- and hypocoagulability in COVID-19 as assessed by thromboelastometry. Two case reports. Korean J. Anesthesiol. 2020. [CrossRef]

38. Raval, J.S.; Burnett, A.E.; Rollins-Raval, M.A.; Griggs, J.R.; Rosenbaum, L.; Nielsen, N.D.; Harkins, M.S. Viscoelastic testing in COVID-19: A possible screening tool for severe disease? Transfusion 2020, 60, 1131-1132. [CrossRef]

39. Nougier, C.; Benoit, R.; Simon, M.; Desmurs-Clavel, H.; Marcotte, G.; Argaud, L.; David, J.S.; Bonnet, A.; Negrier, C.; Dargaud, Y. Hypofibrinolytic state and high thrombin generation may play a major role in SARS-COV2 associated thrombosis. J. Thromb. Haemost. 2020, 18, 2215-2219. [CrossRef]

40. Weiss, E.; Roux, O.; Moyer, J.-D.; Paugam-Burtz, C.; Boudaoud, L.; Ajzenberg, N.; Faille, D.; de Raucourt, E. Fibrinolysis Resistance: A Potential Mechanism Underlying COVID-19 Coagulopathy. Thromb. Haemost. 2020, 120, 1343-1345. [CrossRef]

41. Almskog, L.M.; Wikman, A.; Svensson, J.; Wanecek, M.; Bottai, M.; van der Linden, J.; Ågren, A. Rotational thromboelastometry results are associated with care level in COVID-19. J. Thromb. Thrombolysis 2021, 51, 437-445. [CrossRef] [PubMed]

42. Collett, L.W.; Gluck, S.; Strickland, R.M.; Reddi, B.J. Evaluation of coagulation status using viscoelastic testing in intensive care patients with coronavirus disease 2019 (COVID-19): An observational point prevalence cohort study. Aust. Crit. Care 2021, 34, 155-159. [CrossRef] [PubMed]

43. Ibañez, C.; Perdomo, J.; Calvo, A.; Ferrando, C.; Reverter, J.C.; Tassies, D.; Blasi, A. High D dimers and low global fibrinolysis coexist in COVID19 patients: What is going on in there? J. Thromb. Thrombolysis 2021, 51, 308-312. [CrossRef] [PubMed]

44. Kruse, J.M.; Magomedov, A.; Kurreck, A.; Münch, F.H.; Koerner, R.; Kamhieh-Milz, J.; Kahl, A.; Gotthardt, I.; Piper, S.K.; Eckardt, K.U.; et al. Thromboembolic complications in critically ill COVID-19 patients are associated with impaired fibrinolysis. Crit. Care 2020, 24, 676. [CrossRef]

45. Pavoni, V.; Gianesello, L.; Pazzi, M.; Horton, A.; Suardi, L.R. Derangement of the coagulation process using subclinical markers and viscoelastic measurements in critically ill patients with coronavirus disease 2019 pneumonia and non-coronavirus disease 2019 pneumonia. Blood Coagul. Fibrinolysis 2021, 32, 80-86. [CrossRef]

46. Spiezia, L.; Campello, E.; Cola, M.; Poletto, F.; Cerruti, L.; Poretto, A.; Simion, C.; Cattelan, A.; Vettor, R.; Simioni, P. More Severe Hypercoagulable State in Acute COVID-19 Pneumonia as Compared with Other Pneumonia. Mayo Clin. Proc. Innov. Qual. Outcomes 2020, 4, 696-702. [CrossRef]

47. van der Linden, J.; Almskog, L.; Liliequist, A.; Grip, J.; Fux, T.; Rysz, S.; Ågren, A.; Oldner, A.; Ståhlberg, M. Thromboembolism, Hypercoagulopathy, and Antiphospholipid Antibodies in Critically Ill Coronavirus Disease 2019 Patients: A before and after Study of Enhanced Anticoagulation. Crit. Care Explor. 2020, 2, e0308. [CrossRef] [PubMed]

48. Blasi, A.; Meijenfeldt, F.A.; Adelmeijer, J.; Calvo, A.; Ibañez, C.; Perdomo, J.; Reverter, J.C.; Lisman, T. In vitro hypercoagulability and ongoing in vivo activation of coagulation and fibrinolysis in COVID-19 patients on anticoagulation. J. Thromb. Haemost. 2020, 18, 2646-2653. [CrossRef] [PubMed]

49. van Veenendaal, N.; Scheeren, T.W.L.; Meijer, K.; van der Voort, P.H.J. Rotational thromboelastometry to assess hypercoagulability in COVID-19 patients. Thromb. Res. 2020, 196, 379-381. [CrossRef]

50. Lazar, M.; Tomey, M.I.; Ghia, S.; Katz, D.; Derr, K.; Narula, J.; Bhatt, H.V. Rotational thromboelastometry in young, previously healthy patients with SARS-Cov2. J. Clin. Anesth. 2020, 67, 110038. [CrossRef]

51. Wright, F.L.; Vogler, T.O.; Moore, E.E.; Moore, H.B.; Wohlauer, M.V.; Urban, S.; Nydam, T.L.; Moore, P.K.; McIntyre, R.C., Jr. Fibrinolysis Shutdown Correlation with Thromboembolic Events in Severe COVID-19 Infection. J. Am. Coll. Surg. 2020, 231, 193-203.e1. [CrossRef]

52. Panigada, M.; Bottino, N.; Tagliabue, P.; Grasselli, G.; Novembrino, C.; Chantarangkul, V.; Pesenti, A.; Peyvandi, F.; Tripodi, A. Hypercoagulability of COVID-19 patients in intensive care unit: A report of thromboelastography findings and other parameters of hemostasis. J. Thromb. Haemost. 2020, 18, 1738-1742. [CrossRef]

53. Cordier, P.-Y.; Pierrou, C.; Noel, A.; Paris, R.; Gaudray, E.; Martin, E.; Contargyris, C.; Bélot-De Saint Léger, F.; Lyochon, A.; Astier, H.; et al. Complex and prolonged hypercoagulability in coronavirus disease 2019 intensive care unit patients: A thromboelastographic study. Aust. Crit. Care 2021, 34, 160-166. [CrossRef] [PubMed]

54. Hightower, S.; Ellis, H.; Collen, J.; Ellis, J.; Grasso, I.; Roswarski, J.; Cap, A.P.; Chung, K.; Prescher, L.; Kavanaugh, M.; et al. Correlation of indirect markers of hypercoagulability with thromboelastography in severe coronavirus 2019. Thromb. Res. 2020, 195, 69-71. [CrossRef] [PubMed] 
55. Maatman, T.K.; Jalali, F.; Feizpour, C.; Douglas, A.; McGuire, S.P.; Kinnaman, G.; Hartwell, J.L.; Maatman, B.T.; Kreutz, R.P.; Kapoor, R.; et al. Routine Venous Thromboembolism Prophylaxis May Be Inadequate in the Hypercoagulable State of Severe Coronavirus Disease 2019. Crit. Care Med. 2020. [CrossRef] [PubMed]

56. Mortus, J.R.; Manek, S.E.; Brubaker, L.S.; Loor, M.; Cruz, M.A.; Trautner, B.W.; Rosengart, T.K. Thromboelastographic Results and Hypercoagulability Syndrome in Patients with Coronavirus Disease 2019 Who Are Critically Ill. JAMA Netw. Open 2020, 3 , e2011192. [CrossRef] [PubMed]

57. Sadd, C.; Rowe, T.; Nazeef, M.; Kory, P.; Sultan, S.; Faust, H. Thromboelastography to Detect Hypercoagulability and Reduced Fibrinolysis in Coronavirus Disease 2019 Acute Respiratory Distress Syndrome Patients. Crit. Care Explor. 2020, 2 , e0192. [CrossRef]

58. Yuriditsky, E.; Horowitz, J.M.; Merchan, C.; Ahuja, T.; Brosnahan, S.B.; McVoy, L.; Berger, J.S. Thromboelastography Profiles of Critically Ill Patients with Coronavirus Disease 2019. Crit. Care Med. 2020. [CrossRef]

59. Bocci, M.G.; Maviglia, R.; Consalvo, L.M.; Grieco, D.L.; Montini, L.; Mercurio, G.; Nardi, G.; Pisapia, L.; Cutuli, S.L.; Biasucci, D.G.; et al. Thromboelastography clot strength profiles and effect of systemic anticoagulation in COVID-19 acute respiratory distress syndrome: A prospective, observational study. Eur. Rev. Med. Pharmacol. Sci. 2020, 24, 12466-12479. [CrossRef]

60. Stattin, K.; Lipcsey, M.; Andersson, H.; Pontén, E.; Bülow Anderberg, S.; Gradin, A.; Larsson, A.; Lubenow, N.; von Seth, M.; Rubertsson, S.; et al. Inadequate prophylactic effect of low-molecular weight heparin in critically ill COVID-19 patients. J. Crit. Care 2020, 60, 249-252. [CrossRef]

61. Vlot, E.A.; Van den Dool, E.J.; Hackeng, C.M.; Sohne, M.; Noordzij, P.G.; Van Dongen, E.P.A. Anti Xa activity after high dose LMWH thrombosis prophylaxis in covid 19 patients at the intensive care unit. Thromb. Res. 2020, 196, 1-3. [CrossRef]

62. Patel, B.V.; Arachchillage, D.J.; Ridge, C.A.; Bianchi, P.; Doyle, J.F.; Garfield, B.; Ledot, S.; Morgan, C.; Passariello, M.; Price, S.; et al. Pulmonary Angiopathy in Severe COVID-19: Physiologic, Imaging, and Hematologic Observations. Am. J. Respir. Crit. Care Med. 2020, 202, 690-699. [CrossRef] [PubMed]

63. Salem, N.; Atallah, B.; El Nekidy, W.S.; Sadik, Z.G.; Park, W.M.; Mallat, J. Thromboelastography findings in critically ill COVID-19 patients. J. Thromb. Thrombolysis 2020. [CrossRef]

64. Shah, A.; Donovan, K.; McHugh, A.; Pandey, M.; Aaron, L.; Bradbury, C.A.; Stanworth, S.J.; Alikhan, R.; Von Kier, S.; Maher, K.; et al. Thrombotic and haemorrhagic complications in critically ill patients with COVID-19: A multicentre observational study. Crit. Care 2020, 24, 561. [CrossRef] [PubMed]

65. Fan, B.E.; Chia, Y.W.; Sum, C.L.L.; Kuperan, P.; Chan, S.S.W.; Ling, L.M.; Tan, G.W.L.; Goh, S.S.N.; Wong, L.H.; Lim, S.P.; et al. Global haemostatic tests in rapid diagnosis and management of COVID-19 associated coagulopathy in acute limb ischaemia. $J$. Thromb. Thrombolysis 2020, 50, 292-297. [CrossRef] [PubMed]

66. Masi, P.; Hékimian, G.; Lejeune, M.; Chommeloux, J.; Desnos, C.; Pineton De Chambrun, M.; Martin-Toutain, I.; Nieszkowska, A.; Lebreton, G.; Bréchot, N.; et al. Systemic Inflammatory Response Syndrome Is a Major Contributor to COVID-19-Associated Coagulopathy: Insights From a Prospective, Single-Center Cohort Study. Circulation 2020, 142, 611-614. [CrossRef] [PubMed]

67. Ranucci, M.; Ballotta, A.; Di Dedda, U.; Bayshnikova, E.; Dei Poli, M.; Resta, M.; Falco, M.; Albano, G.; Menicanti, L. The procoagulant pattern of patients with COVID-19 acute respiratory distress syndrome. J. Thromb. Haemost. 2020, 18, 1747-1751. [CrossRef]

68. Zátroch, I.; Smudla, A.; Babik, B.; Tánczos, K.; Kóbori, L.; Szabó, Z.; Fazakas, J. Procoagulatio, hypercoagulatio és fibrinolysis “shut down" kimutatása ClotPro®viszkoelasztikus tesztek segítségével COVID-19-betegekben.: (A COVID-19-pandémia orvosszakmai kérdései). Orv. Hetil. 2020, 161, 899-907. [CrossRef]

69. Görlinger, K.; Dirkmann, D.; Gandhi, A.; Simioni, P. COVID-19-Associated Coagulopathy and Inflammatory Response: What Do We Know Already and What Are the Knowledge Gaps? Anesth. Analg. 2020, 131, 1324-1333. [CrossRef]

70. Tsantes, A.E.; Tsantes, A.G.; Kokoris, S.I.; Bonovas, S.; Frantzeskaki, F.; Tsangaris, I.; Kopterides, P. COVID-19 Infection-Related Coagulopathy and Viscoelastic Methods: A Paradigm for Their Clinical Utility in Critical Illness. Diagnostics 2020, $10,817$. [CrossRef] [PubMed]

71. Hartmann, J.; Ergang, A.; Mason, D.; Dias, J.D. The Role of TEG Analysis in Patients with COVID-19-Associated Coagulopathy: A Systematic Review. Diagnostics 2021, 11, 172. [CrossRef]

72. Słomka, A.; Kowalewski, M.; Żekanowska, E. Hemostasis in Coronavirus Disease 2019-Lesson from Viscoelastic Methods: A Systematic Review. Thromb. Haemost. 2021. [CrossRef]

73. Baker, A.; Young, K.; Potter, J.; Madan, I. A review of grading systems for evidence-based guidelines produced by medical specialties. Clin. Med. 2010, 10, 358-363. [CrossRef] [PubMed]

74. Susen, S.; Tacquard, C.A.; Godon, A.; Mansour, A.; Garrigue, D.; Nguyen, P.; Godier, A.; Testa, S.; Levy, J.H.; Albaladejo, P.; et al. Prevention of thrombotic risk in hospitalized patients with COVID-19 and hemostasis monitoring. Crit. Care 2020, $24,364$. [CrossRef] [PubMed]

75. Rhodes, A.; Evans, L.E.; Alhazzani, W.; Levy, M.M.; Antonelli, M.; Ferrer, R.; Kumar, A.; Sevransky, J.E.; Sprung, C.L.; Nunnally, M.E.; et al. Surviving Sepsis Campaign: International Guidelines for Management of Sepsis and Septic Shock: 2016. Intensive Care Med. 2017, 43, 304-377. [CrossRef] [PubMed] 
76. Vivas, D.; Roldán, V.; Esteve-Pastor, M.A.; Roldán, I.; Tello-Montoliu, A.; Ruiz-Nodar, J.M.; Cosín-Sales, J.; Gámez, J.M.; Consuegra, L.; Ferreiro, J.L.; et al. Recomendaciones sobre el tratamiento antitrombótico durante la pandemia COVID-19. Posicionamiento del Grupo de Trabajo de Trombosis Cardiovascular de la Sociedad Española de Cardiología. Rev. Esp. Cardiol. 2020, 73, 749-757. [CrossRef]

77. Anderson, L.; Quasim, I.; Steven, M.; Moise, S.F.; Shelley, B.; Schraag, S.; Sinclair, A. Interoperator and Intraoperator Variability of Whole Blood Coagulation Assays: A Comparison of Thromboelastography and Rotational Thromboelastometry. J. Cardiothorac. Vasc. Anesth. 2014, 28, 1550-1557. [CrossRef]

78. Kitchen, D.; Kitchen, S.; Jennings, I.; Woods, T.; Walker, I. Quality Assurance and Quality Control of Thrombelastography and Rotational Thromboelastometry: The UK NEQAS for Blood Coagulation Experience. Semin. Thromb. Hemost. 2010, 36, 757-763. [CrossRef]

79. Nicolai, L.; Leunig, A.; Brambs, S.; Kaiser, R.; Weinberger, T.; Weigand, M.; Muenchhoff, M.; Hellmuth, J.C.; Ledderose, S.; Schulz, H.; et al. Immunothrombotic Dysregulation in COVID-19 Pneumonia Is Associated with Respiratory Failure and Coagulopathy. Circulation 2020, 142, 1176-1189. [CrossRef]

80. Ogawa, S.; Szlam, F.; Bolliger, D.; Nishimura, T.; Chen, E.P.; Tanaka, K.A. The Impact of Hematocrit on Fibrin Clot Formation Assessed by Rotational Thromboelastometry. Anesth. Analg. 2012, 115, 16-21. [CrossRef]

81. Solomon, C.; Rahe-Meyer, N. Effect of haematocrit on fibrin-based clot firmness in the FIBTEM test. Blood Transfus. 2013. [CrossRef]

82. Dias, J.D.; Lopez-Espina, C.G.; Bliden, K.; Gurbel, P.; Hartmann, J.; Achneck, H.E. TEG ${ }^{\circledR} 6$ s system measures the contributions of both platelet count and platelet function to clot formation at the site-of-care. Platelets 2020, 31, 932-938. [CrossRef] [PubMed]

83. Schlimp, C.J.; Solomon, C.; Ranucci, M.; Hochleitner, G.; Redl, H.; Schöchl, H. The Effectiveness of Different Functional Fibrinogen Polymerization Assays in Eliminating Platelet Contribution to Clot Strength in Thromboelastometry. Anesth. Analg. 2014, 118, 269-276. [CrossRef]

84. Solomon, C.; Sørensen, B.; Hochleitner, G.; Kashuk, J.; Ranucci, M.; Schöchl, H. Comparison of Whole Blood Fibrin-Based Clot Tests in Thrombelastography and Thromboelastometry. Anesth. Analg. 2012, 114, 721-730. [CrossRef]

85. Solomon, C.; Baryshnikova, E.; Schlimp, C.J.; Schöchl, H.; Asmis, L.M.; Ranucci, M. FIBTEM PLUS Provides an Improved Thromboelastometry Test for Measurement of Fibrin-Based Clot Quality in Cardiac Surgery Patients. Anesth. Analg. 2013, 117, 1054-1062. [CrossRef]

86. DeAnda, A.; Levy, G.; Kinsky, M.; Sanjoto, P.; Garcia, M.; Avandsalehi, K.R.; Diaz, G.; Yates, S.G. Comparison of the Quantra QPlus System with Thromboelastography in Cardiac Surgery. J. Cardiothorac. Vasc. Anesth. 2021, 35, 1030-1036. [CrossRef]

87. Gillissen, A.; van den Akker, T.; Caram-Deelder, C.; Henriquez, D.D.C.A.; Bloemenkamp, K.W.M.; Eikenboom, J.; van der Bom, J.G.; de Maat, M.P.M. Comparison of thromboelastometry by ROTEM ${ }^{\circledR}$ Delta and ROTEM ${ }^{\circledR}$ Sigma in women with postpartum haemorrhage. Scand. J. Clin. Lab. Investig. 2019, 79, 32-38. [CrossRef]

88. Ziegler, B.; Voelckel, W.; Zipperle, J.; Grottke, O.; Schöchl, H. Comparison between the new fully automated viscoelastic coagulation analysers TEG 6s and ROTEM Sigma in trauma patients: A prospective observational study. Eur. J. Anaesthesiol. 2019, 36, 834-842. [CrossRef]

89. Groves, D.S.; Welsby, I.J.; Naik, B.I.; Tanaka, K.; Hauck, J.N.; Greenberg, C.S.; Winegar, D.A.; Viola, F. Multicenter Evaluation of the Quantra QPlus System in Adult Patients Undergoing Major Surgical Procedures. Anesth. Analg. 2020, 130, 899-909. [CrossRef]

90. Walsh, M.; Moore, E.E.; Moore, H.; Thomas, S.; Lune, S.V.; Zimmer, D.; Dynako, J.; Hake, D.; Crowell, Z.; McCauley, R.; et al. Use of Viscoelastography in Malignancy-Associated Coagulopathy and Thrombosis: A Review. Semin. Thromb. Hemost. 2019, 45, 354-372. [CrossRef] [PubMed]

91. Brown, W.; Lunati, M.; Maceroli, M.; Ernst, A.; Staley, C.; Johnson, R.; Schenker, M. Ability of Thromboelastography to Detect Hypercoagulability: A Systematic Review and Meta-Analysis. J. Orthop. Trauma 2020, 34, 278-286. [CrossRef]

92. Harahsheh, Y.; Ho, K.M. Use of viscoelastic tests to predict clinical thromboembolic events: A systematic review and meta-analysis. Eur. J. Haematol. 2018, 100, 113-123. [CrossRef] [PubMed]

93. Whyte, C.; Mitchell, J.; Mutch, N. Platelet-Mediated Modulation of Fibrinolysis. Semin. Thromb. Hemost. 2017, 43, 115-128. [CrossRef] [PubMed]

94. Raza, I.; Davenport, R.; Rourke, C.; Platton, S.; Manson, J.; Spoors, C.; Khan, S.; De' Ath, H.D.; Allard, S.; Hart, D.P.; et al. The incidence and magnitude of fibrinolytic activation in trauma patients: Fibrinolytic activation in trauma patients. J. Thromb. Haemost. 2013, 11, 307-314. [CrossRef]

95. Longstaff, C. Measuring Fibrinolysis. Hämostaseologie 2021, 41, 069-075. [CrossRef]

96. Kupesiz, A.; Rajpurkar, M.; Warrier, I.; Hollon, W.; Tosun, O.; Lusher, J.; Chitlur, M. Tissue plasminogen activator induced fibrinolysis: Standardization of method using thromboelastography: Blood Coagul. Fibrinolysis 2010, 21, 320-324. [CrossRef] [PubMed]

97. Kuiper, G.J.A.J.M.; Kleinegris, M.-C.F.; van Oerle, R.; Spronk, H.M.H.; Lancé, M.D.; ten Cate, H.; Henskens, Y.M. Validation of a modified thromboelastometry approach to detect changes in fibrinolytic activity. Thromb. J. 2016, 14, 1. [CrossRef] [PubMed]

98. Dirkmann, D.; Radü-Berlemann, J.; Görlinger, K.; Peters, J. Recombinant tissue-type plasminogen activator-evoked hyperfibrinolysis is enhanced by acidosis and inhibited by hypothermia but still can be blocked by tranexamic acid. J. Trauma Acute Care Surg. 2013, 74, 482-488. [CrossRef] [PubMed] 
99. Gallimore, M.J.; Harris, S.L.; Tappenden, K.A.; Winter, M.; Jones, D.W. Urokinase induced fibrinolysis in thromboelastography: A model for studying fibrinolysis and coagulation in whole blood. J. Thromb. Haemost. 2005, 3, 2506-2513. [CrossRef]

100. Panigada, M.; Zacchetti, L.; L'Acqua, C.; Cressoni, M.; Anzoletti, M.B.; Bader, R.; Protti, A.; Consonni, D.; D’Angelo, A.; Gattinoni, L. Assessment of Fibrinolysis in Sepsis Patients with Urokinase Modified Thromboelastography. PLoS ONE 2015, 10, e0136463. [CrossRef]

101. Center for Devices and Radiological Health (CDRH); Office of Product Evaluation and Quality (OPEQ). Coagulation Systems for Measurement of Viscoelastic Properties: Enforcement Policy during the Coronavirus Disease 2019 (COVID-19) Public Health Emergency (Revised); U.S. Department of Health and Human Services, Food and Drug Administration: Silver Spring, MD, USA, 2021.

102. Ranucci, M.; Di Dedda, U.; Baryshnikova, E. Trials and Tribulations of Viscoelastic-Based Determination of Fibrinogen Concentration. Anesth. Analg. 2020, 130, 644-653. [CrossRef] [PubMed]

103. Agarwal, S.; Johnson, R.I.; Shaw, M. A comparison of fibrinogen measurement using TEG ${ }^{\circledR}$ functional fibrinogen and Clauss in cardiac surgery patients. Int. J. Lab. Hematol. 2015, 37, 459-465. [CrossRef] [PubMed]

104. Naik, B.I.; Durieux, M.E.; Knisely, A.; Sharma, J.; Bui-Huynh, V.C.; Yalamuru, B.; Terkawi, A.S.; Nemergut, E.C. SEER Sonorheometry Versus Rotational Thromboelastometry in Large Volume Blood Loss Spine Surgery. Anesth. Analg. 2016, 123, 1380-1389. [CrossRef] [PubMed]

105. Baryshnikova, E.; Di Dedda, U.; Ranucci, M. A Comparative Study of SEER Sonorheometry Versus Standard Coagulation Tests, Rotational Thromboelastometry, and Multiple Electrode Aggregometry in Cardiac Surgery. J. Cardiothorac. Vasc. Anesth. 2019, 33, 1590-1598. [CrossRef] [PubMed]

106. Maier, C.L.; Barker, N.A.; Sniecinski, R.M. Falsely Low Fibrinogen Levels in COVID-19 Patients on Direct Thrombin Inhibitors. Anesth. Analg. 2020, 131, e117-e119. [CrossRef]

107. Ranucci, M. In Response. Anesth. Analg. 2020, 131, e119-e120. [CrossRef]

108. Thachil, J.; Juffermans, N.P.; Ranucci, M.; Connors, J.M.; Warkentin, T.E.; Ortel, T.L.; Levi, M.; Iba, T.; Levy, J.H. ISTH DIC subcommittee communication on anticoagulation in COVID-19. J. Thromb. Haemost. 2020, 18, 2138-2144. [CrossRef]

109. Coppell, J.A.; Thalheimer, U.; Zambruni, A.; Triantos, C.K.; Riddell, A.F.; Burroughs, A.K.; Perry, D.J. The effects of unfractionated heparin, low molecular weight heparin and danaparoid on the thromboelastogram (TEG): An in-vitro comparison of standard and heparinase-modified TEGs with conventional coagulation assays: Blood Coagul. Fibrinolysis 2006, 17, 97-104. [CrossRef]

110. Artang, R.; Frandsen, N.J.; Nielsen, J. Application of basic and composite thrombelastography parameters in monitoring of the antithrombotic effect of the low molecular weight heparin dalteparin: An in vivo study. Thromb. J. 2009, 7, 14. [CrossRef]

111. Tekkesin, N.; Tekkesin, M.; Kaso, G. Thromboelastography for the monitoring of the antithrombotic effect of low-molecular-weight heparin after major orthopedic surgery. Anatol. J. Cardiol. 2015, 15, 932-937. [CrossRef] [PubMed]

112. Ranucci, M.; Cotza, M.; Isgrò, G.; Carboni, G.; Ballotta, A.; Baryshnikova, E.; Surgical Clinical Outcome REsearch (SCORE) Group. Anti-Factor Xa-Based Anticoagulation during Extracorporeal Membrane Oxygenation: Potential Problems and Possible Solutions. Semin. Thromb. Hemost. 2020, 46, 419-427. [CrossRef] [PubMed]

113. Mittermayr, M.; Margreiter, J.; Velik-Salchner, C.; Klingler, A.; Streif, W.; Fries, D.; Innerhofer, P. Effects of protamine and heparin can be detected and easily differentiated by modified thrombelastography (Rotem ${ }^{\circledR}$ ): An in vitro study. Br. J. Anaesth. 2005, 95, 310-316. [CrossRef] [PubMed]

114. Thomas, O.; Larsson, A.; Tynngård, N.; Schött, U. Thromboelastometry versus free-oscillation rheometry and enoxaparin versus tinzaparin: An in-vitro study comparing two viscoelastic haemostatic tests' dose-responses to two low molecular weight heparins at the time of withdrawing epidural catheters from ten patients after major surgery. BMC Anesth. 2015, 15, 170. [CrossRef]

115. Spadarella, G.; Di Minno, A.; Donati, M.B.; Mormile, M.; Ventre, I.; Di Minno, G. From unfractionated heparin to pentasaccharide: Paradigm of rigorous science growing in the understanding of the in vivo thrombin generation. Blood Rev. 2020, 39. [CrossRef]

116. Lippi, G.; Cervellin, G.; Franchini, M.; Favaloro, E.J. Biochemical markers for the diagnosis of venous thromboembolism: The past, present and future. J. Thromb. Thrombolysis 2010, 30, 459-471. [CrossRef]

117. Kintigh, J.; Monagle, P.; Ignjatovic, V. A review of commercially available thrombin generation assays. Res. Pract. Thromb. Haemost. 2018, 2, 42-48. [CrossRef]

118. Ninivaggi, M.; de Laat-Kremers, R.M.W.; Carlo, A.; de Laat, B. ST Genesia reference values of 117 healthy donors measured with STG-BleedScreen, STG-DrugScreen and STG-ThromboScreen reagents. Res. Pract. Thromb. Haemost. 2021, 5, 187-196. [CrossRef]

119. Loeffen, R.; Kleinegris, M.-C.F.; Loubele, S.T.B.G.; Pluijmen, P.H.M.; Fens, D.; van Oerle, R.; Ten Cate, H.; Spronk, H.M. Preanalytic variables of thrombin generation: Towards a standard procedure and validation of the method. J. Thromb. Haemost. JTH 2012, 10, 2544-2554. [CrossRef]

120. Siddiqui, F.; Hoppensteadt, D.; Bontekoe, E.; Farooqui, A.; Jeske, W.; Fareed, J. Comparative Anticoagulant and Thrombin Generation Inhibitory Profile of Heparin, Sulodexide and Its Components. Clin. Appl. Thromb. Off. J. Int. Acad Clin. Appl. Thromb. 2020, 26. [CrossRef]

121. Van de Berg, T.W.; Hulshof, A.-M.M.; Nagy, M.; van Oerle, R.; Sels, J.-W.; van Bussel, B.; Ten Cate, H.; Henskens, Y.; Spronk, H.M.H. Suggestions for global coagulation assays for the assessment of COVID-19 associated hypercoagulability. Thromb. Res. 2021, 201, 84-89. [CrossRef]

122. Bouck, E.G.; Denorme, F.; Holle, L.A.; Middelton, E.A.; Blair, A.; de Laat, B.; Schiffman, J.D.; Yost, C.C.; Rondina, M.T.; Wolberg, A.S.; et al. COVID-19 and Sepsis Are Associated with Different Abnormalities in Plasma Procoagulant and Fibrinolytic Activity. Arterioscler. Thromb. Vasc. Biol. 2020. [CrossRef] 
123. Ranucci, M.; Sitzia, C.; Baryshnikova, E.; Di Dedda, U.; Cardani, R.; Martelli, F.; Corsi Romanelli, M. Covid-19-Associated Coagulopathy: Biomarkers of Thrombin Generation and Fibrinolysis Leading the Outcome. J. Clin. Med. 2020, 9, 3487. [CrossRef] [PubMed]

124. White, D.; MacDonald, S.; Edwards, T.; Bridgeman, C.; Hayman, M.; Sharp, M.; Cox-Morton, S.; Duff, E.; Mahajan, S.; Moore, C.; et al. Evaluation of COVID-19 coagulopathy; laboratory characterization using thrombin generation and nonconventional haemostasis assays. Int. J. Lab. Hematol. 2021, 43, 123-130. [CrossRef] [PubMed]

125. Chistolini, A.; Ruberto, F.; Alessandri, F.; Santoro, C.; Barone, F.; Cristina Puzzolo, M.; Ceccarelli, G.; De Luca, M.L.; Mancone, M.; Alvaro, D.; et al. Effect of low or high doses of low-molecular-weight heparin on thrombin generation and other haemostasis parameters in critically ill patients with COVID-19. Br. J. Haematol. 2020, 190. [CrossRef] [PubMed]

126. Hardy, M.; Michaux, I.; Lessire, S.; Douxfils, J.; Dogné, J.-M.; Bareille, M.; Horlait, G.; Bulpa, P.; Chapelle, C.; Laporte, S.; et al. Prothrombotic disturbances of hemostasis of patients with severe COVID-19: A prospective longitudinal observational study. Thromb. Res. 2021, 197, 20-23. [CrossRef] [PubMed]

127. Campello, E.; Bulato, C.; Spiezia, L.; Boscolo, A.; Poletto, F.; Cola, M.; Gavasso, S.; Simion, C.; Radu, C.M.; Cattelan, A.; et al. Thrombin generation in patients with COVID-19 with and without thromboprophylaxis. Clin. Chem. Lab. Med. CCLM 2021. [CrossRef] [PubMed]

128. Hardy, M.; Lecompte, T.; Douxfils, J.; Lessire, S.; Dogné, J.M.; Chatelain, B.; Testa, S.; Gouin-Thibault, I.; Gruel, Y.; Medcalf, R.L.; et al. Management of the thrombotic risk associated with COVID-19: Guidance for the hemostasis laboratory. Thromb. J. 2020, 18, 17. [CrossRef] 